DOE/PC/91309--T14

\title{
HIGH TEMPERATURE ALKALI CORROSION OF CERAMICS \\ IN COAL GAS
}

Final Report

December 31, 1994

Research sponsored by the U.S. Department of Energy's

Pittsburgh Energy Technology Center

\author{
Report prepared by \\ G.R. Pickrell, T. Sun, J.J. Brown, Jr. \\ Department of Materials Science and Engineering \\ Virginia Polytechnic Institute \\ and State University \\ Blacksburg, VA 24061 \\ (703) 231-6777
}

Under

Grant \# DE-FG22-91PC91309

for

Pittsburgh Energy Technology Center 


\title{
PREFACE
}

This investigation was initiated in 1991 in an attempt to understand the comparative corrosive effects of alkalis on silicon carbide, silicon nitride, alumina, aluminum titanate, zirconia, mullite and cordierite. Data pertaining to the corrosion kinetics of each material as a function of temperature in a fixed alkali concentration environment is presented. The results presented herein are applicable to many components within the coal gasification system.

The research presented in this report formed the basis for a Ph.D. dissertation in Materials Engineering Science for Gary R. Pickrell and support in part for a post-doctoral student, Tawei Sun. At this time, Dr. Pickrell has completed his graduate program.

\section{DISCLAIMER}

\begin{abstract}
This report was prepared as an account of work sponsored by an agency of the United States Government. Neither the United States Government nor any agency thereof, nor any of their employees, makes any warranty, express or implied, or assumes any legal liability or responsibility for the accuracy, completeness, or usefulness of any information, apparatus, product, or process disclosed, or represents that its use would not infringe privately owned rights. Reference herein to any specific commercial product, process, or service by trade name, trademark, manufacturer, or otherwise does not necessarily constitute or imply its endorsement, recommendation, or favoring by the United States Government or any agency thereof. The views and opinions of authors expressed herein do not necessarily state or reflect those of the United States Government or any agency thereof.
\end{abstract}




\section{DISCLAIMER}

Portions of this document may be illegible in electronic image products. Images are produced from the best available original document. 


\section{TABLE OF CONTENTS}

Page

\section{Chapter}

1. INTRODUCTION................................................................... 1

2. REVIEW OF LITERATURE........................................................ 4

2.1 Silicon Carbide and Silicon Nitride.................................... 4

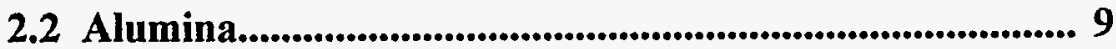

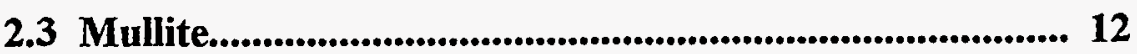

2.4 Cordierite............................................................................................. 14

2.5 Zirconia................................................................................. 15

2.6 Aluminum Titanate.................................................................... 17

3. EXPERIMENTAL PROCEDURE............................................ 19

3.1 Alkali Reaction Products.................................................... 21

3.1.1 Soda-Cordierite System............................................. 23

3.1.2 Potassia-Cordierite System.................................... 23

3.1.3 Soda-Zirconia System..................................................... 23

3.1.4 Soda-Calcia Stabilized Cubic Zirconia System.... 24

3.1.5 Soda-Aluminum Titanate System.............................. 24

3.2 Sol-gel Material Synthesis of Starting Reagents................ 25

3.3 Alkali Reaction Kinetics....................................................... 26 
4. EXPERIMENTAL RESULTS........................................ 34

4.1 Alkali Reaction Kinetics................................................ 34

4.1.1 Silicon Nitride....................................................... 34

4.1.1.1 Silicon Nitride Alkali Reaction Mechanism and Rate Controlling Step............................ 43

4.1.1.2 Alkali Corrosion Induced Microstructural Changes in Silicon Nitride........................... 50

4.1.2 Silicon Carbide......................................................... 53

4.1.2.1 Silicon Carbide Alkali Reaction Mechanism and Rate Controlling Step..........................56

4.1.1.2 Alkali Corrosion Induced Microstructural Changes in Silicon Carbide......................... 59

4.1.2.3 Comparison of the Alkali Corrosion Kinetics of Silicon Carbide and Silicon Nitride......... 61

4.1.3 Alumina............................................................. 63

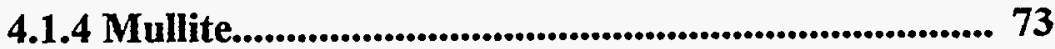

4.1.5 Cordierite......................................................... 78

4.1.6 Zirconia........................................................... 83

4.1.7 Aluminum Titanate.......................................... 88

4.2 Alkali Reaction Products.............................................. 91 
4.2.1 Soda - Cordierite................................................... 91

4.2.2 Potassia - Cordierite........................................ 97

4.2.3 Soda - Zirconia................................................. 101

4.2.4 Soda-Calcia Stabilized Cubic Zirconia.................... 105

4.2.5 Soda - Aluminum Titanate.................................... 108

5. SUMMARY AND CONCLUSIONS.................................. 119

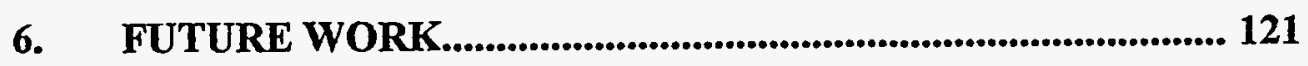

REFERENCES.......................................................................... 123 


\section{Chapter 1. Introduction}

The demand for higher energy efficiencies (which in general requires higher operating temperatures and more efficient heat recovery systems) and a longer service life, and the need for particulate removal in corrosive environments have necessitated the development of ceramic materials that can provide the requisite high temperature stability. Applications for these materials include hot section structural components for gas turbines and piston engines; heat exchanger tubes and other ceramic components for the glass, steel, aluminum, and petrochemical industries; and for filters to remove particulate from combustion gas streams for advanced coal conversion systems. These applications require operation of the ceramic components in potentially corrosive environments containing combustion products as well as impurities from the fuel, coal, or raw materials. In many applications, the ceramic components will be subjected to numerous thermal cycles during their service life, requiring that the materials have good thermal shock resistance in addition to good corrosion resistance. Impurities such as alkalies can have a particularly deleterious effect, forming low melting point, high thermal expansion and low thermal conductivity phases.

Alkali-containing species present in coal combustion and coal conversion systems originate from many sources including coal feedstock, atmospheric impurities, the ceramic construction materials and as additives from particulate and sulfur removal systems. Although the weight percentage of alkalis present in general is low (only a few ppm), under typical coal gasifying conditions a species with a partial pressure as low as $10^{-6} \mathrm{~atm}$ can be deposited in 
metric ton quantities on a yearly basis. ${ }^{1}$ Different areas within the coal combustion system may experience higher or lower alkali concentrations depending upon the temperature and gas flow conditions. Areas where the gas flow is restricted or where particulate accumulation is high may experience much higher alkali concentrations especially if the temperature and pressure are such that condensation of alkali species occurs.

The materials selected for these systems must be able to withstand the corrosive environments to which they will be subjected without significant adverse reactions. In general, these reactions fall primarily into two categories. The first category is formation of low melting point (or low viscosity in the case of glass formation) phases. Once formed, these phases may flow from the surface of the component resulting in a reduction in the component's physical dimensions and therefore it's load bearing capacity. These phases may also penetrate into or act as a flux for the boundary region between grains, resulting in enhanced creep and material loss. The second category is formation of phases with significantly different thermal and/or mechanical properties than the parent material. If the corrosion reactions produce phases which have significantly different thermal expansions and thermal conductivities than the original material, large stresses may be developed during heating and cooling cycles. This may cause spalling of the corrosion layer or catastrophic failure of the entire component depending upon the magnitude of the thermal stresses and the mechanical properties of the corrosion layer, the interface region, and the original material. The alkali corrosion reactions may also form pits in the surface of the component. These pits may serve as fracture initiation sites and therefore significantly decrease the strength of the 
component, depending upon the shape, size and depth of these pits.

There are several ceramic materials which are currently being considered for use as structural elements in coal combustion and coal conversion systems because of their thermal and mechanical properties. These include alumina (refractories, membranes, heat engines); silicon carbide and silicon nitride (turbine engines, internal combustion engines, heat exchangers, particulate filters); zirconia (internal combustion engines, turbine engines, refractories); and mullite and cordierite (particulate filters, refractories, heat exchangers). ${ }^{2}$

High temperature alkali corrosion has been known to cause premature failure of ceramic components used in advanced high temperature coal combustion systems such as coal gasification and clean-up, coal fired gas turbines, and high efficiency heat engines. The objective of this research is to systematically evaluate the alkali corrosion resistance of the most commonly used structural ceramics including silicon carbide, silicon nitride, cordierite, mullite, alumina, aluminum titanate, and zirconia. The study consists of identification of the alkali reaction products and determination of the kinetics of the alkali reactions as a function of temperature and time. 


\section{Chapter 2. Review of Literature}

\subsection{Silicon Carbide and Silicon Nitride}

Silicon carbide and silicon nitride are promising candidates for a variety of high temperature structural applications because of their high thermal shock resistance, high thermal conductivity, low thermal expansion, resistance to oxidation (in certain environments), and high fracture toughness and creep resistance at high temperature. ${ }^{9-13}$ Both of these materials are unstable in the presence of oxygen at elevated temperatures and exhibit either active or passive oxidation depending upon the partial pressure of oxygen that is present. Due to the overwhelming similarities in the oxidation processes for these materials and since a large number of investigators have chosen to study these materials in tandem, the literature for silicon carbide and silicon nitride will be reviewed together.

In the presence of low oxygen partial pressures, active oxidation of these materials results in formation of SiO gas. ${ }^{14-18}$ At higher oxygen partial pressures, passive oxidation occurs whereby $\mathrm{SiO}_{2}$ forms on the surface of the carbide or nitride. ${ }^{19-39}$ In the passive oxidation of $\mathrm{SiC}$, gaseous reaction products $\mathrm{CO}$ or $\mathrm{CO}_{2}$ are also produced in addition to $\mathrm{SiO}_{2}$. These reaction products must diffuse out through the silica layer in order to escape to the atmosphere, while at the same time oxygen must diffuse inward through the silica layer in order to react with the $\mathrm{SiC}$. It is generally accepted that the oxidation process occurs by inward diffusion of oxygen rather than outward diffusion of silicon and carbon. The reaction 
kinetics of this oxidation process are reportedly parabolic (at longer reaction times) in dry $\mathrm{O}_{2}$ and the rate controlling mechanism appears to be the diffusion of oxygen through the $\mathrm{SiO}_{2}$ layer (although this is still the subject of some debate). ${ }^{23-39}$

Therefore, the silica layer is responsible for the observed oxidation resistance of $\mathrm{SiC}$ at high temperatures because the rate of diffusion of oxygen through this layer is relatively slow. Any chemical species that reacts with the protective silica layer and alter the oxygen transport properties of this layer will change the observed oxidation rates.

For silicon nitride the oxidation process is somewhat different. Between the $\mathrm{Si}_{3} \mathrm{~N}_{4}$ and $\mathrm{SiO}_{2}$ layers an oxynitride layer reportedly forms. ${ }^{40-50}$ The diffusivity of oxygen through the oxynitride layer is much lower than through the silica layer. As a result, the oxidation rate of $\mathrm{Si}_{3} \mathrm{~N}_{4}$ in dry air or oxygen is much lower than the oxidation rate of $\mathrm{SiC}$ in the same environment. Both of these materials have been reported to exhibit linear oxidation kinetics at very short times. At longer times the oxidation kinetics become parabolic.

Several authors have also studied the oxidation of $\mathrm{SiC}$ or $\mathrm{Si}_{3} \mathrm{~N}_{4}$ in wet $\mathrm{O}_{2}$ or $\mathrm{H}_{2} \mathrm{O}$. They observe much higher oxidation rates and longer linear oxidation rate regions than are present in the oxidation of these materials without water vapor in the atmosphere. ${ }^{51-60}$ Some of these authors report only a linear region, while others report a linear region followed by a linear to parabolic transition at longer times. The range of experimental activation energies reported in the literature for the linear oxidation rate region of $\mathrm{SiC}$ in wet $\mathrm{O}_{2}$ or air varies widely, from approximately 100 to over $400 \mathrm{~kJ} / \mathrm{mol}$. There have been several excellent reviews of the SiC and $\mathrm{Si}_{3} \mathrm{~N}_{4}$ oxidation literature, especially Jacobson ${ }^{61}$ and Luthra ${ }^{62}$ and therefore this will not 
be discussed extensively here.

In addition to water vapor, other species if present in the reaction atmosphere can have dramatic effects on the stability of the $\mathrm{SiO}_{2}$ scale and therefore on the observed oxidation rates. There have been several corrosion studies of $\mathrm{SiC}$ and $\mathrm{Si}_{3} \mathrm{~N}_{4}$ which have shown that the protective $\mathrm{SiO}_{2}$ scale, when in contact with molten sodium salts, reacts to form a sodium silicate liquid, resulting in a substantial increase in the oxidation rate. ${ }^{61-83}$ The increased oxidation rate is generally attributed to the higher oxygen diffusivity in the sodium silicate liquid as compared to the vitreous silica. In addition to the higher oxidation rates, the formation of cracks or corrosion pits on the surface has resulted in significant strength reductions in these materials.

There are several methods which investigators have used to study the alkali corrosion process. These include burner rig studies where the combustion flame is seeded with an aspirated aqueous solution containing the dissolved alkali salt; application of a thin film of an aqueous alkali-containing salt solution with subsequent heating of the coated specimen to the appropriate temperature; partial or complete immersion of the specimen in a crucible containing the molten alkali salt; or injection of an aqueous alkali salt containing solution into the reaction chamber held at the appropriate temperature.

Molten salt corrosion of $\mathrm{SiC}$ has been studied as early as 1952 when $\mathrm{Horn}^{84}$ investigated the corrosive effects of immersion of single crystal alpha-SiC in molten sodium carbonate at $1000^{\circ} \mathrm{C}$ and observed dislocation etch pitting. Amelincks et al ${ }^{85}$ and Buchner et al ${ }^{86}$ also looked at molten sodium carbonate corrosion of SiC. The former reported dislocation etch 
pitting at $1000^{\circ} \mathrm{C}$ and the latter reported complete dissolution at temperatures less than $900^{\circ} \mathrm{C}$. McKee et al ${ }^{82}$ studied both salt immersion and thin film depositions of sodium sulfate and sodium carbonate on beta- $\mathrm{SiC}$ and reported active corrosion by deep basic melts with carbon added. Tressler et a $1^{87}$ studied the corrosion of reaction bonded and hot pressed $\mathrm{SiC}$ in mixtures of sodium chloride and sodium sulfate at $1200^{\circ} \mathrm{C}$. They found that $\mathrm{SiC}$ corroded rapidly provided the $\mathrm{O}^{2-}$ activity was sufficiently high. $B e c h e{ }^{66}$ and Ferber et $a^{80}$ examined the reactions between $\mathrm{SiC}$ and slurry coatings of powdered coal combustion slags at 1200 $1300^{\circ} \mathrm{C}$. The former found faster corrosion in basic slags, but more strength reduction in acidic slags. The latter reported pitting and strength reduction for coal slurry coatings greater than $100 \mu \mathrm{m}$. Blachere et $\mathrm{a}^{88}$ deposited thin films of sodium sulfate on CVD, single crystal and hot pressed $\mathrm{SiC}$ at $1000^{\circ} \mathrm{C}$, noting that bubble formation, devitrification and cracking of the $\mathrm{SiO}_{2}$ layer occurred. Jacobson et $\mathrm{al}^{63}$ studied the effects of thin film coatings of sodium sulfate and sodium carbonate on $\mathrm{SiC}$ at $1000^{\circ} \mathrm{C}$ and found that the acid attack was severe only in the presence of free carbon, but the basic attack led to severe pitting in all the materials studied. Jacobson ${ }^{67}$ also used a burner rig at 4 atm and $1000^{\circ} \mathrm{C}$ seeded with $4 \mathrm{ppm}$ $\mathrm{Na}$ to model the continuous deposition of sodium sulfate that is likely to occur in real systems. It was found that corrosive attack led to a $32 \%$ decrease in strength of $\mathrm{SiC}$. Smialek et al ${ }^{78}$ using thin films of sodium sulfate and sodium carbonate on sintered alpha-SiC noted a $13-49 \%$ reduction in strength depending upon the salt and the gaseous environment used, and concluded that pitting was the major factor in strength reduction. In other experiments, the salt transpiration method has been used. ${ }^{65,88}$ 
In most cases, the oxidation of $\mathrm{Si}_{3} \mathrm{~N}_{4}$ leads to the formation of a $\mathrm{SiO}_{2}$ scale on the surface and an interlayer of $\mathrm{Si}_{2} \mathrm{~N}_{2} \mathrm{O}^{50}$ The development of the $\mathrm{SiO}_{2}$ scale, which serves as a diffusion barrier for oxygen, retards further oxidation of $\mathrm{Si}_{3} \mathrm{~N}_{4} \cdot{ }^{42,47,48}$ The presence of alkali vapors, as in many combustion environments, has especially adverse effects on the stability of the $\mathrm{SiO}_{2}$ scale. Various corrosion studies of $\mathrm{Si}_{3} \mathrm{~N}_{4}$ showed that the protective $\mathrm{SiO}_{2}$ scale, when in contact with sodium salts, was transformed to a sodium silicate liquid, resulting in an increase in the oxidation rate. ${ }^{61,69-76}$ The accelerated oxidation rate is generally attributed to fast oxygen diffusion in the sodium silicate liquid. Because of the formation of cracks or corrosion pits on the surface, a significant strength reduction was observed following the alkali reaction. ${ }^{71}$

Many of the alkali corrosion studies have been conducted by depositing a thin film of sodium salt, $\mathrm{Na}_{2} \mathrm{CO}_{3}$ or $\mathrm{Na}_{2} \mathrm{SO}_{4}$, on the surface of the $\mathrm{SiC}$ or $\mathrm{Si}_{3} \mathrm{~N}_{4}$ samples with subsequent heating of the coated specimens. In general, the reactions proceeded by simultaneous oxidation of the $\mathrm{SiC}$ or $\mathrm{Si}_{3} \mathrm{~N}_{4}$ and dissolution of $\mathrm{SiO}_{2}$ in the sodium silicate melt until the sodium silicate liquid is saturated with $\mathrm{SiO}_{2},{ }^{73}$ the composition of which is indicated by the liquidus on the $\mathrm{Na}_{2} \mathrm{O}-\mathrm{SiO}_{2}$ phase diagram. When the liquidus composition was reached, a $\mathrm{SiO}_{2}$ layer grew between the carbide or nitride substrate and the liquid phase and the dissolution process ceased. While the thin film studies demonstrate the rapid oxidation occurring in the presence of alkali, much of the fundamental information, such as the reaction rate constants, activation energy and the rate-controlling step, cannot be derived from the 

found, but the type sintering atmosphere had a significant effect. The vacuum sintering technique gave samples with the best corrosion resistance. Other authors have also reported on the fast ion transport in the beta-alumina family ${ }^{90-95}$. Huggins ${ }^{96}$ investigated the effect of temperature, stoichiometry of the beta-alumina phase and variation of the chemical identity of the cations on the ionic conductivity. In general for sodium beta-alumina, the conductivity increased exponentially with increasing reciprocal temperature.

Many authors have studied the corrosive effects of alkali metals in relation to the high pressure sodium vapor lamps. With et $\mathrm{al}^{97}$ investigated the effects of additives and sintering conditions on the sodium corrosion resistance of translucent alumina. Samples of alumina were reacted with the sodium metal in sealed molybdenum crucibles at temperatures from 800 to $1000^{\circ} \mathrm{C}$. The only phases detected by $\mathrm{x}$-ray diffraction were alpha-alumina and sodium aluminate. Effects of the concentration of $\mathrm{CaO}$ and $\mathrm{MgO}$ sintering aids on the alkali corrosion were studied by comparing with the corrosion of a sapphire fiber under similar conditions. No preferential corrosion along the grain boundaries was detected in the low calcia ( $2 w t \%)$ samples. Increasing the calcia content resulted in increased corrosion and increased attack at the grain boundaries. Togawa et al ${ }^{98}$ studied the interaction of betaalumina and beta"-alumina and liquid sodium at $700^{\circ} \mathrm{C}$. After exposure to the liquid sodium for up to $8 \mathrm{hrs}$, the materials became discolored, but no new phases were detected by $\mathrm{x}$-ray diffraction.

$\operatorname{Sun}^{99}$ studied the effect of alkali attack on coal gasifier linings. Samples of $53 \%$ and $72 \%$ alumina cement were mixed with sodium or potassium carbonate in a 1:1 weight ratio. The 
phases determined by $\mathrm{x}$-ray diffraction analysis were calcia and sodium aluminate or potassium aluminate.

Susnitzky et al ${ }^{100}$ studied the localization of potassium in alumina. In sintered samples the potassium was accumulated along the grain boundaries enclosing abnormally large alphaalumina grains. The alpha-alumina grains were found to be essentially free of potassium. In hot pressed samples, however, the potassium formed large, randomly distributed, polycrystalline potassium beta-alumina precipitates. The lens shaped precipitates were enclosed in a region of potassium-free alumina which was in turn enclosed with a thin shell of potassium-rich material.

Jung et $\mathrm{al}^{101}$ investigated the compatibility of alumina ceramics with liquid sodium by exposing alumina pellets of various densities and purities to sodium vapor in sealed stainless steel vessels at temperatures from 600 to $900^{\circ} \mathrm{C}$. The extent of the reaction zone progress was inversely proportional to the density of the alumina material. The higher the density the smaller the extent of the penetration zone into the pellet. The authors suggest that the effect of the grain boundaries is responsible for the differences in corrosion kinetics between the different density materials.

Hodge $\mathrm{e}^{102}$ investigated the effects of calcium oxide and magnesium oxide on the rate of formation of beta-alumina. The author concludes that the formation of beta-alumina is kinetically limited at low temperatures and that the addition of the alkaline earth oxides allows formation of alkaline earth aluminates which have the same structure as the beta-alumina. These can act as nucleation sites for the beta-alumina and therefore increase the rate of 
formation of the beta-alumina phase.

\subsection{Mullite}

Mullite is also being considered for use as particulate filters and heat exchangers. ${ }^{2}$ There have been several studies of the corrosive effects of silicate melts (with and without alkalis) on various composition alumina-silica mixtures. These are usually related to the refractories used in the glass and steel industries. Farris et $a^{103}$ studied the effects of mixing powdered sodium or potassium carbonate with ground refractories ranging in composition from 42 to 90 percent alumina and heating the mixtures between 900 and $1400^{\circ} \mathrm{C}$. At temperatures below $1100^{\circ} \mathrm{C}$ the primary phase formed was nepheline. The amount of nepheline formed reportedly decreased as the alumina content of the refractory increased. The 70 and 90 percent alumina refractories formed no nepheline. Above $1100^{\circ} \mathrm{C}$ beta-alumina also formed. Alkali cup tests were also performed wherein higher silica refractories performed better, in direct contrast to the results of the powder tests. This was attributed to the alkali being completely absorbed and contained in the silicate phase thus limiting the attack area.

Rigby et al ${ }^{104}$ studied the effects of an alkali-vanadium oxide slag on a series of aluminasilica specimens ranging from pure alumina to pure silica. Mixtures of sodium carbonate and/or vanadium pentoxide were mixed with the powdered alumina-silica mixtures. The pellets pressed from these mixtures were heated up to $1700^{\circ} \mathrm{C}$. Reaction products included 
sodium aluminate, albite, nepheline, and jadeite. Large volume changes were observed in some samples and were related to the formation of sodium aluminate. Liquid formation occurred for a $40 \%$ alumina refractory above $1000^{\circ} \mathrm{C}$.

Kashcheev et al ${ }^{105}$ studied the corrosion of mullite by a sodium containing silicate melt. In general the amount of corrosion as measured by optical microscopy decreased as the porosity of the specimen decreased. Hiragushi et a $1^{106}$ studied the effects of alkalis on blast furnace refractories by reacting coke with potassium carbonate to form potassium metal vapor. The alkali resistance of alumina-silica refractories was found to increase with increasing alumina content. Havrane ${ }^{107}$ studied the effects of potassium carbonate on blast furnace refractories using cup tests with controlled $\mathrm{CO} / \mathrm{CO}_{2}$ atmospheres. Results of alkali tests with these methods were not reproducible. Several additives were tested, but none significantly improved the corrosion resistance of the refractories. The conclusion that the authors reached was that the only way to improve the alkali corrosion resistance was to cool the refractories.

Kennedy ${ }^{108}$ studied the effects of alkali attack on mullite refractories used in the Grand Forks Energy Technology Center Slagging Gasifier. The author observed that the mullite refractory reacted with a sodium compound to form carnegieite and beta alumina after intermittent exposure to the gasifier atmosphere for $125 \mathrm{~h}$ at $1000^{\circ} \mathrm{C}$. The mullite lining cracked and spalled as a result of the alkali reactions. 


\subsection{Cordierite}

Cordierite is a potential candidate for use as particulate filters and heat exchangers. ${ }^{2}$ It is used extensively as substrates for automotive exhaust catalysts due to its low thermal expansion (average value of $1.57 \times 10^{-6}$ from $25-1000^{\circ} \mathrm{C}$ ), refractoriness and relatively good mechanical strength. ${ }^{109}$ Very little information is available in the literature on the alkali corrosion of cordierite. Jacobson et al ${ }^{110}$ studied the corrosive effects of thin films of sodium sulfate deposited on the cordierite surface. Samples were airbrushed with an aqueous solution containing approximately $2.5 \mathrm{mg}$ of sodium sulfate and were heat treated at $1000^{\circ} \mathrm{C}$ up to $70 \mathrm{hrs}$ in an oxygen or oxygen-sulfur dioxide atmosphere. In oxygen atmospheres the authors report formation of $\mathrm{NaAlSiO}_{4}$. It is speculated that forsterite is also formed based on the EDS measurements, but this phase was not observed in the x-ray diffraction pattern. In oxygen-sulfur dioxide atmospheres, XRD analysis could not be used to identify the reaction products conclusively. A more complex reaction sequence is suggested as possibly occurring in this atmosphere as compared to the pure oxygen atmosphere based on the EDS measurements. Burner rig studies were also performed as a comparison using $2 \mathrm{ppm}$ of sodium aspirated into the combustion flame. Exposures were conducted at $4 \mathrm{~atm}, 1000^{\circ} \mathrm{C}$, for $40 \mathrm{~h}$. More severe corrosion was observed for the burner rig tests than for the thin film studies. Samaddar et $\mathrm{al}^{111}$ studied the dissolution of alumina, mullite, and silica in a calciumaluminum-silicate slag. Alumina was found to be the most corrosion resistant at low temperatures. At higher temperatures, the differences between the corrosion rates of the 
materials became smaller. The dissolution was found to be controlled by transport within the liquid boundary layer. Sun ${ }^{112}$ has recently studied the reaction rates of mixtures of cordierite and sodium carbonate powders. The samplès were sealed in platinum tubes to avoid loss of soda and were heated isothermally at various temperatures and times. Peak areas of the phases in the XRD patterns were compared to determine the relative amounts of the phases present as a function of time and temperature. The phases formed from the reaction of the cordierite with the alkali were forsterite and nepheline. In general, the reaction rates could be characterized by the shrinking core model assuming spherical particles reacting at the surface.

\subsection{Zirconia}

Pure zirconia is of little use as a high temperature refractory material due to the large volume change associated with the monoclinic to tetragonal transformation which occurs around $1170^{\circ} \mathrm{C} .^{5,113,114}$ Calcia, magnesia and yttria are the three most common stabilizing agents which are added to the zirconia to stabilize the tetragonal or cubic phases. By adding the appropriate amount of the stabilizing agent, the tetragonal solid solution phase becomes stable at low temperatures, commonly referred to as partially stabilized zirconia, PSZ. Adding additional stabilizing agent results in the cubic solid solution phase becoming stable at low temperatures, called fully stabilized zirconia. A material that generated considerable 
interest in the ceramic community was transformation toughened zirconia, TTZ. This material consisted of tetragonal zirconia particles dispersed in the cubic zirconia matrix. These materials exhibit relatively high toughnesses for a ceramic material. This is due to the transformation of the tetragonal particles into monoclinic particles in the deformation zone at the crack tip. A large volume increase is associated with this transformation which acts to squeeze the crack shut and thus toughens the material.

Many investigators have attempted to produce a corrosion resistant coating to be applied to ceramic heat exchangers or engine components. Van Roode et $\mathrm{al}^{115}$ investigated coating silicon carbide tubular substrates with alumina, mullite, chromia, zircon and various types of zirconia. Mullite coatings were the only ones that survived thermal cycling 60 times from 1010 to $371^{\circ} \mathrm{C}$. Based on this data, mullite/yttria stabilized zirconia coatings were developed. However, during alkali exposure testing $(50 \% \mathrm{NaCl}, 45 \% \mathrm{KCl}, 5 \mathrm{wt} \%$ cryolite evaporated from a crucible) the zirconia layer spalled from the surface of the substrate early on in the testing. This was attributed to the differences in the thermal properties of the coating and the substrate.

Wada et al ${ }^{116}$ studied the effects of vanadia-sodium sulfate-sodium chloride mixtures on alumina, mullite, zirconia (PSZ), silicon carbide and silicon nitride. Attack of the zirconia ceramics was much more severe when vanadia was present and resulted in fracture of the specimens for long reaction times. The PSZ showed no measurable corrosion in the sodium chloride salt coating experiments and only a slight mass change with the sodium sulfate salt coatings at $900^{\circ} \mathrm{C}$ for $20 \mathrm{~h}$. The zirconia material containing alumina in addition to the yttria 
corroded more severely in both the sodium chloride and sodium sulfate cases.

McKee et $\mathrm{al}^{117}$ studied the resistance of thermal barrier coatings to hot salt corrosion. Various composition yttria-zirconia coatings were tested at $900^{\circ} \mathrm{C}$ with sodium sulfate thin film coatings. In general, no change was observed after a $100 \mathrm{~h}$ exposure with pure sodium sulfate salt coatings. When vanadia was added to the salt coating, however, the zirconia coatings cracked and spalled. Coatings that were prepared with powders of fine particle size were reportedly less susceptible to vanadium corrosion.

\subsection{Aluminum Titanate}

Aluminum titanate is being considered for use in many high temperature structural applications. Charlton et $\mathrm{al}^{118}$ tested silicon nitride, syalon, tetragonal zirconia polycrystals and aluminum titanate diesel engine swirl chamber components. Aluminum titanate and syalon were the only two materials to complete satisfactorily the lower chamber design testing. Aluminum titanate was selected for vehicle testing because of it's greater thermal insulation and higher exhaust temperature. A total of $254 \mathrm{~h}$ of engine testing was completed without any catastrophic engine failure.

Interest in aluminum titanate as a high temperature structural material has sparked several investigations into novel processing methods to produce pure aluminum titanate or in composites with other materials. Mani et $\mathrm{al}^{119}$ prepared powders of aluminum titanate by 
thermal decomposition of transparent gels formed by mixing titanium butoxide with a boehmite sol in acetic acid-butanol solutions. Grains larger in size than 2 microns reportedly showed microcracking apparently due to the thermal expansion anisotropy of the aluminum titanate. Morishima et a ${ }^{120}$ reported development of aluminum titanate-mullite composites with the strength of the composite increasing as the mullite content increased but the thermal shock resistance increasing as the aluminum titanate content increased. Parker ${ }^{121}$ investigated aluminum titanate-zirconium titanate-zirconia composites and reported average thermal expansions as low as -1 to $1 \times 10^{-6} /{ }^{\circ} \mathrm{C}$ with microcracking of the aluminum titanate a significant contributor in the low thermal expansion materials. Brown et $\mathrm{al}^{122}$ have developed a method of sol-gel coating of a magnesia stabilized aluminum titanate material that is stable at low temperatures. Ball et $\mathrm{al}^{123}$ have studied the hydrothermal durability of titanate ceramics of various compositions at low temperatures.

There is very little data available on the alkali corrosion kinetics of aluminum titanate. Kang ${ }^{124}$ investigated the effects of high temperature, high pressure, steam-alkali environments on the corrosion resistance of silicon carbide coated with aluminum titanate. The aluminum titanate coatings significantly improved the alkali corrosion resistance of the silicon carbide as compared to the uncoated material. 


\section{Chapter 3. Experimental Procedure}

The following reagents and equipment were used in the alkali reaction product and alkali reaction kinetic studies:

\section{REAGENTS/MATERIALS}

Sodium carbonate

Potassium carbonate

Alumina

Ascarite II

Silica gel

Alumina, activated

Zirconia

Magnesium ethoxide

Aluminum tri-sec butoxide

Titanium butoxide

Diamond Blade

Platinum Tubing

Alumina muffle furnace tube

Alumina combustion boats

Acetone
SOURCE

Aldrich

Aldrich

Aldrich

Aldrich

Aldrich

Aldrich

Aldrich

Aldrich

Aldrich

Aldrich

Beuhler

JMI

Coors

Coors

Baxter

\section{PURITY/GRADE}

99+\% ACS Reagent Grade

99+\% ACS Reagent Grade

$99.8 \%$

20-30 mesh

Grade 44 Tel-Tale

Standard Grade

$99 \%$

$98 \%$

$97 \%$

$99 \%$

Low Concentration

High Purity

Dense, high purity

Dense, high purity

Analytical reagent 


\section{REAGENTS/MATERIALS}

Sodium nitrate

Ethyl alcohol

EQUIPMENT

X-ray Diffractometer

DTA

SEM

Analytical Balance

Micrometer

Heating Tape

Variac

Flow Meter

Hot/Stirrer Plate

Muffle Furnace

Box Furnace

Diamond saw

Box Furnace

Oxygen-acetylene torch $\underline{\text { SOURCE }}$

Aldrich

Aldrich

SOURCE

Phillips 1170

Perkin Elmer 1700

ISI-SX-40

Sartorius 2255

Starrett \#230M

Thermolyne

Staco Energy Prod.

Century

Corning

Lindberg

Lindberg

Beuhler

Eurotherm

in-house
PURITY/GRADE

ACS Reagent Grade

Spectrophotometric Grade
PARAMETERS

$40 \mathrm{kV}, 30 \mathrm{~mA}$

$10^{\circ} \mathrm{C} / \mathrm{min}$

Noran EDX

Samox, high temp.

$120 \mathrm{~V}, 0-100 \%$

$1200^{\circ} \mathrm{C} \max$

$1400^{\circ} \mathrm{C} \max$

Isomet, low speed

$1600^{\circ} \mathrm{C} \max$ 


\subsection{Alkali Reaction Products}

The general procedure for the alkali reaction studies for all systems is outlined below. Variations to this procedure are noted under each specific system. The samples for isothermal reaction were prepared by repeatedly grinding and mixing appropriate amounts of sodium or potassium carbonate and the appropriate reagents in acetone with a glass, agate or alumina mortar and pestle. The samples were air dried for several hours to allow evaporation of the acetone. The samples were packed into platinum tubes approximately 0.125 inches in diameter and 2 inches long such that approximately $75 \%$ of the tube was occupied. The platinum tubes were sealed on one end with an oxygen-acetylene torch, before packing with the samples. After the samples had been packed into the platinum tubes they were heated at $840^{\circ} \mathrm{C}$ for $24 \mathrm{hrs}$. Samples were weighed before and after the $840^{\circ} \mathrm{C}$ firing to ensure soda was not being lost. The platinum tubes were immersed in water such that the open end remained approximately 0.25 inches from the surface of the water. Immersion of the platinum tubes in water allowed the open end of the tube to be sealed without significantly heating the samples inside the tube and therefore minimizing loss of any volatile constituents. The platinum tubes were arranged in a cylindrical fashion and wrapped with platinum wire to bind them together.

The samples were inserted into a Lindberg tube furnace (equipped with a 1 inch I.D. alumina tube) and heated at the appropriate temperature for the specified period of time. A thermocouple was inserted beside the samples to ensure the proper temperature was 
maintained throughout the heat treatment schedule. In general the temperatures were maintained within $5^{\circ} \mathrm{C}$ of the reported temperatures. The samples were pulled immediately from the hot zone of the furnace onto a setter in order to air quench the samples. When cool, the platinum tubes were cut open at the top and the samples were removed. The powder samples were ground under acetone and dried.

The low temperature heat treatment at $840^{\circ} \mathrm{C}$ was conducted in air without sealing the platinum tubes because the weight loss of soda or potassia was negligible. The platinum tubes containing these samples were placed vertically in an alumina crucible containing alumina powder (which was used to keep the samples in an upright position). The crucible containing the samples was placed in a Lindberg box furnace. A thermocouple was inserted through the roof of the furnace into the center of the samples. The temperature was monitored periodically throughout the firing schedule to ensure precise control of the heat treatment temperature. In general, the temperatures were maintained within $5^{\circ} \mathrm{C}$ of the desired temperature. The phases formed after the heat treatments were determined by $\mathrm{x}$-ray diffraction $(\mathrm{XRD})$ using a Philips $1170 \mathrm{x}$-ray diffractometer operated at $40 \mathrm{kV}$ and $30 \mathrm{~mA}$. The solidus temperatures were determined by differential thermal analysis (DTA) using a Perkin Elmer 1700 thermal analysis system. Heating and cooling rates were set at $10^{\circ} \mathrm{C} / \mathrm{min}$ for all specimens. In general, the compositions studied ranged from 0 to 40 weight percent soda, and the temperature range was from 840 to $1100^{\circ} \mathrm{C}$. 


\subsubsection{Soda-Cordierite System}

The soda-cordierite phase relations were investigated in the region from $0-30 \mathrm{wt} \%$ soda and from $840-1305^{\circ} \mathrm{C}$ for up to $62 \mathrm{~h}$. The cordierite powders were derived from sol-gel synthesis using magnesium nitrate, aluminum tri-sec butoxide, and tetraethyl orthosilicate as precursors as described in the sol-gel synthesis section below.

\subsubsection{Potassia-Cordierite System}

The potassia-cordierite phase relations were investigated in the region from $0-32 \mathrm{wt} \%$ potassia and from $840-1100^{\circ} \mathrm{C}$ for 114 to $144 \mathrm{~h}$. In this system also, the cordierite powders were derived from sol-gel synthesis using magnesium nitrate, aluminum tri-sec butoxide, and tetraethyl orthosilicate as precursors as described in the sol-gel synthesis section below.

\subsubsection{Soda-Zirconia System}

The soda-zirconia phase relations were investigated in the region from $0-40 \mathrm{wt} \%$ soda and from $840-1500^{\circ} \mathrm{C}$ for reaction times up to $144 \mathrm{~h}$. Samples were prepared by repeatedly grinding and mixing appropriate amounts of sodium carbonate and zirconia in acetone with 
a glass mortar and pestle, drying, and packing into platinum tubes.

\subsubsection{Soda-Calcia Stabilized Cubic Zirconia System}

The soda-calcia stabilized cubic zirconia (20 mol\% calcia) phase relations were investigated in the region from $0-30 \mathrm{wt} \%$ soda and from $840-1100^{\circ} \mathrm{C}$ for reaction times up to $100 \mathrm{~h}$. The cubic zirconia solid solution was prepared by mixing the appropriate amounts of calcium carbonate and zirconia under acetone. The mixture was dried and fired at successively higher temperatures up to $1500^{\circ} \mathrm{C}$, followed by $\mathrm{x}$-ray diffraction analysis of the powders after each firing. After the $1500^{\circ} \mathrm{C}$ firing, the calcia stabilized cubic zirconia (CSZ) was the only phase present in the diffraction pattern. Samples used for the alkali reaction study were prepared by repeatedly grinding and mixing appropriate amounts of sodium carbonate and CSZ in acetone with a glass mortar and pestle, drying, and packing into platinum tubes.

\subsubsection{Soda-Aluminum Titanate System}

The soda-aluminum titanate phase relations were investigated in the region from $0-40$ $w t \%$ soda and from $840-1100^{\circ} \mathrm{C}$. Samples used for the alkali reaction study were prepared by repeatedly grinding and mixing appropriate amounts of sodium carbonate and aluminum titanate in acetone with a glass mortar and pestle, drying, and packing into platinum tubes. The aluminum titanate was prepared by mixing the appropriate amounts of aluminum tri-sec 
butoxide and titanium butoxide using sol-gel techniques described below. Additional samples were prepared by mixing sodium carbonate, alumina, and titania under acetone with a mortar and pestle. These samples were dried and fired in open crucibles. The weight loss of the samples was measured. The amount of weight loss (in addition to the theoretical weight loss for the sodium carbonate decomposition to soda and carbon dioxide) was negligible.

\subsection{Sol-gel Material Synthesis of Starting Reagents}

Some of the starting reagents were prepared by sol-gel techniques. Mullite was prepared by mixing tetra ethyl orthosilicate (TEOS) and aluminum trisec butoxide (ATB) in a 1:3:5 weight ratio in a pyrex beaker. The milky white solution was stirred continuously on a hot plate. Distilled water and nitric acid were added slowly until a clear solution was obtained. The solution was stirred for $12 \mathrm{~h}$ in a fume hood and then placed in a drying oven for several days. The mixture was fired in a Lindberg box furnace up to $1350^{\circ} \mathrm{C}$ for several days. Mullite was the only phase detected in the x-ray diffraction pattern.

Cordierite was prepared by mixing ATB, TEOS, and magnesium nitrate hexahydrate (MNH) in a 1:1.05:0.51 weight ratio in a pyrex beaker. The brownish white solution was stirred continuously on a stirring plate. Distilled water and nitric acid were added slowly until a clear solution was obtained. The solution was stirred for $12 \mathrm{~h}$ in a fume hood and then placed in a drying oven for several days. The mixture was fired in a Lindberg box furnace up 
to $1350^{\circ} \mathrm{C}$ for several days. Cordierite was the only phase detected in the $\mathrm{x}$-ray diffraction pattern.

Sodium aluminate and nepheline were prepared by mixing sodium carbonate (SC) and ATB in a 1:4.6 ratio, and by mixing ATB, SC and TEOS in a 1:0.2:1:2 weight ratio, respectively. Distilled water and nitric acid were added slowly until a clear solution was obtained. The solution was stirred for $12 \mathrm{~h}$ in a fume hood and then placed in a drying oven for several days. The mixture was fired in a Lindberg box furnace up to $1350^{\circ} \mathrm{C}$ for several days. Sodium aluminate and nepheline respectively were the only phases detected in the x-ray diffraction patterns.

Aluminum titanate was prepared by mixing ATB and titanium butoxide in a 1:0.7 weight ratio. Distilled water and nitric acid were added slowly until a clear solution was obtained. The solution was stirred for $12 \mathrm{~h}$ in a fume hood and then placed in a drying oven for several days. The mixture was dried and fired at successively higher temperatures up to $1350^{\circ} \mathrm{C}$, followed by $\mathrm{x}$-ray diffraction analysis of the powders after each firing. After the $1350^{\circ} \mathrm{C}$ firing, the aluminum titanate was the only phase indicated by the diffraction pattern.

\subsection{Alkali Reaction Kinetics}

The alkali corrosion of silicon carbide, silicon nitride, alumina, mullite, cordierite, zirconia and aluminum titanate was studied in an atmosphere containing a constant $1.0+/-0.1 \mathrm{vol} \%$ 
$\mathrm{NaNO}_{3}$ concentration. A schematic of the apparatus used for the alkali corrosion experiments is shown in Figure 1. Sodium nitrate (Aldrich, ACS Reagent) was chosen as the alkali source because of the high vapor pressure of the sodium species in the $700-800^{\circ} \mathrm{C}$ temperature range as compared to sodium carbonate or sodium sulfate. The system was constructed with two separately controlled heating zones such that the thermal profile of the region containing the salt (zone 1) could be controlled independently of the temperature of the region containing the test samples (zone 2). A smaller alumina boat filled with the $\mathrm{NaNO}_{3}$ salt was placed inside a larger alumina boat and inserted into the gas inlet side of the alumina tube. These boats were slowly pushed into the first heating zone which was maintained at $720+/$ $10^{\circ} \mathrm{C}$ for all testing temperatures. The flow rate of the compressed air was fixed at 86 $\mathrm{cm}^{3} / \mathrm{min}$ using a flowmeter and as the salt was kept at a constant temperature, this fixed the concentration of alkali throughout all of the experiments. The alkali containing species were carried to the reaction zone by compressed air which was filtered to remove $\mathrm{CO}_{2}$ and moisture prior to entering the alumina tube. This was accomplished by using a plastic tube approximately $15 \mathrm{ft}$ long filled with silica gel in the first segment, Ascarite II in the second segment, activated alumina in the third segment, and silica gel in the final segment. The thermal profile of both the salt region and the sample region was measured periodically throughout the experimentation. This was accomplished using an S-type thermocouple in conjunction with a digital linearization and conversion unit such that the millivolt signal from the thermocouple was automatically converted to a digital temperature display. Initially a potentiometer was also used to measure the millivolt output directly and was compared to the 


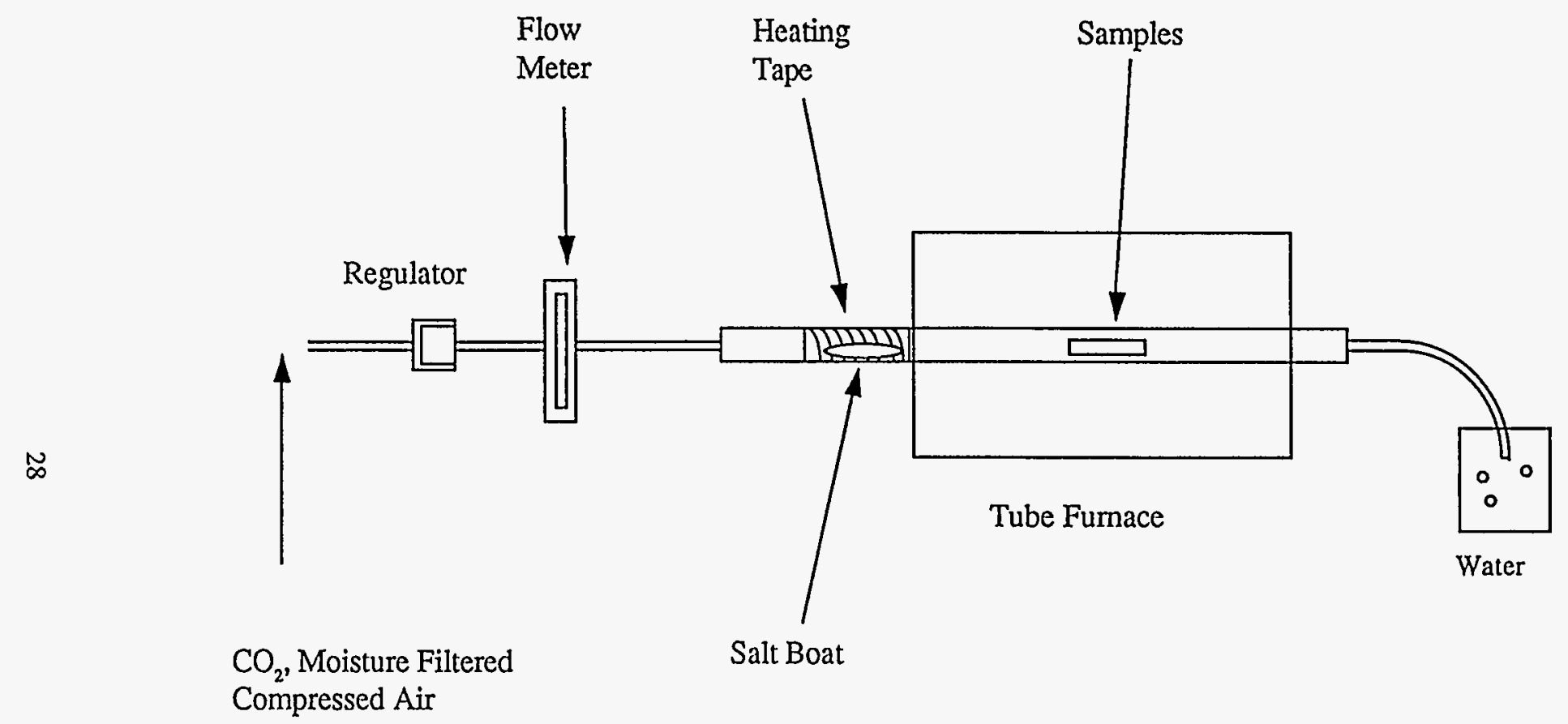

Figure 1. Schematic of the alkali corrosion apparatus 
temperature displayed on the digital unit. The agreement between the two units was very close and therefore the use of the potentiometer was discontinued.

The weight loss of the alumina boats containing the $\mathrm{NaNO}_{3}$ powders was monitored after each run to ensure the alkali concentration was consistent from run to run. The typical weight loss of the salt as a function of time for all testing temperatures is shown in Figure 2. Assuming the vapors behave as ideal gases and using the weight loss rate of $\mathrm{NaNO}_{3}$ and the flow rate of the compressed air, the concentration of the $\mathrm{NaNO}_{3}$ vapors was calculated to be approximately $1.0+/-0.1$ vol\%.

The $\mathrm{SiC}$ used was alpha-SiC (Carborundum) with boron and carbon as the major impurities and a density of $3.10 \mathrm{~g} / \mathrm{cc}$. Energy dispersive $\mathrm{x}$-ray analysis of the $\mathrm{Si}_{3} \mathrm{~N}_{4}$ (Kyocera, SN220M) specimens revealed the presence of a small amount of alumina. The reported density for this material was $3.2 \mathrm{~g} / \mathrm{cc}$. The Coors alumina $(99.8 \%)$ had a reported density of $3.92 \mathrm{~g} / \mathrm{cc}$. The mullite was obtained from Superior Technical Ceramics with a reported density of $3.0 \mathrm{~g} / \mathrm{cc}$. The density for this material was measured and was found to be 3.00 g/cc. The transformation toughened zirconia (TTZ), cordierite, and aluminum titanate were obtained from Coors with a reported density $5.75 \mathrm{~g} / \mathrm{cc}, 3.10 \mathrm{~g} / \mathrm{cc}$, and $2.51 \mathrm{~g} / \mathrm{cc}$, respectively.

The materials tested were cut into pellets (approximately $3 \times 3 \times 6 \mathrm{~mm}$ ) using a diamond blade mounted on a low speed saw with Beuhler cutting fluid. After cutting, the samples were soaked in acetone to remove the cutting fluid and any particulate debris.

The sample pellets were placed vertically in an alumina holder containing alumina powder 


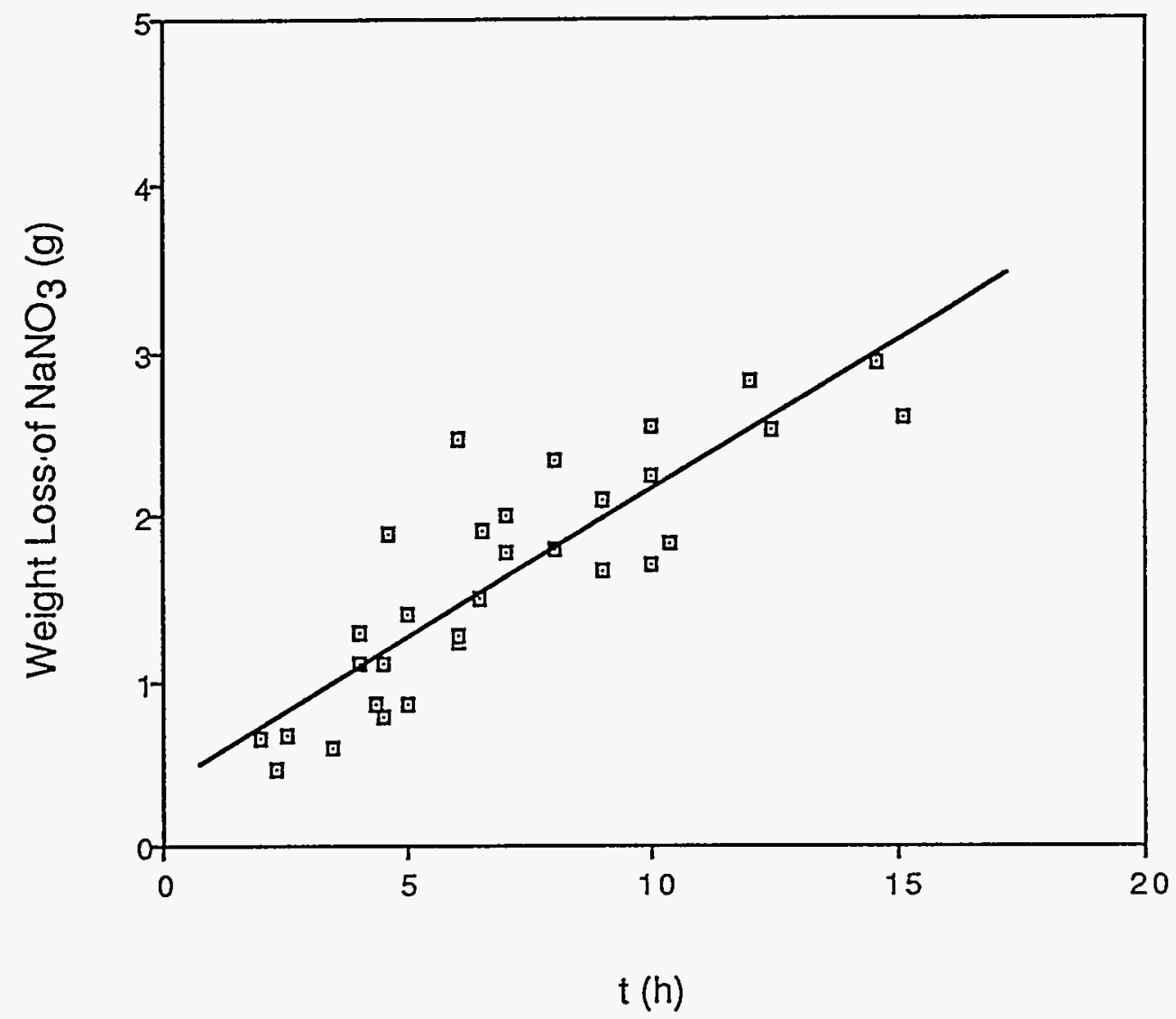

Figure 2. Weight loss of $\mathrm{NaNO}_{3}$ as a function of reaction time. 
to support the specimens and protect the back of the pellets from reaction as shown in Figure 3. The specimens were isothermally heated between $950^{\circ} \mathrm{C}$ and $1100^{\circ} \mathrm{C}$ for $2 \mathrm{~h}$ to 15 $\mathrm{h}$ (except for alumina where the test temperature was extended to $1150^{\circ} \mathrm{C}$ ), followed by airquenching. After the alkali reaction, the specimens which were used for atomic absorption analysis were rinsed in acetone to remove any physically adsorbed salt. The reaction layer formed on the surface of the pellets was then dissolved in dilute hydrofluoric acid and analyzed by atomic absorption analysis. The thickness of the $\mathrm{SiC}, \mathrm{Si}_{3} \mathrm{~N}_{4}$ and alumina pellets before exposure to the alkali-containing atmosphere, and after removal of the reaction layer in dilute HF solution, was measured using a micrometer (model 230MV, The L.S. Starrett Company, Athol, Mass.). The thickness change of the pellets of all other materials was measured with the micrometer directly after reaction without removing the reaction layer.

A simplified repeatability study was performed on the micrometer by reading several pellets fifteen times each. The standard deviation of these sets was approximately $0.002 \mathrm{~mm}$. A considerable amount of effort was directed at maintaining a consistent micrometer measurement procedure.

Four specimens of each material were used for each run. The thickness of each sample was measure three times. The average value of the three readings was used as the thickness of the pellet before the reaction. In a similar manner three thickness measurements were performed after the reaction. The difference between the two averages was used as the thickness change for each specimen due to the reaction. The average value of the thickness change of all four specimens used for each material is taken as the thickness change for the 


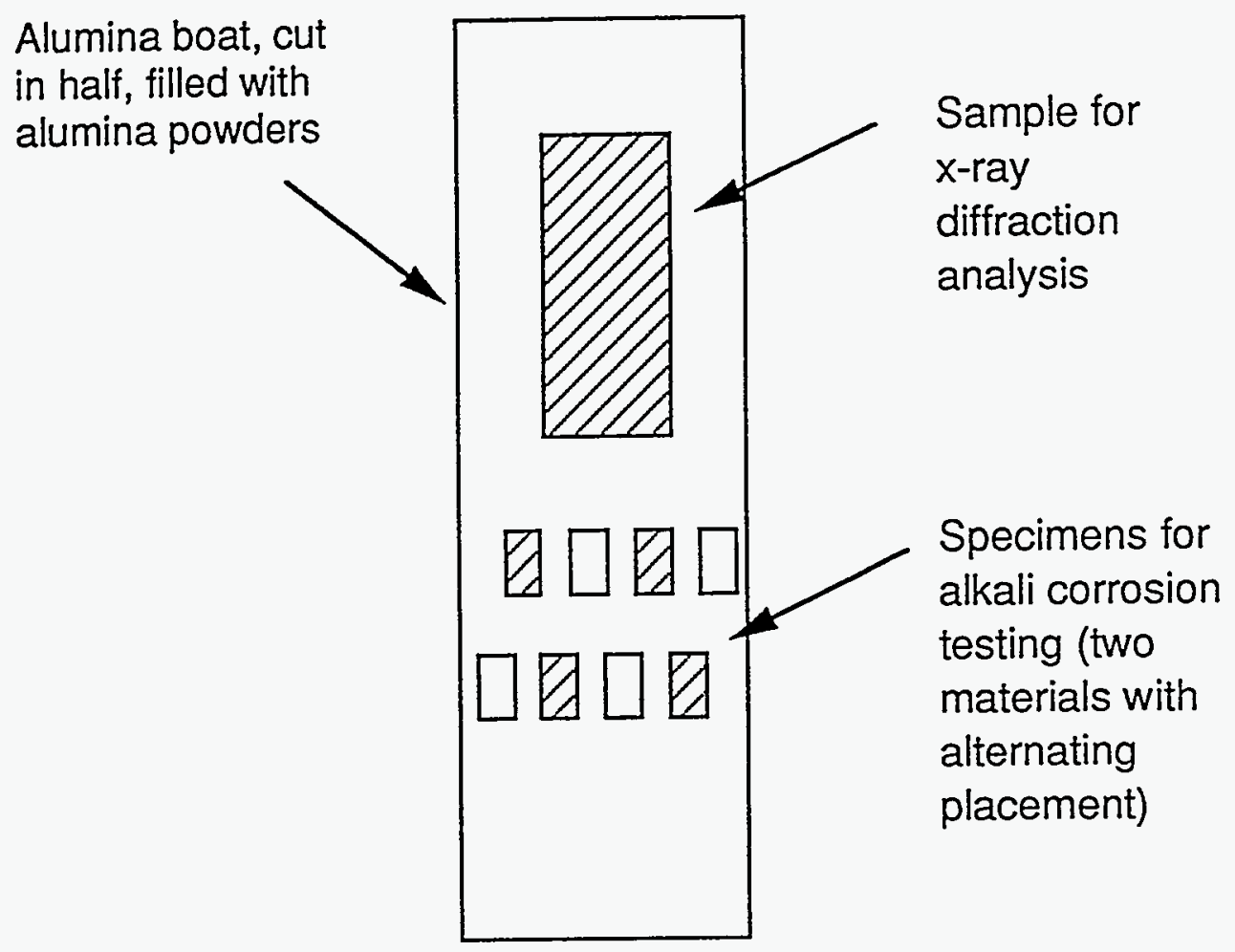

Figure 3. Schematic of the alumina sample holder and sample placement 
temperature and time for which that material was reacted. Thus each data point used in the figures represents the average of four specimens.

Rectangular sections of each material approximately $0.5 \times 0.125 \times 1.0$ inches were placed periodically in the back of the sample boat. After reaction, the phases present on the surface of these rectangular sections were analyzed by $\mathrm{x}$-ray diffraction. The microstructure of the corroded specimens were examined and compared to the microstructure of the as-received specimens using a scanning electron microscope. 


\section{Chapter 4. Experimental Results}

\subsection{Alkali Reaction Kinetics}

\subsubsection{Silicon Nitride}

The calculated reaction layer thickness of the $\mathrm{Si}_{3} \mathrm{~N}_{4}$ samples as a function of reaction temperature and time is shown in Figure 4. To determine if the reaction follows linear or parabolic reaction kinetics, linear regression was performed on $\log (x)$ versus $\log (t)$, where $\mathrm{x}$ is the reaction layer thickness and $\mathrm{t}$ is the time. The resulting slope is the exponent, $\mathrm{n}$, in the $\mathrm{x}=\mathrm{kt}^{\mathrm{n}}$ equation. Performing this type of analysis, $\mathrm{n}$ equals $0.9,1.2,1.1$, and 1.1 for 950 , 1000,1050 , and $1100^{\circ} \mathrm{C}$ indicating that the reaction rate is approximately linear. As mentioned above in the experimental procedure section, the reaction thickness in Figure 4 represents the average of four specimens tested under each experimental condition. These results have been reported in a previous paper. ${ }^{125}$ The sodium silicate phase that formed on the surface of the $\mathrm{Si}_{3} \mathrm{~N}_{4}$ pellets during the alkali exposure was a liquid at the test temperatures and had a tendency to bead up during cooling. Because of this, direct measurement of the thickness of the corrosion layer resulted in poor repeatability between samples within a run. Therefore, the corrosion reaction layer thickness was calculated from the thickness change of the $\mathrm{Si}_{3} \mathrm{~N}_{4}$ pellet before and after exposure in the alkali-containing atmosphere (with the glassy layer removed) according to the reaction: 


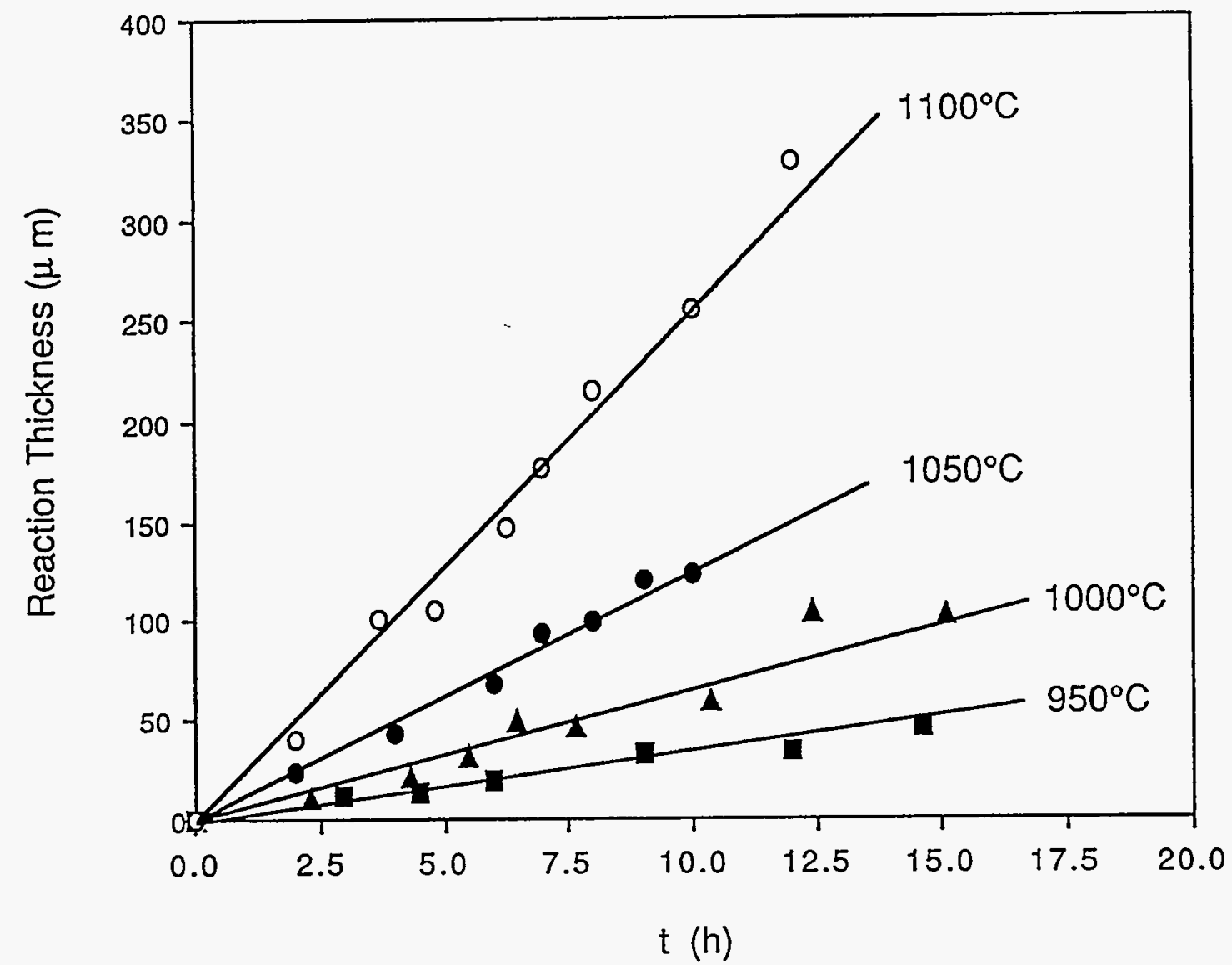

Figure 4. Reaction layer thickness versus time for silicon nitride 


$$
\mathrm{Na}_{2} \mathrm{O}+x \mathrm{xi}_{3} \mathrm{~N}_{4}+3 \mathrm{xO}_{2}=\mathrm{Na}_{2} \mathrm{O} \cdot 3 \times \mathrm{SiO}_{2}+2 \mathrm{xN}_{2}
$$

The composition of the sodium silicate glass which formed on the surface of the pellets during the alkali exposure was determined by atomic absorption analysis. Using the thickness of the $\mathrm{Si}_{3} \mathrm{~N}_{4}$ pellet before and after reaction (with the glassy layer removed) and the densities of the $\mathrm{Si}_{3} \mathrm{~N}_{4}$ and the sodium silicate formed, ${ }^{9,126}$ the equivalent thickness of the sodium silicate glass can be calculated. Figure 5 shows the Arrhenius plot of the natural $\log$ of the reaction rate constant versus reciprocal temperature. The resulting experimental activation energy associated with the alkali reaction is $199 \mathrm{~kJ} / \mathrm{mol}$ (with an associated standard deviation of approximately $15 \mathrm{~kJ} / \mathrm{mol}$ ). Table 1 lists the results of the atomic absorption analysis of the sodium silicate glass formed after the alkali reaction and the rate constants at various temperatures determined in this study.

This alkali corrosion process is quite complex and there are many possible rate-controlling steps. These include: 1.) transport of the sodium species through the gas phase to the sample surface; 2.) reaction of the sodium species with the silicate (this may include adsorption and decomposition of the sodium containing species); 3.) diffusion of the sodium species through the silicate layer; 4.) dissolution of the $\mathrm{SiO}_{2}$ (formed at the $\mathrm{Si}_{3} \mathrm{~N}_{4} /$ silicate interface) in the silicate; 5.) diffusion of oxygen through the silicate layer; 6.) reaction of oxygen with $\mathrm{Si}_{3} \mathrm{~N}_{4}$ at the $\mathrm{Si}_{3} \mathrm{~N}_{4} /$ silicate interface; 7.) diffusion of the gaseous nitrogen or $\mathrm{NO}_{\mathrm{x}}$ reaction products through the silicate layer. It is also possible that two or more reaction steps are sufficiently slow that each of these has a significant contribution to the overall reaction rate. The linear relationship between the reaction thickness and time at all temperatures indicates that the 


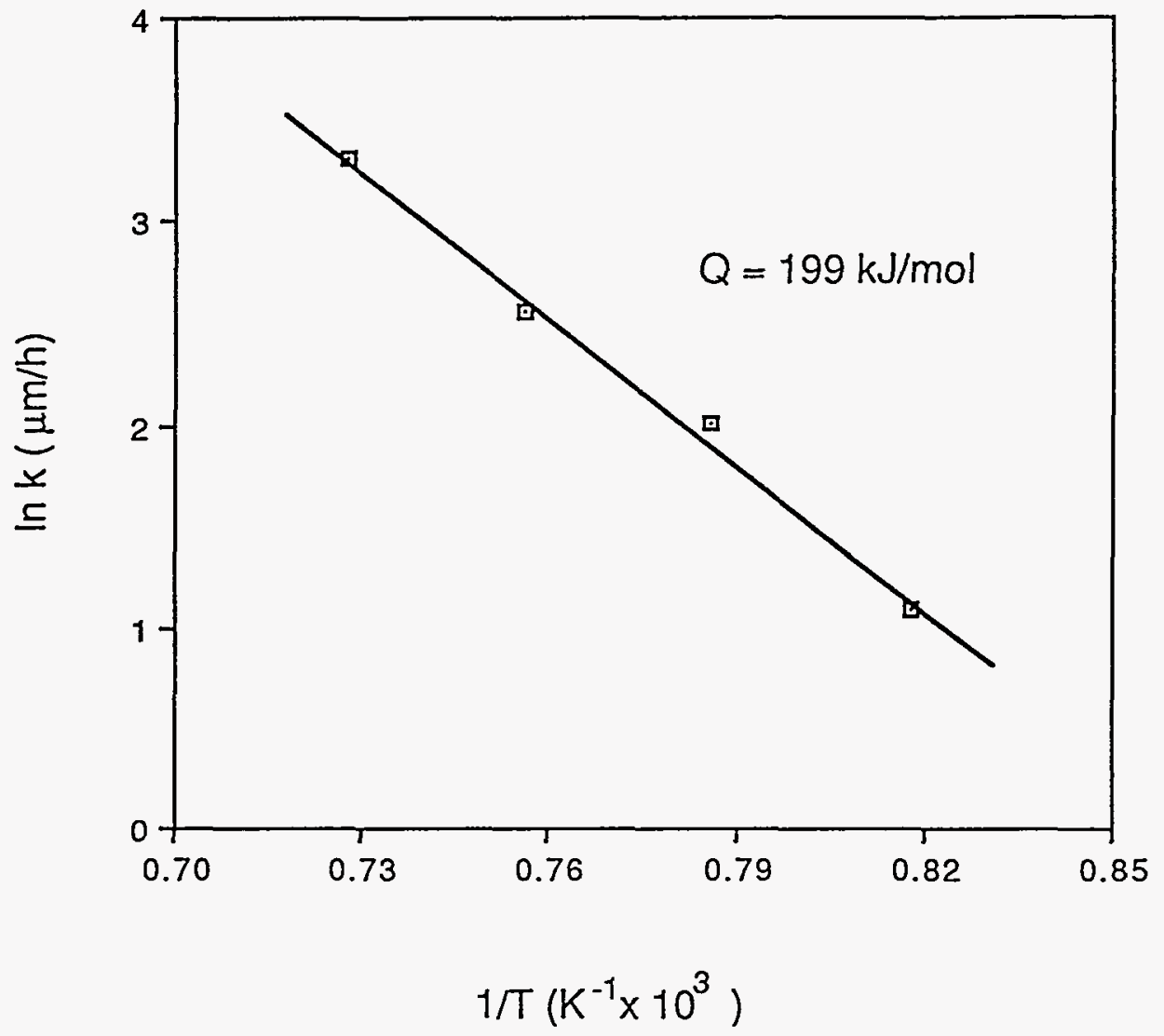

Figure 5. Reaction rate constant versus reciprocal temperature for silicon nitride 
Table 1. Alkali Reaction Kinetics of $\mathrm{Si}_{3} \mathrm{~N}_{4}$ and Chemical Analysis of the Silicate Liquids

\begin{tabular}{cc}
\hline Temp $\left({ }^{\circ} \mathrm{C}\right)$ & Reaction rate $(\mu \mathrm{m} / \mathrm{h})$ \\
\hline 950 & 3.00 \\
1000 & 7.40 \\
1050 & 12.95 \\
& \\
1100 & 27.22 \\
\hline
\end{tabular}

Activation energy: $199 \mathrm{~kJ} / \mathrm{mol}$

Average $\mathrm{SiO}_{2} / \mathrm{Na}_{2} \mathrm{O}$ molar ratio: $2.22 \pm 0.64$ 
alkali corrosion process for $\mathrm{Si}_{3} \mathrm{~N}_{4}$ is interface-controlled.

Figure 6 shows the comparison of the pure oxidation (in oxygen or air) and the alkalienhanced oxidation of $\mathrm{Si}_{3} \mathrm{~N}_{4}$ from $1000^{\circ} \mathrm{C}$ to $1100^{\circ} \mathrm{C}$. Since most of the kinetic data for pure oxidation of $\mathrm{Si}_{3} \mathrm{~N}_{4}$ were obtained by other authors at temperatures higher than $1100^{\circ} \mathrm{C}$, the data used for comparison were extrapolated from the high temperature results. Based on the results of the current study, the oxidation rate of $\mathrm{Si}_{3} \mathrm{~N}_{4}$ in the alkali-containing atmosphere is approximately $10^{2}$ to $10^{4}$ times faster than the oxidation rate of $\mathrm{Si}_{3} \mathrm{~N}_{4}$ in pure oxygen, depending on the type of the $\mathrm{Si}_{3} \mathrm{~N}_{4}$ material. The accelerated oxidation in the presence of $\mathrm{NaNO}_{3}$ vapors, relative to the pure oxidation where a solid silica layer forms, is attributed to the formation of a sodium silicate liquid, which allows oxygen to quickly diffuse to the liquid- $\mathrm{Si}_{3} \mathrm{~N}_{4}$ interface. Based on ionic diffusion, the oxygen diffusivity in vitreous silica is between $10^{-14}$ and $10^{-15} \mathrm{~cm}^{2} / \mathrm{s},{ }^{132-134}$ whereas the oxygen diffusivity in a sodium silicate liquid $\left(\mathrm{Na}_{2} \mathrm{O} \cdot 4 \mathrm{SiO}_{2}\right)$ is approximately $10^{-9} \mathrm{~cm}^{2} / \mathrm{s}^{135}$ In the present study, the atomic absorption analysis reveals that the sodium silicate glass has an average composition of $\mathrm{Na}_{2} \mathrm{O} \cdot 2.22 \mathrm{SiO}_{2}$ (Table 1). The oxygen diffusivity data in the $\mathrm{Na}_{2} \mathrm{O} \cdot 2.22 \mathrm{SiO}_{2}$ glass are not available; however, they are likely to be greater than $10^{-9} \mathrm{~cm}^{2} / \mathrm{s}$ because of the higher soda content.

The oxidation of $\mathrm{Si}_{3} \mathrm{~N}_{4}$ in dry air or $\mathrm{O}_{2}$ without alkalis present is generally accepted to be controlled by oxygen diffusion through the silica layer ${ }^{19-23,61,63}$ and hence exhibits parabolic reaction kinetics. In the alkali-containing atmosphere, however, the reaction becomes interface-controlled, as evidenced by the linearity of the thickness versus time plots shown in Figure 4. The transition from the diffusion-controlled reaction (pure oxidation) to the 


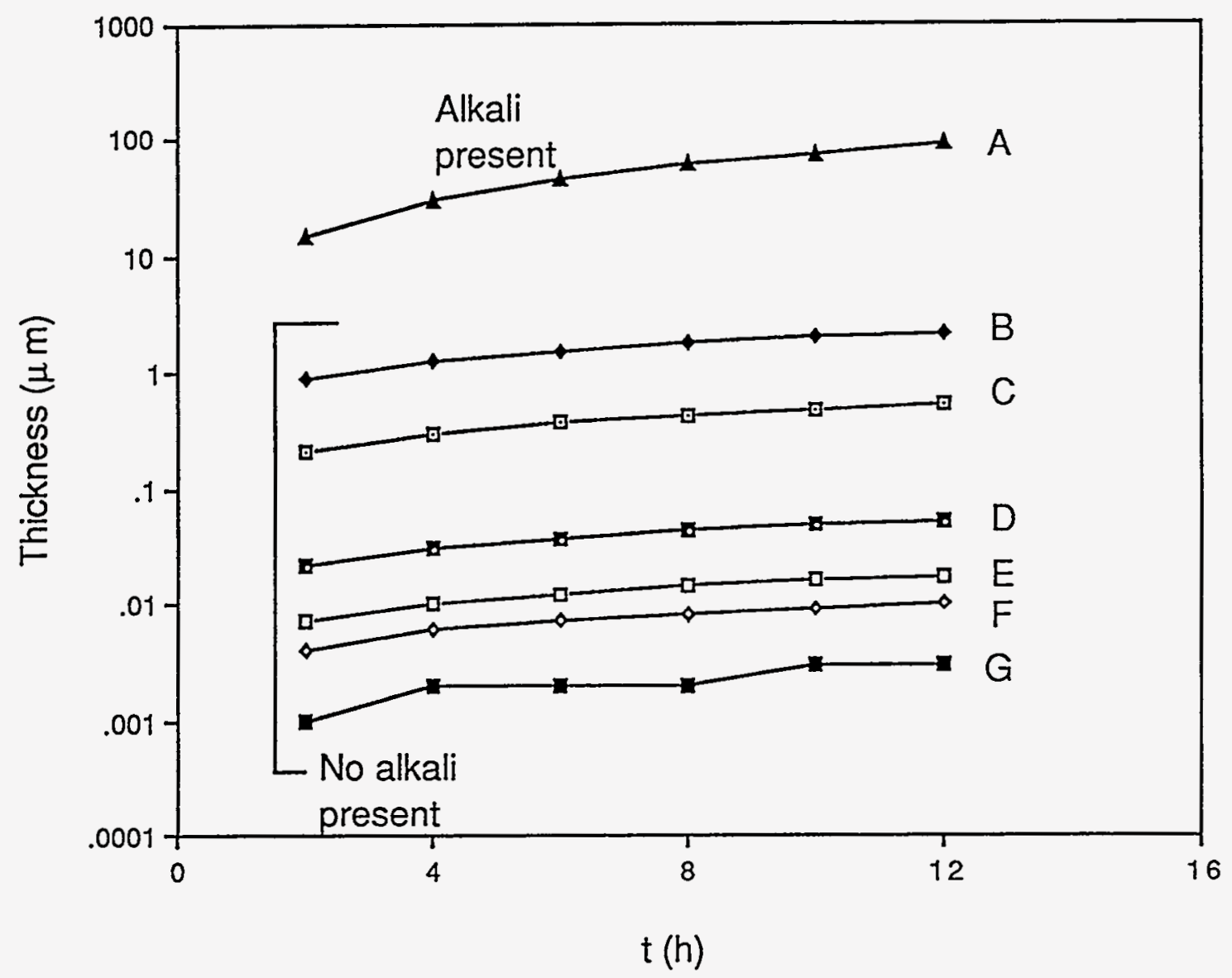

(a)

Figure 6. Comparison of oxidation of silicon nitride in oxygen or air and in the atmosphere containing 0.98 vol\% $\mathrm{NaNO}_{3}$ at (a) $1000^{\circ} \mathrm{C}$, (b) $1050^{\circ} \mathrm{C}$, and (c) $1100^{\circ} \mathrm{C}$; A: present work, B: hot pressed (1 wt\% $\mathrm{MgO}$ ) in air (ref. 60), C: hot pressed (1 wt\% MgO) (ref. 49), D: hot pressed (5 wt\% MgO) (ref. 44), E: CVD (ref. 42), F: CVD (ref. 40), G: CVD (ref. 64). 


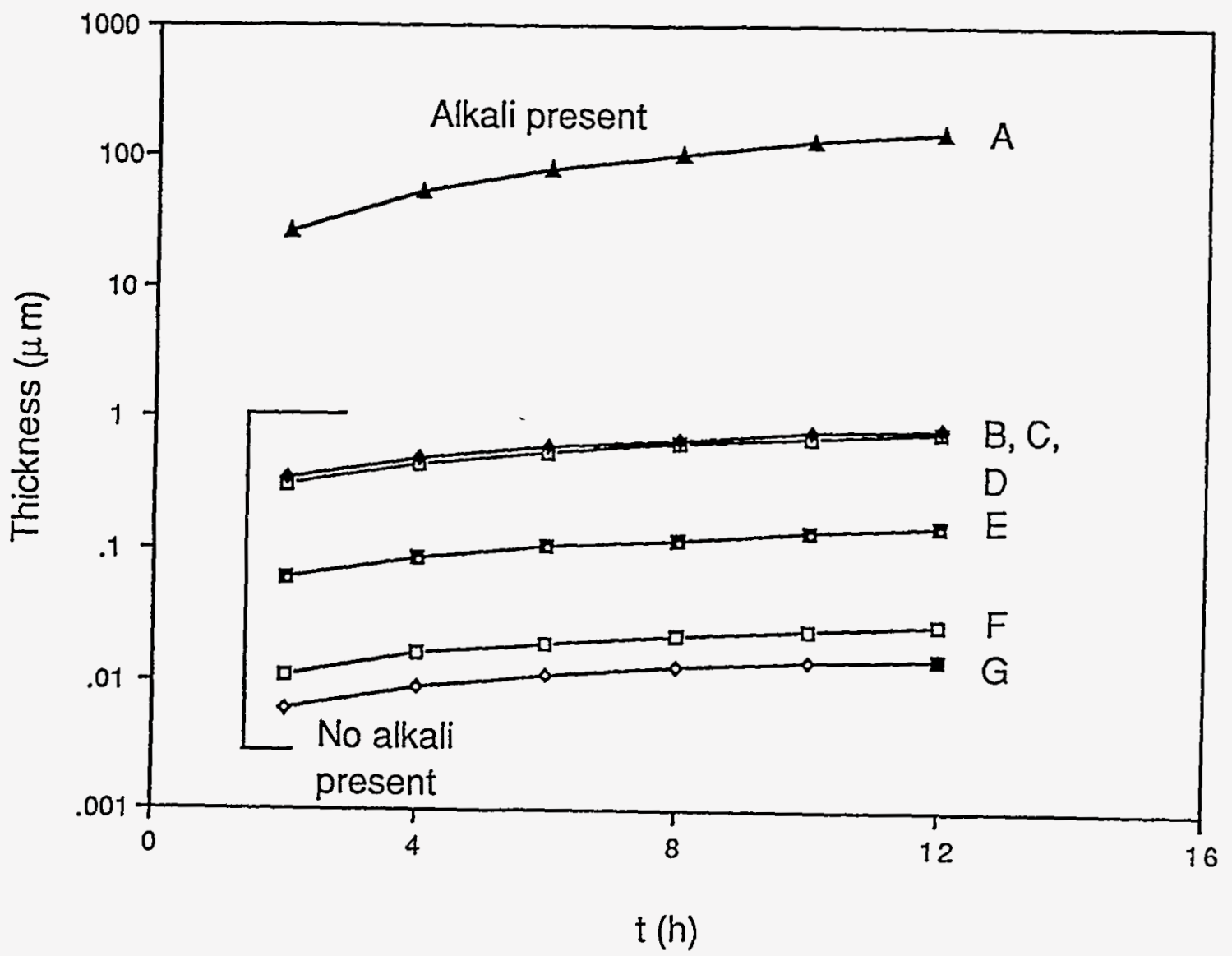

(b) 


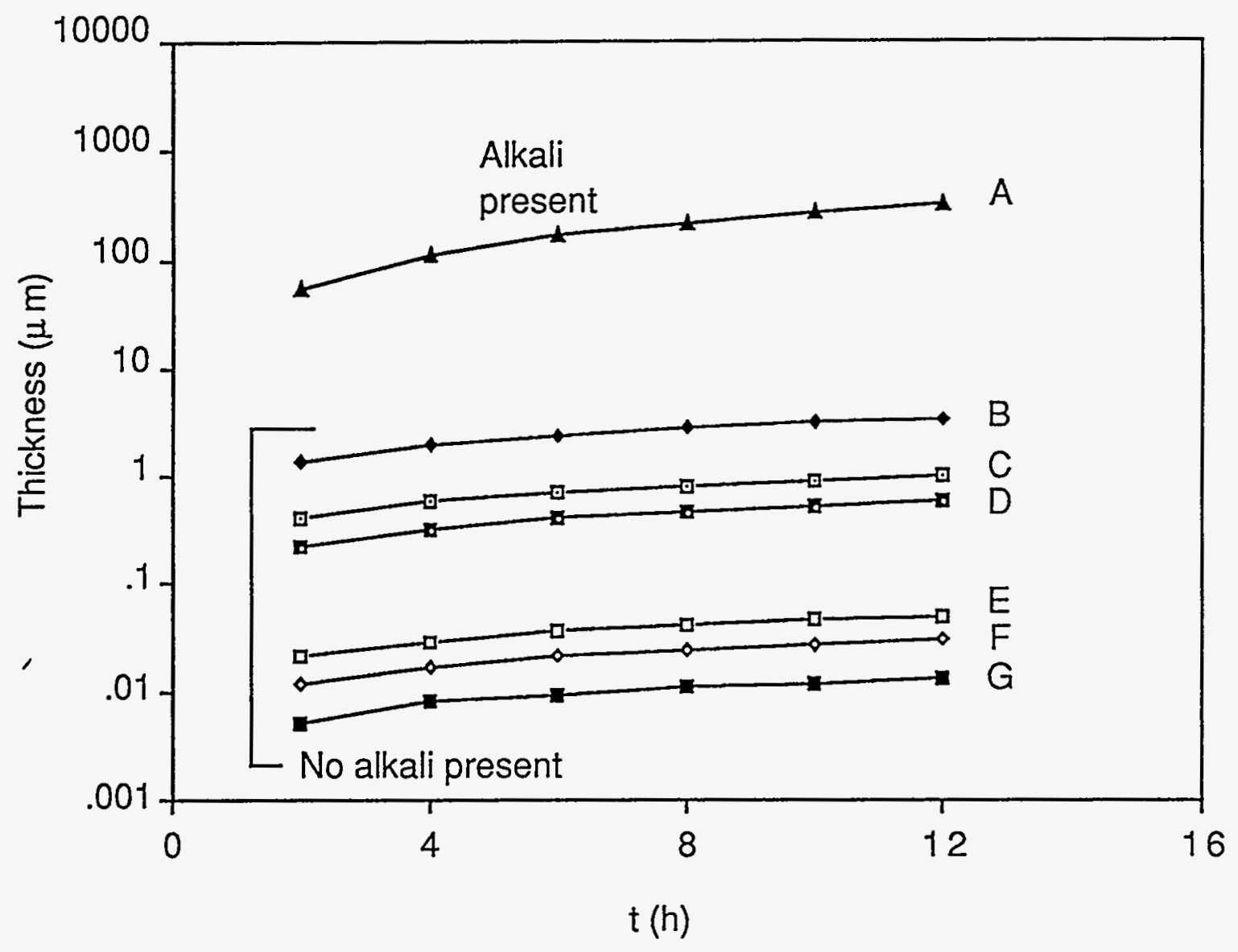

(c) 
interface-controlled reaction (alkali-enhanced oxidation) can be explained in terms of the difference in the transport properties of oxygen in silica as compared to the sodium silicate. In the case of pure oxidation (in the absence of alkalis), the rate of transport of oxygen through the $\mathrm{SiO}_{2}$ layer is reportedly slower than the rate of the interfacial oxidation reaction; therefore, the overall reaction is controlled by the oxygen diffusion. When the $\mathrm{SiO}_{2}$ layer reacts with the alkali to form a sodium silicate liquid, the rate of oxygen transport becomes relatively fast in comparison with the interfacial oxidation reaction. This is due to the fact that the oxygen diffusivity in vitreous $\mathrm{SiO}_{2}$ is approximately 6 orders of magnitude slower than in a 1:4 sodium silicate liquid at $1000^{\circ} \mathrm{C}$, as mentioned above. If the oxidation of $\mathrm{Si}_{3} \mathrm{~N}_{4}$ in the alkali-containing atmosphere is also controlled by oxygen diffusion, the alkali-enhanced oxidation rate should be at least $10^{5}$ to $10^{6}$ times higher than the pure oxidation rate and should exhibit parabolic reaction kinetics. However, the parabolic reaction characteristics commonly associated with the pure oxidation of $\mathrm{Si}_{3} \mathrm{~N}_{4}$ were not observed in the alkalicontaining atmosphere.

\subsubsection{1 $\mathrm{Si}_{3} \mathrm{~N}_{4}$ Alkali Reaction Mechanism and Rate Controlling Step}

A schematic of the alkali assisted oxidation process for $\mathrm{Si}_{3} \mathrm{~N}_{4}$ is shown in Figure 7. The magnitude of the oxidation rate of $\mathrm{Si}_{3} \mathrm{~N}_{4}$ in the presence of $\mathrm{NaNO}_{3}$ vapors, as demonstrated demonstrated in Figure 6, suggests that the protective $\mathrm{SiO}_{2}$ and $\mathrm{Si}_{2} \mathrm{~N}_{2} \mathrm{O}$ layers are no longer present during the reaction. If these layers were present during the alkali reaction, the 


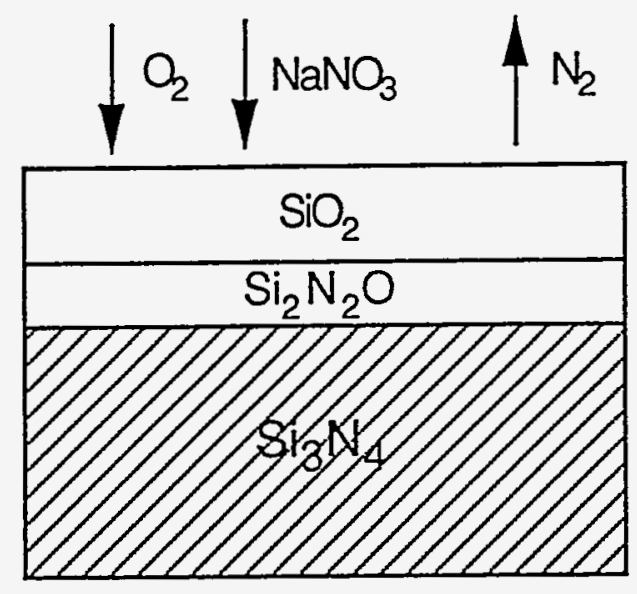

(1)

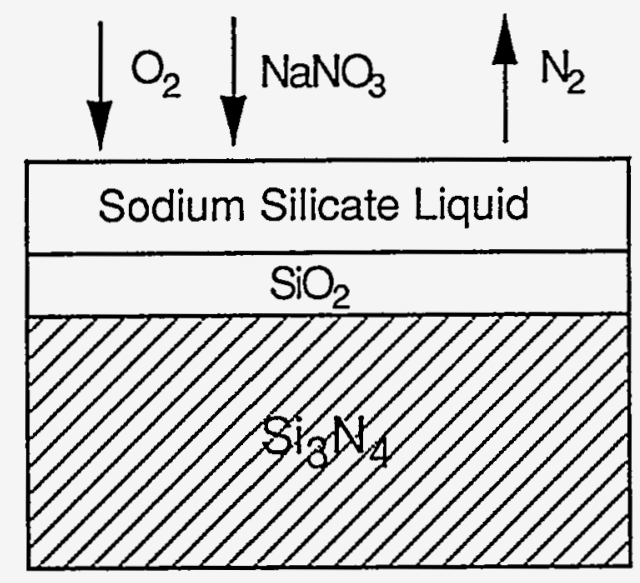

(2)

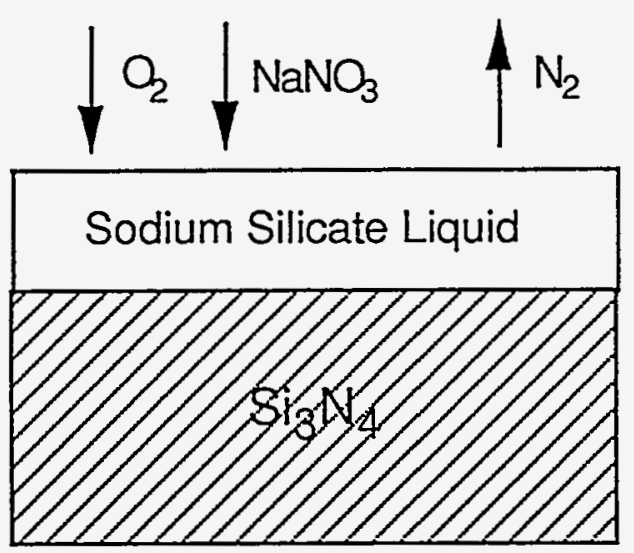

(3)

Figure 7. Schematic of the oxidation process of silicon nitride in an

alkali-containing atmosphere 
oxidation rate would be much lower, comparable to the pure oxidation case because oxygen would still be required to diffuse through these layers. The initial reaction should consist of the removal of the $\mathrm{SiO}_{2}$ and the $\mathrm{Si}_{2} \mathrm{~N}_{2} \mathrm{O}$ layers if present prior to alkali exposure:

$$
\begin{aligned}
& \mathrm{Na}_{2} \mathrm{O}+x \mathrm{xiO}_{2}=\mathrm{Na}_{2} \mathrm{O} \cdot \mathrm{xSiO}_{2} \\
& \mathrm{Si}_{2} \mathrm{~N}_{2} \mathrm{O}+1.5 \mathrm{O}_{2}=2 \mathrm{SiO}_{2}+\mathrm{N}_{2}
\end{aligned}
$$

After removal of the silica and oxynitride layers, the reaction proceeds by oxidation of the $\mathrm{Si}_{3} \mathrm{~N}_{4}$ to form $\mathrm{SiO}_{2}$. The $\mathrm{SiO}_{2}$ formed, quickly dissolves in the sodium silicate liquid:

$$
\begin{aligned}
& \mathrm{Si}_{3} \mathrm{~N}_{4}+3 \mathrm{O}_{2}=3 \mathrm{SiO}_{2}+2 \mathrm{~N}_{2} \\
& \mathrm{SiO}_{2}+\mathrm{Na}_{2} \mathrm{O} \cdot x \mathrm{SiO}_{2}=\mathrm{Na}_{2} \mathrm{O} \cdot(\mathrm{x}+1) \mathrm{SiO}_{2}
\end{aligned}
$$

The soda required for the above reactions was continuously supplied from the sodium nitrate vapors, which were maintained at a constant concentration throughout all of the experimentation.

For comparison, the oxidation sequence of $\mathrm{Si}_{3} \mathrm{~N}_{4}$ in pure oxygen or air as reported in the literature is shown in Figure $8 .^{61}$ The overall oxidation process involves adsorption of oxygen on the surface; inward diffusion of oxygen through the $\mathrm{SiO}_{2}$ and the $\mathrm{Si}_{2} \mathrm{~N}_{2} \mathrm{O}$ layers; oxidation at the $\mathrm{SiO}_{2}-\mathrm{Si}_{2} \mathrm{~N}_{2} \mathrm{O}$ and the $\mathrm{Si}_{3} \mathrm{~N}_{4}-\mathrm{Si}_{2} \mathrm{~N}_{2} \mathrm{O}$ interfaces; and outward diffusion of the gaseous product $\mathrm{N}_{2}$ through the $\mathrm{SiO}_{2}$ and the $\mathrm{Si}_{2} \mathrm{~N}_{2} \mathrm{O}$ layers. ${ }^{136}$ This oxidation process is relatively slow because of the presence of the $\mathrm{SiO}_{2}$ and $\mathrm{Si}_{2} \mathrm{~N}_{2} \mathrm{O}$ layers which serve as diffusion barriers for oxygen. In the gaseous alkali corrosion, following the removal of $\mathrm{SiO}_{2}$ and $\mathrm{Si}_{2} \mathrm{~N}_{2} \mathrm{O}$ at the initial stage, there appears to be no silica or oxynitride layer between the sodium silicate and the $\mathrm{Si}_{3} \mathrm{~N}_{4}$ as evidenced by the relatively high oxidation rates. If either the silica or oxynitride 

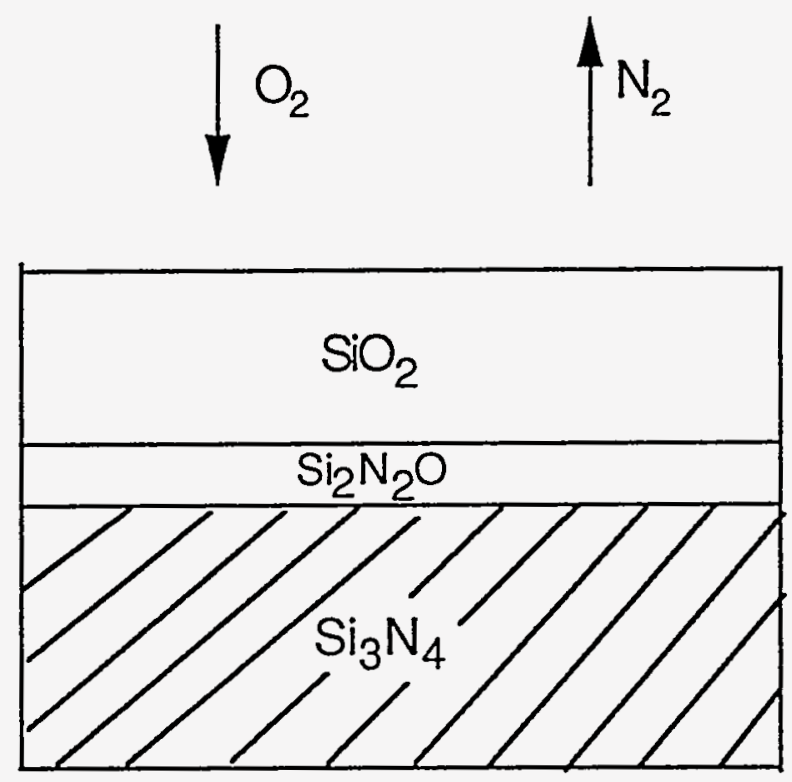

Figure 8. Schematic of the oxidation process for silicon nitride in air with no alkalis present (after Jacobson, reference 63) 
layer were present in a coherent form, the reaction rates would be expected to be comparable to those observed in pure oxygen or air. The atomic absorption analysis of all the specimens indicates that the average $\mathrm{Na}_{2} \mathrm{O}$ content in the sodium silicate glass is about $31 \mathrm{~mol} \%$. This composition lies in a single liquid phase region (between $950^{\circ} \mathrm{C}$ and $1100^{\circ} \mathrm{C}$ ) according to the $\mathrm{Na}_{2} \mathrm{O}-\mathrm{SiO}_{2}$ phase diagram, ${ }^{137}$ and therefore forbids the precipitation of $\mathrm{SiO}_{2}$ if equilibrium conditions are maintained. Assuming equilibrium conditions are maintained, the $\mathrm{SiO}_{2}$ formed during the alkali reaction is immediately dissolved in the sodium silicate liquid.

This type of gaseous alkali corrosion of $\mathrm{Si}_{3} \mathrm{~N}_{4}$, where the alkali species is continuously supplied to the sample surface, is notably different from the thin film alkali corrosion experiments reported in the literature. ${ }^{61,69,70}$ The quantity of alkali present in the thin film experiments in fixed by the initial salt loading. As the reaction proceeds, the alkali silicate liquid becomes progressively richer in silica. This alkali-enhanced oxidation will eventually terminate when the solubility limit of $\mathrm{SiO}_{2}$ in the sodium silicate is reached, and the composition of which is given by the liquidus composition in the $\mathrm{Na}_{2} \mathrm{O}-\mathrm{SiO}_{2}$ system. After reaching the saturation limit of silica in the sodium silicate liquid, the $\mathrm{SiO}_{2}$ and oxynitride layers begin to grow between the $\mathrm{Si}_{3} \mathrm{~N}_{4}$ substrate and the sodium silicate. The oxidation in this case becomes equivalent to the oxidation in pure oxygen or air, since further reaction requires oxygen diffusion through the $\mathrm{SiO}_{2}$ and the $\mathrm{Si}_{2} \mathrm{~N}_{2} \mathrm{O}$ layers. In contrast, for the case of the gaseous alkali corrosion in the present study, the dissolution-oxidation process proceeds without the formation of the protective $\mathrm{SiO}_{2}$ and $\mathrm{Si}_{2} \mathrm{~N}_{2} \mathrm{O}$ layers because of the continuous supply of soda from the vapor phase. 
The overall gaseous alkali corrosion process for $\mathrm{Si}_{3} \mathrm{~N}_{4}$ is composed of a series of step reactions: adsorption, decomposition, diffusion, dissolution, and oxidation as discussed above. In order to identify the rate-controlling step, it is necessary to know the relative reaction rate of each step involved in the overall reaction. All of the kinetic data associated with the step reactions are not available. However, by using the expected time dependency of each reaction step, some of these steps can be eliminated from consideration as the rate-controlling step.

Consider first the adsorption, decomposition and diffusion of alkali in the liquid phase. The atomic absorption analysis of the sodium silicate glass indicates that the average soda content is much higher than that of the corresponding liquidus composition in the $\mathrm{Na}_{2} \mathrm{O}-\mathrm{SiO}_{2}$ system. If the alkali absorption process were the slowest step, the liquid phase should be saturated with $\mathrm{SiO}_{2}$ as the oxidation and dissolution reactions progress, similar to what happens in the thin film experiments discussed above. This is clearly not the case according to the atomic absorption analysis of the present study. Therefore, the absorption of alkali in the sodium silicate liquid cannot be the rate-controlling step. Consider next the dissolution of $\mathrm{SiO}_{2}$ in the sodium silicate liquid. Reported in the literature is a study of the dissolution of vitreous silica rods, disks and crucibles in a variety of sodium silicate liquids all of which followed the parabolic rate law. ${ }^{138}$ In addition, the dissolution rate of fused $\mathrm{SiO}_{2}$ in a $30 \%$ $\mathrm{Na}_{2} \mathrm{O}-70 \% \mathrm{SiO}_{2}$ liquid, which corresponds to the glass composition in the present study, is approximately twice as fast as the observed alkali reaction rate of $\mathrm{Si}_{3} \mathrm{~N}_{4}$. Therefore, the dissolution of silica cannot be the rate-controlling step either. Also, because the overall reaction of $\mathrm{Si}_{3} \mathrm{~N}_{4}$ in the gaseous alkali environment exhibits interface-controlled 
characteristics, the diffusion of oxygen, as well as the outward diffusion of $\mathrm{N}_{2}$, can be ruled out as the rate-controlling step. As discussed, the linear reaction characteristics and the magnitude of the reaction rate suggest that the $\mathrm{Si}_{2} \mathrm{~N}_{2} \mathrm{O}$ layer was not likely to exist during the alkali reaction of $\mathrm{Si}_{3} \mathrm{~N}_{4}$. The presence of a $\mathrm{Si}_{2} \mathrm{~N}_{2} \mathrm{O}$ layer implies that the oxidation of $\mathrm{Si}_{3} \mathrm{~N}_{4}$ requires the diffusion of oxygen through the $\mathrm{Si}_{2} \mathrm{~N}_{2} \mathrm{O}$ layer. Since this process is extremely slow, the overall reaction rate would be much lower than the rate observed in the present study. The interfacial oxidation reaction would be expected to exhibit linear reaction kinetics. The oxidation of $\mathrm{SiC}$ (in which the oxidation process is believed to be very similar to silicon nitride as discussed in the following section) and $\mathrm{Si}_{3} \mathrm{~N}_{4}$ in pure oxygen or air with a small percentage of water present also exhibits linear reaction kinetics. ${ }^{53-61}$ This is generally attributed to the increased solubility of water in the silica layer as compared to oxygen or the disruption of the silica layer and resulting increased oxygen diffusivity. The rate controlling step is presumed to be the interfacial oxidation reaction of either $\mathrm{H}_{2} \mathrm{O}$ or oxygen with the carbide or nitride. In the alkali assisted oxidation reaction, the soda completely disrupts the silica structure, forming a sodium silicate liquid. As reported in the wet oxidation mentioned above, the supply of oxygen is no longer the rate-limiting step. It appears that the ratecontrolling step in the alkali corrosion reactions in the current study is the interfacial oxidation of $\mathrm{Si}_{3} \mathrm{~N}_{4}$ to $\mathrm{SiO}_{2}$.

The reaction and dissolution of the silica and oxynitride layers initially present on the $\mathrm{Si}_{3} \mathrm{~N}_{4}$ most likely occurs under a different rate-controlling mechanism from the subsequent reaction, which, as described above, appears to be controlled by the oxidation of $\mathrm{Si}_{3} \mathrm{~N}_{4}$ to $\mathrm{SiO}_{2}$ at the 
liquid-Si $\mathrm{N}_{4}$ interface. This initial reaction stage involves dissolution of the relatively thick (as compared to later stages in the reaction) $\mathrm{SiO}_{2}$ layer originally present on the surface of the $\mathrm{Si}_{3} \mathrm{~N}_{4}$ sample. This process should exhibit parabolic reaction characteristics with the ratecontrolling step being the molecular diffusion of $\mathrm{SiO}_{2}$ in the sodium silicate liquid followed by a parabolic to linear reaction kinetics transition. This initial reaction most likely occurs very rapidly due to the limited thickness of the $\mathrm{SiO}_{2}$ layer that is present on the sample before reaction. This two stage oxidation process most likely exhibits a parabolic to linear transition in contrast to the linear to parabolic transition that is reported for the pure oxidation of $\mathrm{Si}_{3} \mathrm{~N}_{4}$. A mixed interface reaction/diffusion control model has also been proposed for the pure oxidation of $\mathrm{Si}_{3} \mathrm{~N}_{4}{ }^{139}$ It is likely that at very short times the oxidation of $\mathrm{Si}_{3} \mathrm{~N}_{4}$ in pure oxygen or air is interface-controlled and the subsequent growth of the oxide at longer times is controlled by the diffusion of oxygen. In the gaseous alkali corrosion of $\mathrm{Si}_{3} \mathrm{~N}_{4}$, the initial reaction stage is likely to be governed by a diffusion-controlled reaction (dissolution of $\mathrm{SiO}_{2}$ ) at very short times, followed by an interface-controlled reaction (oxidation of $\mathrm{Si}_{3} \mathrm{~N}_{4}$ ) at longer times.

\subsubsection{Alkali Corrosion Induced Microstructural Changes of $\mathrm{Si}_{3} \mathrm{~N}_{4}$}

Figure 9 shows the SEM micrographs of the fracture surface of the as-received specimen and the surface of the $\mathrm{Si}_{3} \mathrm{~N}_{4}$ after a $19 \mathrm{~h}$ exposure at $1000^{\circ} \mathrm{C}$ in the alkali-containing atmosphere (with the glassy layer removed by a 15 minute etch in dilute HF). As can be seen 
in Figure 9b, the grain boundaries appear to be preferentially attacked by the alkali corrosion reaction. This preferential grain boundary attack has been observed by other investigators for various types of $\mathrm{Si}_{3} \mathrm{~N}_{4}{ }^{61}$ EDAX measurements of the as-received $\mathrm{Si}_{3} \mathrm{~N}_{4}$ specimens used in this study revealed that alumina is present, most likely added as a sintering aid. The presence of small amounts of $\mathrm{Al}_{2} \mathrm{O}_{3}$ can significantly reduce the solidus temperature of the silica layer that forms on the surface of the specimen. Compared to the melting temperature of $\mathrm{SiO}_{2}$ $\left(1720^{\circ} \mathrm{C}\right)$, a metastable eutectic associated with the $\mathrm{Al}_{2} \mathrm{O}_{3}-\mathrm{SiO}_{2}$ system is reported to exist around $1250^{\circ} \mathrm{C} .{ }^{140}$ The preferential attack of the grain boundary regions that is observed for this material may be caused by the segregation of the $\mathrm{Al}_{2} \mathrm{O}_{3}$ at the grain boundaries. 
a.)

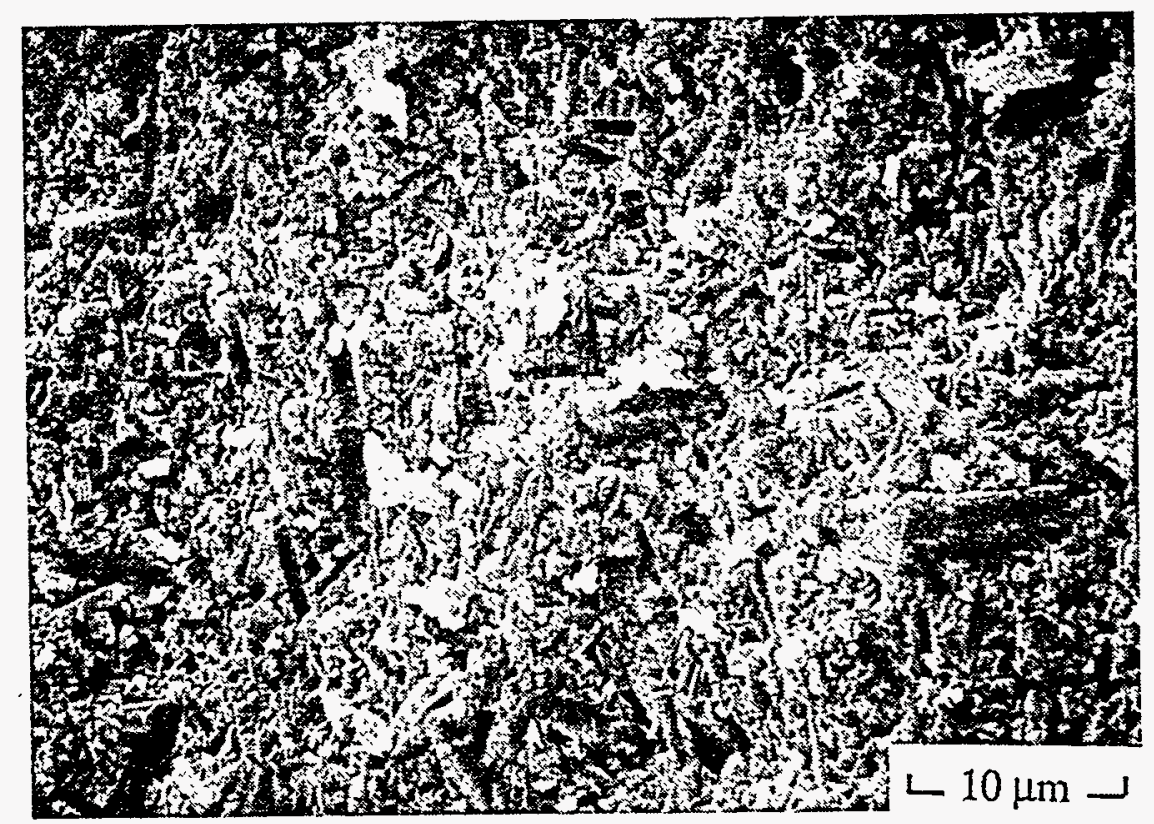

b.)

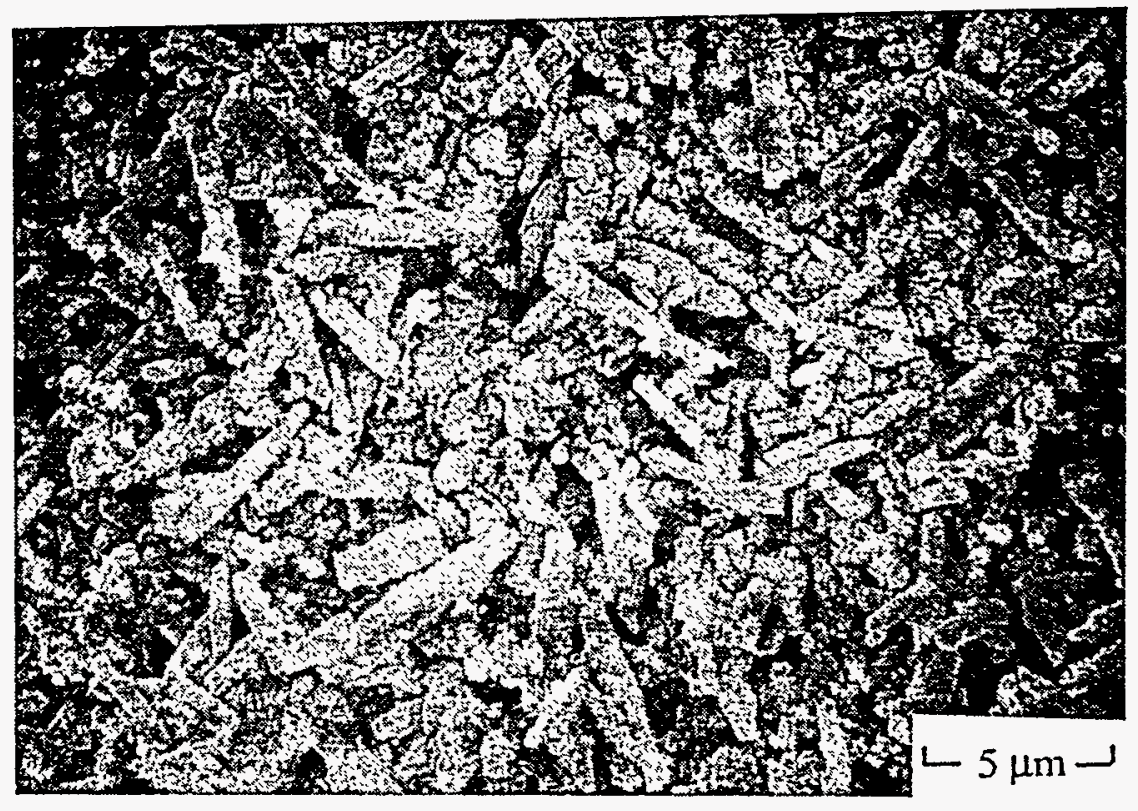

Figure 9. SEM micrograph of (a) fracture surface of as-received $\mathrm{Si}_{3} \mathrm{~N}_{4}$ and (b) $\mathrm{Si}_{3} \mathrm{~N}_{4}$ after $19 \mathrm{~h}$ at $1000^{\circ} \mathrm{C}$, glass etched away 


\subsubsection{Silicon Carbide}

The calculated corrosion layer thickness of $\alpha$-SiC in dry air containing $\mathrm{NaNO}_{3}$ vapors is plotted as a function of reaction temperature and time in Figure 10 (with each data point representing the average of four specimens tested for that experimental condition). To determine if the reaction follows linear or parabolic reaction kinetics, linear regression was performed on $\log (\mathrm{x})$ versus $\log (\mathrm{t})$, where $\mathrm{x}$ is the reaction layer thickness and $\mathrm{t}$ is the time. The resulting slope is the exponent, $n$, in the $x=k t^{n}$ equation. Performing this type of analysis, $\mathrm{n}$ equals $1.3,1.4,1.0$, and 1.0 for $950,1000,1050$, and $1100^{\circ} \mathrm{C}$ indicating that the reaction rate is approximately linear. Table 2 lists the reaction rate constants at each temperature, the experimental activation energy and the average composition of the sodium silicate reaction layer for $\mathrm{SiC}$. Since both $\mathrm{SiC}$ and $\mathrm{Si}_{3} \mathrm{~N}_{4}$ form a sodium silicate liquid phase on the surface, the step reactions are very similar. Where the individual step reactions are the same a lengthy discussion will not be repeated. Instead, the reader will be referred to the appropriate part in the $\mathrm{Si}_{3} \mathrm{~N}_{4}$ section. The corrosion kinetics of the $\mathrm{SiC}$ in the alkali-containing atmosphere appear to follow a linear rate law instead of the parabolic rate law often observed for pure oxidation of $\mathrm{SiC}^{22-39}$ As discussed previously for silicon nitride, the glassy layer that formed on the surface of the $\mathrm{SiC}$ had a tendency to bead up during cooling, causing poor repeatability in the determination of the corrosion layer thickness. Therefore, the corrosion thickness was calculated from the thickness change of $\mathrm{SiC}$ before and after corrosion according to the 


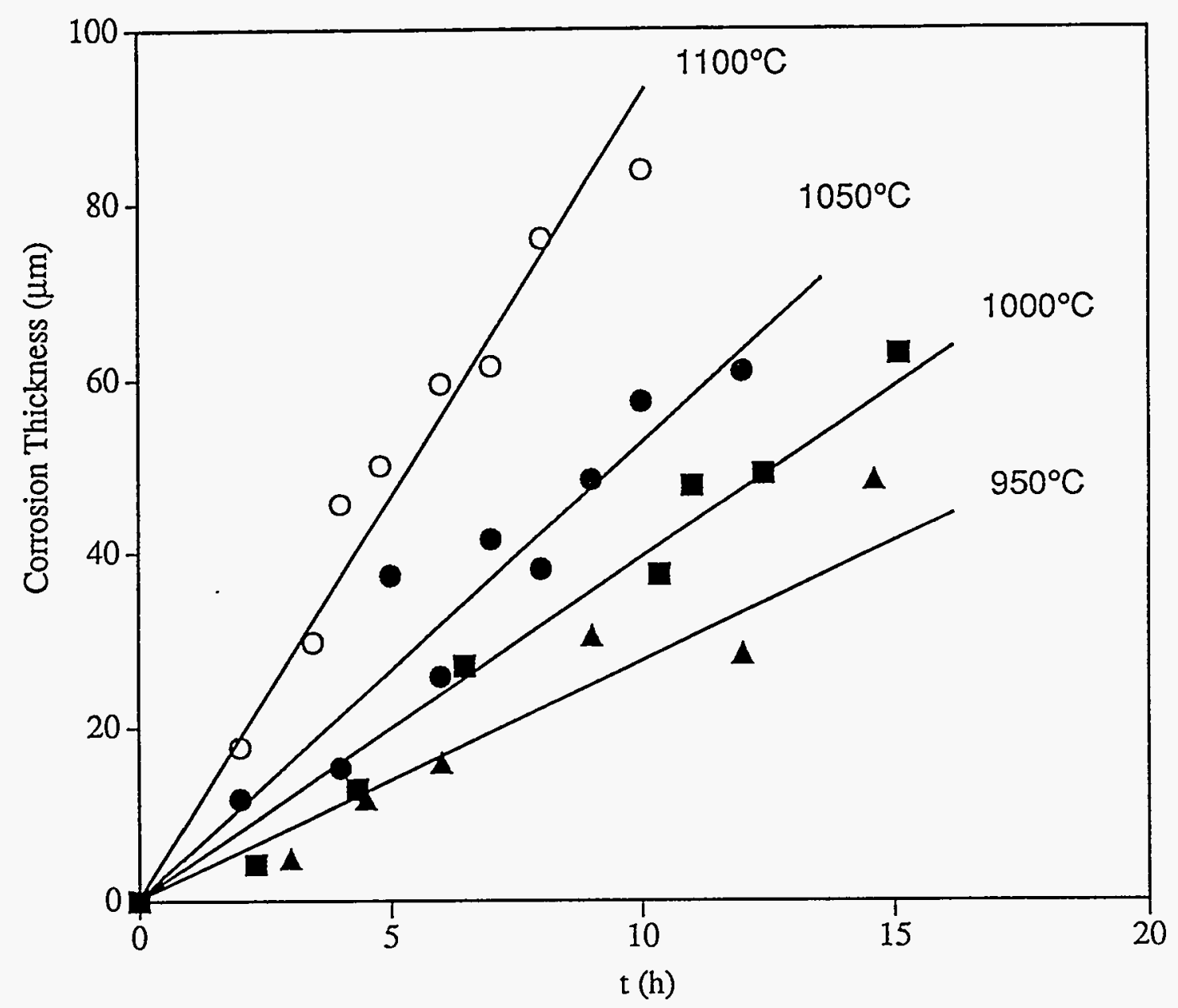

Figure 10. Corrosion thickness of $\mathrm{SiC}$ as a function of temperature and time in dry air containing 0.98 vol\% sodium nitrate vapors 
Table 2. Alkali Reaction Kinetics of $\mathrm{SiC}$ and Chemical Analysis of the Silicate Liquids

\begin{tabular}{|c|c|}
\hline Temp $\left({ }^{\circ} \mathrm{C}\right)$ & Reaction rate $(\mu \mathrm{m} / \mathrm{h})$ \\
\hline 950 & 2.95 \\
\hline 1000 & 4.01 \\
\hline 1050 & 5.33 \\
\hline 1100 & 9.20 \\
\hline Activation energy: & $104 \mathrm{~kJ} / \mathrm{mol}$ \\
\hline \multicolumn{2}{|l|}{ Average $\mathrm{SiO}_{2} / \mathrm{Na}_{2} \mathrm{O}$} \\
\hline molar ratio: & $2.55 \pm 0.45$ \\
\hline
\end{tabular}


reaction:

$$
\mathrm{Na}_{2} \mathrm{O}+x \mathrm{SiC}+1.5 \times \mathrm{X}_{2}=\mathrm{Na}_{2} \mathrm{O} \cdot x \mathrm{SiO}_{2}+x \mathrm{CO}
$$

The average composition of the sodium silicate glass was determined by atomic absorption analysis. Using the thickness change of the $\mathrm{SiC}$ specimen after corrosion product removal and the densities of the $\mathrm{SiC}$ and the glass formed, ${ }^{10,126}$ the equivalent corrosion thickness can be calculated. This calculated corrosion layer thickness is plotted versus reaction time in Figure 10. The lines shown are the calculated regression lines for each data set. The slope of these lines represent the reaction rate constant for each temperature. Using these rate constants, the Arrhenius plot of the natural log of the rate constant versus reciprocal temperature is shown in Figure 11. The experimental activation energy associated with the alkali corrosion process is $104 \mathrm{~kJ} / \mathrm{mol}$ (standard deviation of approximately 15 $\mathrm{kJ} / \mathrm{mol}$ ). The average composition of the sodium silicate glass which formed on the surface of the $\mathrm{SiC}$ pellets was determined by atomic absorption analysis to be approximately $\left(\mathrm{Na}_{2} \mathrm{O}\right) \cdot\left(\mathrm{SiO}_{2}\right)_{2.55}$.

\subsubsection{SiC Alkali Reaction Mechanism and Rate Controlling Step}

The initial stage of the gaseous alkali corrosion of the $\mathrm{SiC}$ is probably very similar to the initial stage for silicon nitride discussed above. The alkali corrosion process begins with the 


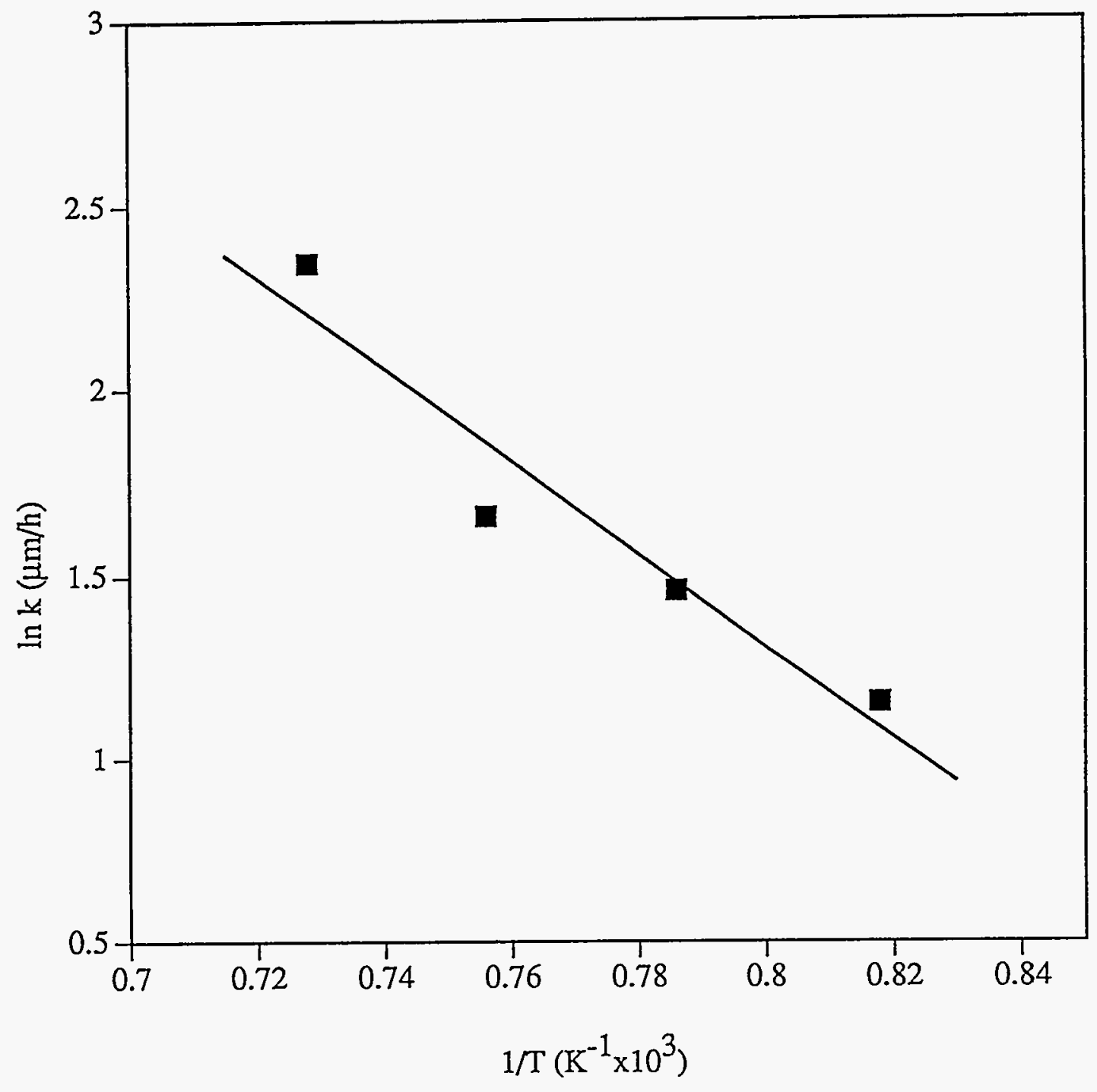

Figure 11. Arrhenius plot of rate constant versus temperature for the alkali corrosion of $\mathrm{SiC}$ 
reaction of the protective silica layer that was originally present on the surface of the $\mathrm{SiC}$ specimens with the alkali species, adsorbed from the vapor phase, to form a sodium silicate liquid. After the dissolution of the protective $\mathrm{SiO}_{2}$ layer, the reaction proceeds by simultaneous oxidation of $\mathrm{SiC}$ to $\mathrm{SiO}_{2}$ and dissolution of $\mathrm{SiO}_{2}$ in the sodium silicate liquid. As these processes are occurring, soda is also being absorbed in the sodium silicate liquid from the $\mathrm{NaNO}_{3}$ vapors. The overall reaction is very complex and involves the dissolution of silica in the sodium silicate liquid, inward diffusion of oxygen through the silicate layer, interfacial oxidation of $\mathrm{SiC}$, outward diffusion of $\mathrm{CO}$ or $\mathrm{CO}_{2}$ and diffusion of soda through the silicate liquid phase, analogous to the reaction sequence described above for $\mathrm{Si}_{3} \mathrm{~N}_{4}$.

The rate-controlling step can be arrived at using the same reasoning as was used in the discussion for $\mathrm{Si}_{3} \mathrm{~N}_{4}$. The atomic absorption analysis for the $\mathrm{SiC}$ samples indicates that the soda content in the sodium silicate is much higher than the soda content for the corresponding liquidus composition of the $\mathrm{Na}_{2} \mathrm{O}-\mathrm{SiO}_{2}$ system, suggesting that the alkali absorption process is not the rate-controlling step. The dissolution of the silica layer as well as all of the other diffusion controlled steps mentioned above would be expected to exhibit parabolic reaction kinetics. The reaction kinetics observed in the present study are linear, not parabolic. Therefore the diffusion controlled processes can be ruled out as the rate controlling step in the overall alkali corrosion reaction. As a result, the rate-controlling step for this alkali corrosion process appears to be the interfacial oxidation of the $\mathrm{SiC}$ at the substrate-liquid interface.

The transition from the oxygen diffusion controlled process that is reported for the pure 
oxidation of $\mathrm{SiC}$ to the interface-controlled reaction in the presence of $\mathrm{NaNO}_{3}$ vapors is attributed to the variation in the magnitude of the oxygen diffusivity in vitreous silica as compared to that in the sodium silicate liquid. As mentioned above, the oxygen diffusivity in vitreous silica is approximately 5 to 6 orders of magnitude lower than that in the sodium silicate liquid. Consider first the pure oxidation of $\mathrm{SiC}$ (oxidation in oxygen or dry air without alkalis present). The oxygen diffusion through the silica layer is reportedly slower than the oxidation reaction of $\mathrm{SiC}$ at the $\mathrm{SiC}$-silica interface, and hence the overall oxidation process is controlled by the diffusion of oxygen through the vitreous $\mathrm{SiO}_{2}$ layer. In the alkali assisted oxidation process, the silica reacts with soda to form a sodium silicate liquid. In this case, the oxygen diffusion step becomes relatively fast when compared to the interfacial oxidation step, and therefore is no longer the rate-controlling step in the overall process.

\subsubsection{Alkali Corrosion Induced Microstructural Changes of SiC}

Figure 12 shows the SEM micrographs of the as-received fracture surface and the surface of the $\mathrm{SiC}$ sample after a $1000^{\circ} \mathrm{C}$ for $24 \mathrm{~h}$ alkali exposure (with the glassy layer removed). The grain boundaries appear to be preferentially attacked by the alkali corrosion process as has been reported previously for this material. ${ }^{61}$ Boron and carbon are reportedly the major impurities for this type of $\mathrm{SiC}^{63}$ It is likely that segregation of the boron to the grain boundaries enhances the alkali corrosion in these regions. 
a.)

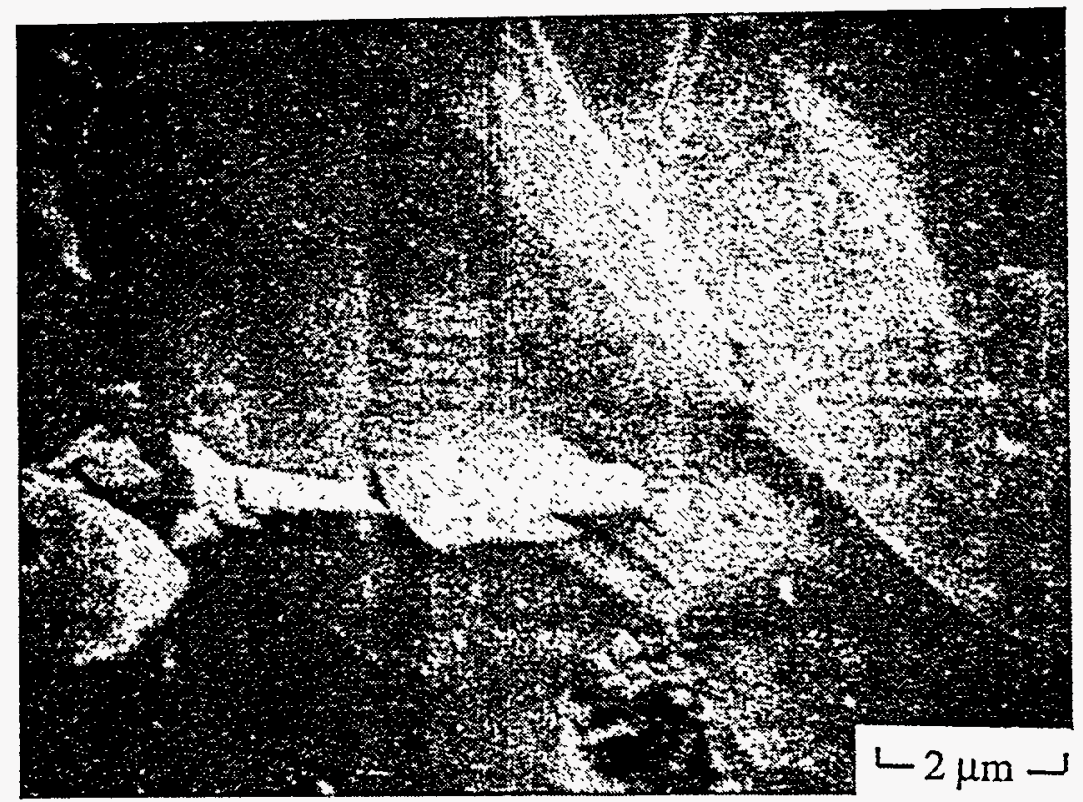

b.)

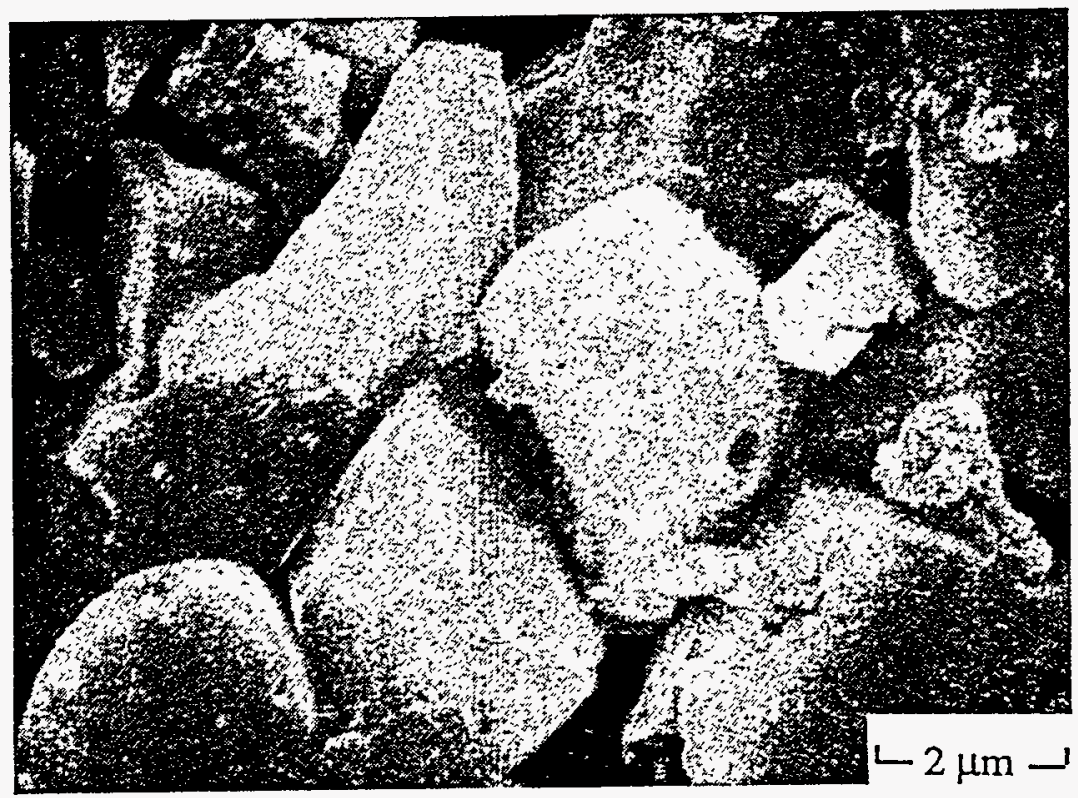

Figure 12. SEM micrograph of (a) fracture surface of as-received SiC and (b) after $24 \mathrm{~h}$ at $1000^{\circ} \mathrm{C}$ 


\subsubsection{Comparison of the Alkali Corrosion Kinetics of $\mathrm{SiC}$ and $\mathrm{Si}_{3} \mathrm{~N}_{4}$}

Except for the oxynitride layer that initially may be present on the $\mathrm{Si}_{3} \mathrm{~N}_{4}$, the alkali assisted oxidation reactions of these two materials appear to be very similar. Both materials react in the alkali-containing environment to form a sodium silicate liquid on the surface of the carbide or nitride. The kinetic processes involved in the supply of soda and oxygen to the surface of the silicate liquid and the diffusion of these species through the silicate liquid are expected to be the identical (ignoring any blocking effects of the $\mathrm{CO}$ or $\mathrm{N}_{2}$ diffusing outward through the silicate). It is interesting to note that the experimental activation energies for these two materials are quite different. The only kinetic processes that can account for the differences in reaction rates between the two materials (assuming the desorption of the product gases at the silicate-air interface occurs relatively fast) are: 1.) outward diffusion of $\mathrm{CO}$ versus $\mathrm{N}_{2}$; 2.) interfacial oxidation at the carbide/nitride-silicate interface. The diffusional processes cannot be rate-limiting as discussed above, since the observed reaction kinetics are linear. The linearity of the reaction thickness versus time data for both $\mathrm{SiC}$ and $\mathrm{Si}_{3} \mathrm{~N}_{4}$ indicates that the overall reaction in each case is controlled by a surface reaction. It appears that for both materials this surface reaction is the interfacial oxidation reaction at the silicate/carbide or nitride interface. A comparison of the relative rates of alkali assisted oxidation of these materials as a function of temperature is shown in Figure 13. As shown in this figure, the reaction rates above $950^{\circ} \mathrm{C}$ are higher for $\mathrm{Si}_{3} \mathrm{~N}_{4}$ than for $\mathrm{SiC}$. The difference between the 


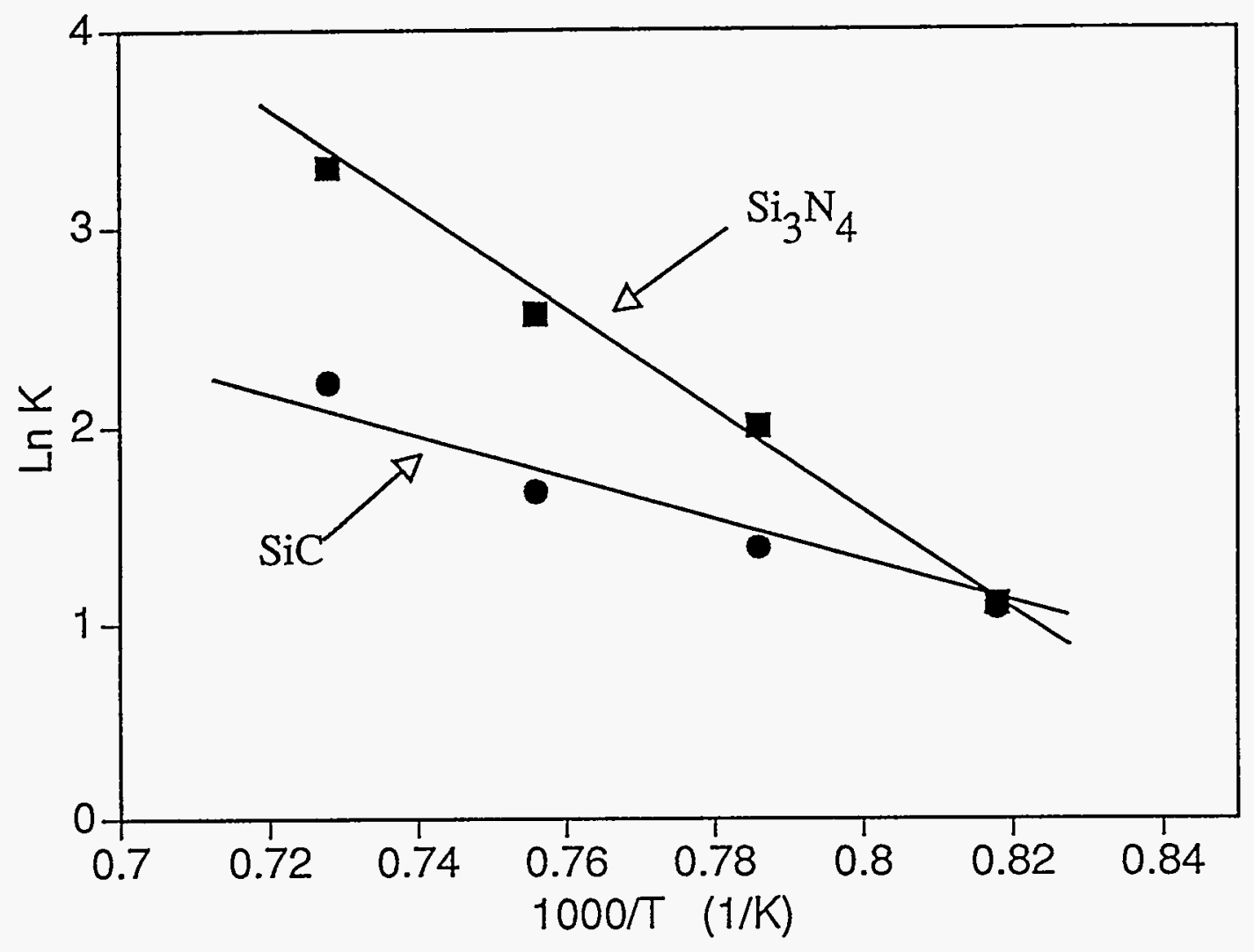

Figure 13. Comparison of the activation energies of $\mathrm{SiC}$ and $\mathrm{Si}_{3} \mathrm{~N}_{4}$ 
reaction rates of these two materials decreases as the temperature decreases until at $950^{\circ} \mathrm{C}$ the rates are approximately the same. Both of these materials are preferentially attacked at the grain boundary regions by the alkali corrosion process and this may be due in both cases to the segregation of their respective sintering aids to the grain boundaries.

\subsubsection{Alumina}

The gaseous alkali corrosion kinetics of alumina (Coors) were also examined in the same alkali-containing atmosphere from 1050 to $1150^{\circ} \mathrm{C}$. The reaction thickness of $\mathrm{Al}_{2} \mathrm{O}_{3}$ in the alkali-containing atmosphere versus reaction time is shown in Figure 14. The thickness change of the alumina pellet after alkali reaction at $1050^{\circ} \mathrm{C}$ for $48 \mathrm{~h}$ was less than $5 \mu \mathrm{m}$. Because of the prohibitively slow nature of the alkali reaction with alumina at low temperatures, the alkali reaction rates for temperatures lower than $1050^{\circ} \mathrm{C}$ were not measured in this study. The reaction temperature was increased to $1150^{\circ} \mathrm{C}$ in order to produce a measurable reaction layer in a reasonable period of time. To determine if the reaction follows linear or parabolic reaction kinetics, linear regression was performed on log (x) versus $\log (t)$, as mentioned above. Performing this type of analysis, $n$ equals $0.9,1.1$, and 1.3 for 1050,1100 , and $1150^{\circ} \mathrm{C}$ indicating that the reaction rate is approximately linear. The reaction rate constants for 1050,1100 and $1150^{\circ} \mathrm{C}$ are $0.12,0.24$ and $0.45 \mu \mathrm{m} / \mathrm{h}$, 


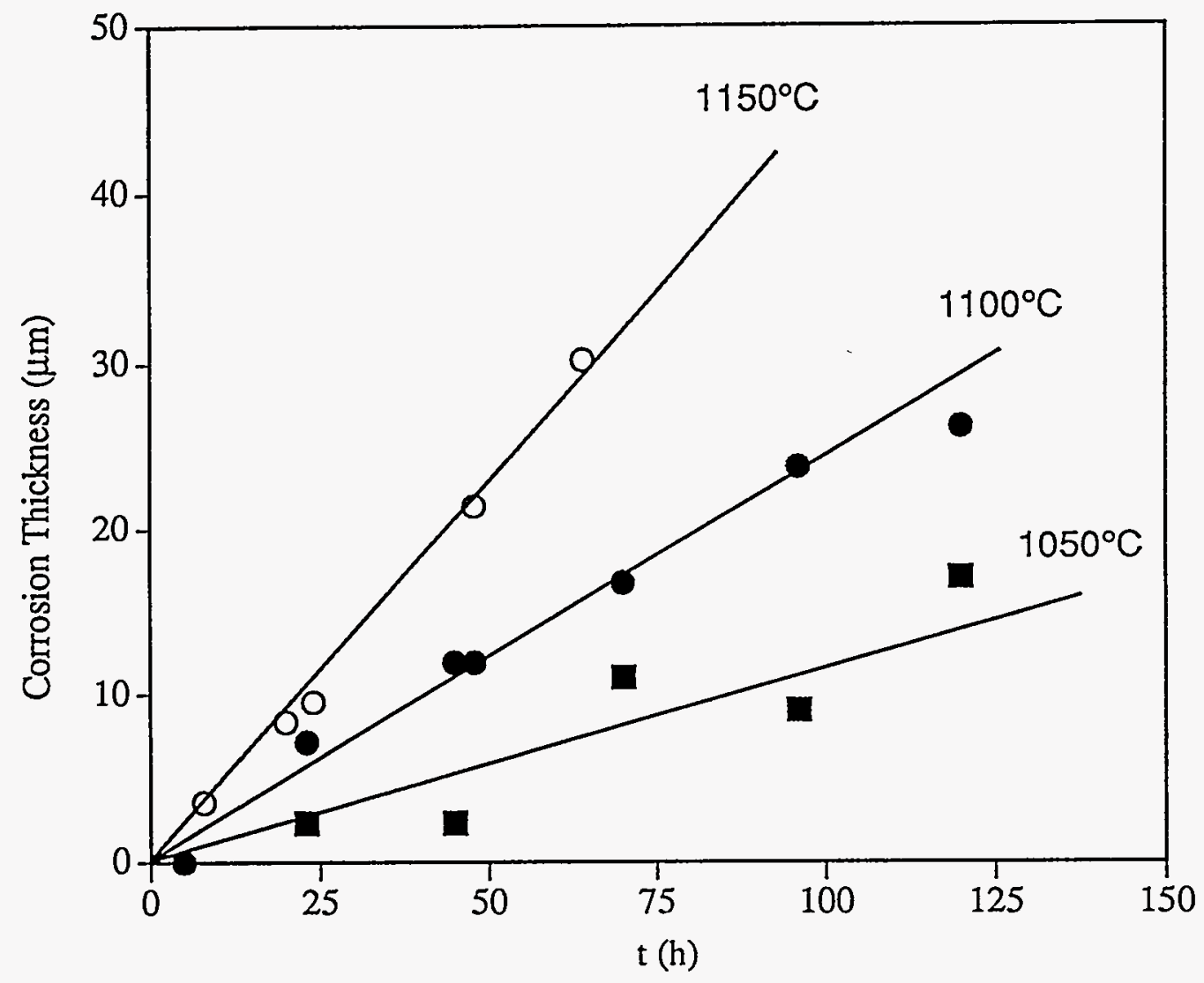

Figure 14. Corrosion thickness of alumina as a function of reaction temperature and time. 
respectively. The linearity of the thickness versus time plot indicates the reaction is interfacecontrolled. The alkali reaction rates for alumina appear to be much slower than those for the $\mathrm{SiC}$ or $\mathrm{Si}_{3} \mathrm{~N}_{4}$. Figure 15 shows the Arrhenius plot of the rate constant as a function of reciprocal temperature. The activation energy calculated from these data is approximately $200 \mathrm{~kJ} / \mathrm{mol}$ (standard deviation of approximately $5 \mathrm{~kJ} / \mathrm{mol}$ ). SEM, EDX, XRD and AA analysis were performed on the as-received and corroded specimens to determine if microstructural, compositional or structural data might aid in explaining the kinetic data.

$\mathrm{X}$-ray diffraction analysis of the alumina pellets after reaction at $1050^{\circ} \mathrm{C}$ for 48 hours revealed only alumina and sodium aluminate were present. However, $\mathrm{x}$-ray diffraction analysis of the alumina pellets after reaction at $1100^{\circ} \mathrm{C}$ for $48 \mathrm{~h}$ and $1150^{\circ} \mathrm{C}$ for $45 \mathrm{~h}$ revealed the presence of corundum (substrate), sodium aluminate, and an unidentified phase with some of the peak positions corresponding to the two-theta values for beta-alumina. There are several beta-alumina phases reported in the literature and without obtaining the phase in the pure form, it is very difficult to distinguish between these phases. As a result, the term betaalumina is used to refer to all of these phases. To identify this unknown phase, atomic absorption (AA) and $\mathrm{x}$-ray diffraction analyses were performed on the corroded specimen as a function of etching time, as shown in Table 3 . After a $2 \mathrm{~h}$ etching in the dilute hydrofluoric acid $(10 \%)$, the sodium aluminate was no longer present in the $\mathrm{x}$-ray diffraction pattern. During this etching period, AA analysis revealed that the alumina/soda molar ratio was approximately $0.65-0.95$. For the cumulative etching time longer than $2 \mathrm{~h}$, the alumina/soda molar ratio was approximately 4-7. X-ray diffraction analysis of the corresponding specimens 


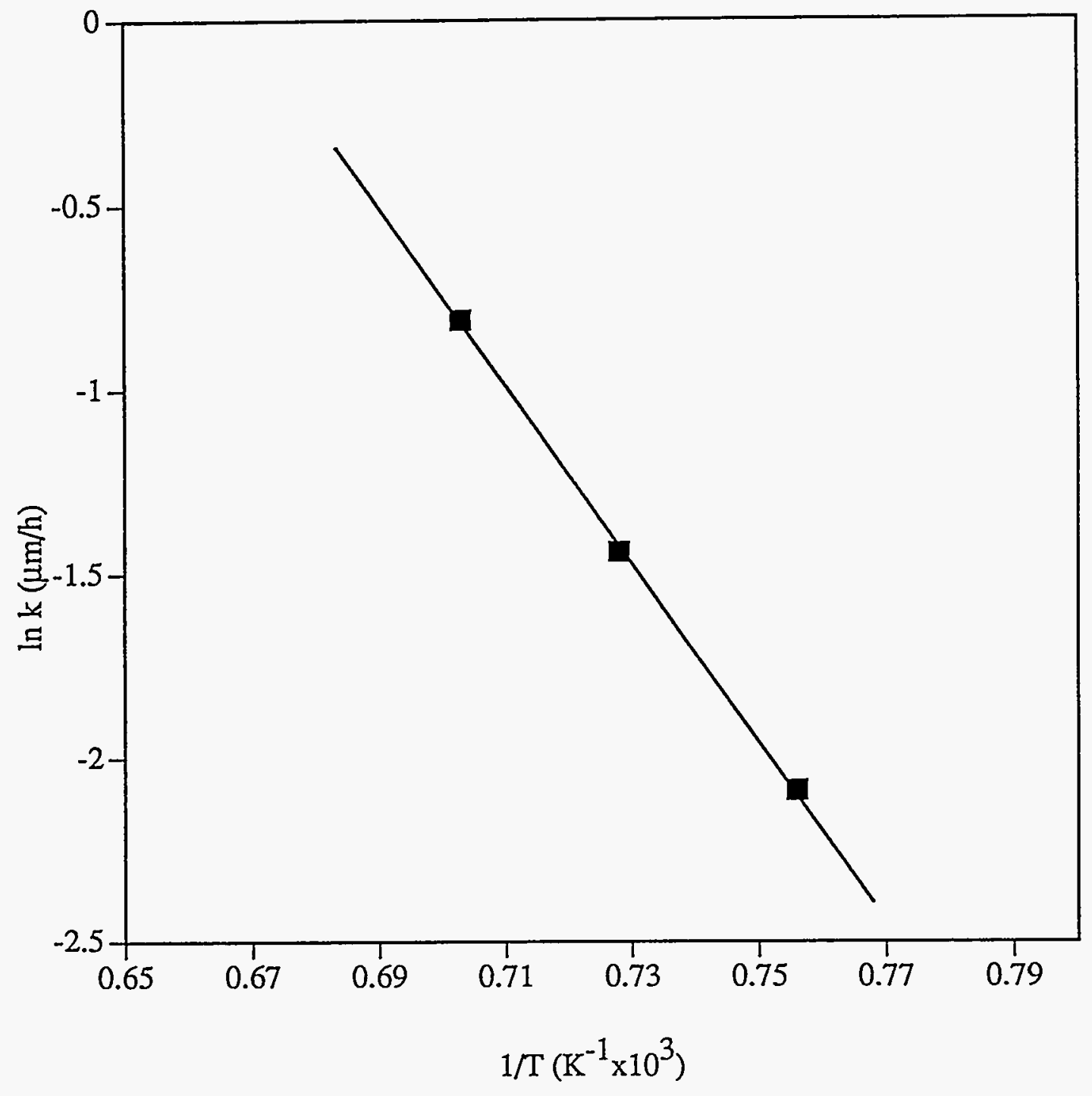

Figure 15. Arrhenius plot of rate constant versus temperature for the alkali corrosion of alumina 
Table 3. Chemical Analysis of Alumina-Alkali Reaction Products

\begin{tabular}{cccc}
\hline Cumulative & Alumina (moles) & Soda (moles) & $\begin{array}{c}\text { Alumina/Soda } \\
\text { Molar Ratio }\end{array}$ \\
Etch Time (h) & & & \\
\hline 0.5 & 6.22 & 6.52 & 0.95 \\
1.0 & 4.30 & 6.70 & 0.64 \\
2.0 & 2.89 & 4.06 & 0.71 \\
4.0 & 4.48 & 1.14 & 3.94 \\
6.0 & 2.37 & 0.45 & 5.24 \\
10 & 3.52 & 0.57 & 6.23 \\
14 & 3.37 & 0.45 & 7.45 \\
\hline
\end{tabular}


indicated that only alumina and the unknown phase were present. This suggests that the unknown phase has an average composition of $\mathrm{NaAl}_{7} \mathrm{O}_{11}$ (beta-alumina). After a $26 \mathrm{~h}$ cumulative etching, the unknown phase disappeared according to the $\mathrm{x}$-ray diffraction pattern and corundum was the only phase detected.

In order to quantify the beta-alumina to alumina ratio as a function of etching time more fully, the relative amounts of each phase were determined in a semiquantitative fashion. This was accomplished by tracing a selected peak for the alumina phase and one for the betaalumina phase in each XRD pattern (at each etching time). The peaks for each phase were cut out and weighed and a ratio of the weight of the beta-alumina to the weight of the alumina peak was calculated. Since the density and thickness of the paper are assumed to be uniform, this allows comparison of the peak area. The data obtained in this fashion are shown in Table 4. The beta-alumina to alumina peak area ratio is plotted as a function of etching time in Figure 16. Assuming the data follows a linear relationship and performing the linear regression analysis, these data indicate that the beta-alumina phase would be completely dissolved after approximately $18-20 \mathrm{~h}$. The as-received alumina pellets were etched in the dilute acid up to $48 \mathrm{~h}$ with no significant change in the specimen dimensions. Additionally several sets of alumina pellets reacted in the alkali-containing atmosphere for various times were etched for $24 \mathrm{~h}$ measured and etched for an additional $24 \mathrm{~h}$ and measured again. No significant change in the thickness was observed between these two measurements. Hence, an etch of $24 \mathrm{~h}$ was used for all of the alumina specimens to remove the alkali reaction products. 
Table 4. Ratio of the XRD Peak Area of Beta-Alumina to Alumina

\begin{tabular}{cccc}
\hline Cumulative & Beta-Alumina & Alumina & Beta-Alumina/Alumina \\
Etch Time & Peak Area & Peak Area & Peak Area Ratio \\
\hline 0.5 & 0.0172 & 0.0338 & 0.5089 \\
1.0 & 0.0230 & 0.0500 & 0.4600 \\
2.0 & 0.0248 & 0.0555 & 0.4468 \\
4.0 & 0.0157 & 0.0513 & 0.3060 \\
6.0 & 0.0182 & 0.0678 & 0.2684 \\
10 & 0.0120 & 0.0531 & 0.2260 \\
14 & 0.0065 & 0.0570 & 0.1140 \\
\hline
\end{tabular}




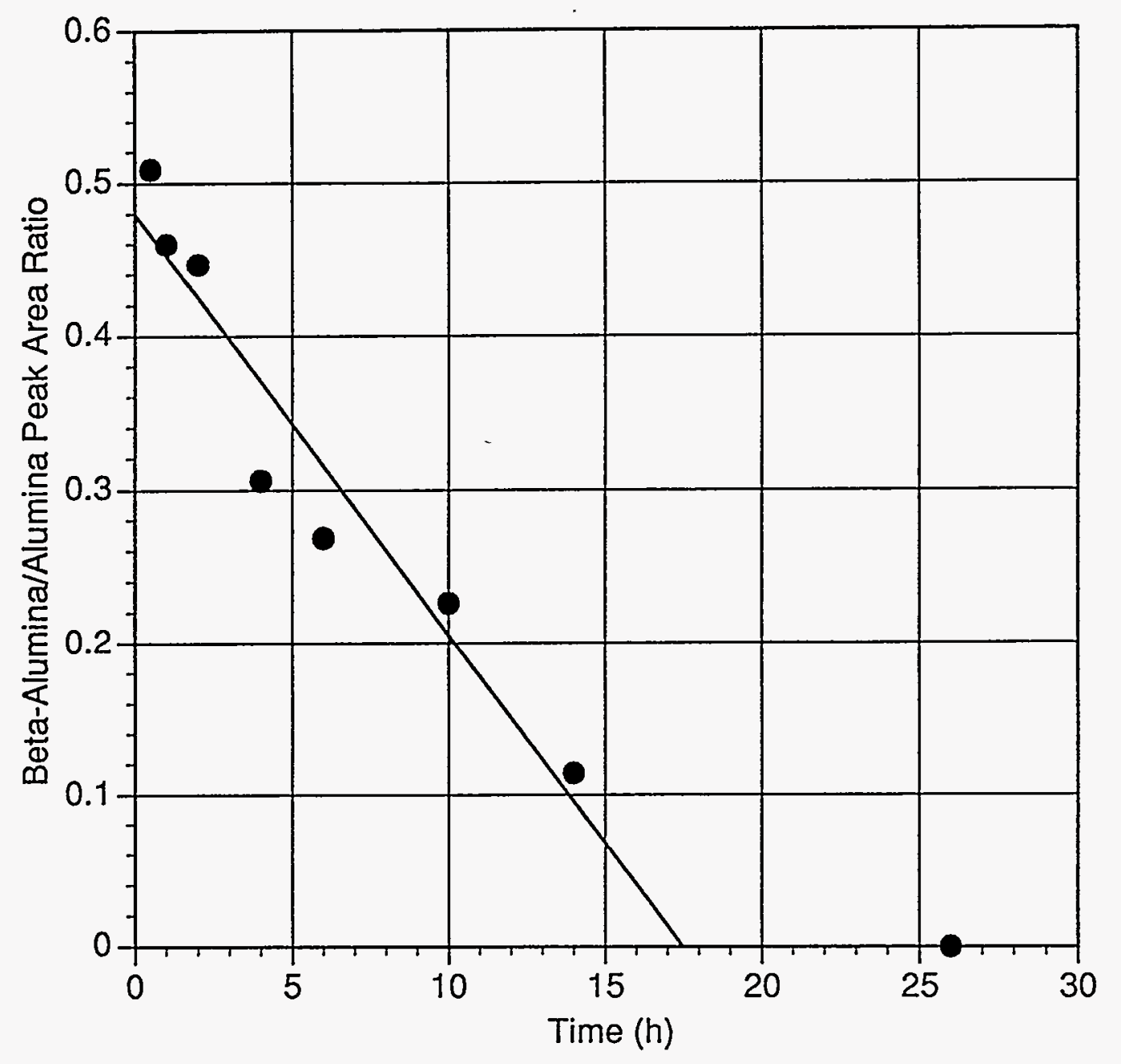

Figure 16. Beta-alumina to alumina peak area ratio 
a.)

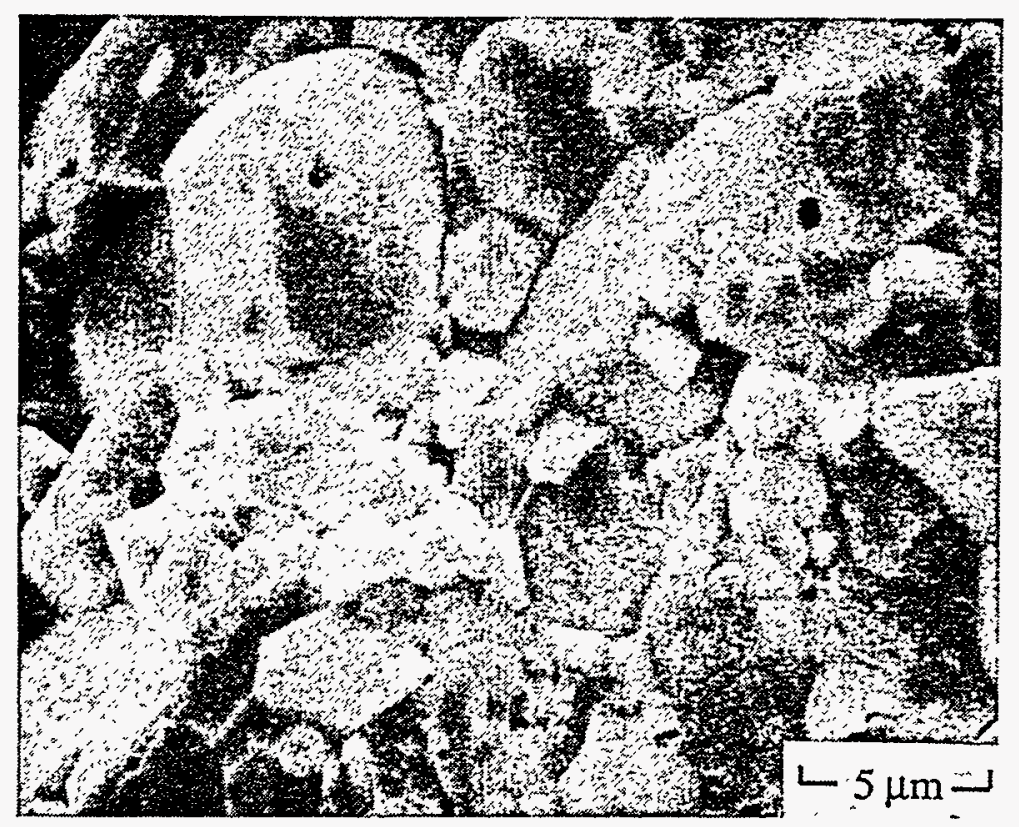

b.)

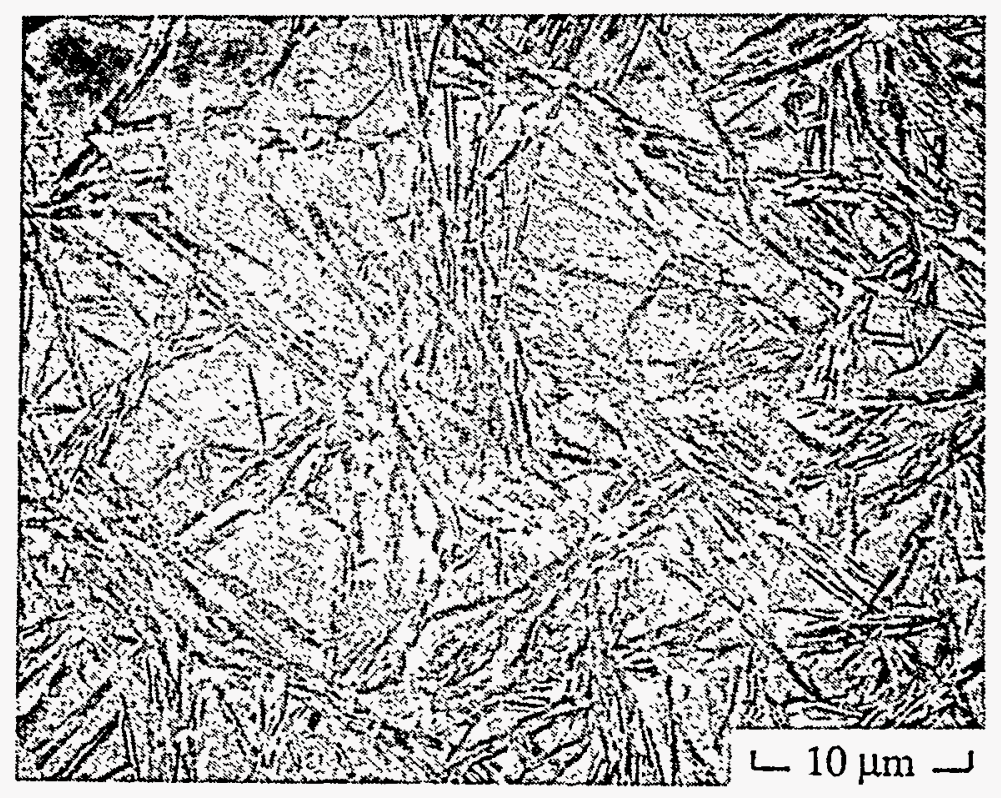

Figure 17. SEM micrograph of (a) fracture surface of as-received alumina and (b) after $24 \mathrm{~h}$ at $1000^{\circ} \mathrm{C}$ 
Figure 17 shows the SEM micrographs of the as-received $\mathrm{Al}_{2} \mathrm{O}_{3}$ and the specimen corroded at $1100^{\circ} \mathrm{C}$ for $120 \mathrm{~h}$ (corrosion layer removed by etching for $12 \mathrm{~h}$ in dilute $\mathrm{HF}$ ). There appeared to be some preferential attack along certain crystallographic directions. It is very likely that the lathes that appear between the alumina grains are the beta-alumina phase according to the $\mathrm{AA}$ and $\mathrm{XRD}$ analysis. These lathes appeared to be preferentially oriented with respect to the alumina grains. This preferred orientation is likely the reason why only some of the diffraction peaks of the beta-alumina phase were detected in the $\mathrm{x}$-ray diffraction pattern. Similar microstructures have been observed for potassium corrosion of alumina. ${ }^{1+1}$ The author suggests that the appearance of these laths is due to the orientation of the fast ionconducting layer in the beta-alumina phase perpendicular to the sample surface. In this manner the sodium can diffuse quickly through the beta-alumina phase in a direction perpendicular to the sample surface, but not in a direction parallel to the sample surface. The formation of the beta-alumina phase appears to occur only at the grain boundaries, most likely due to the faster sodium transport that might be expected in these regions. For heavily corroded samples (longer reaction times and higher temperatures), the beta-alumina formation appears to occur within grains also.

The occurrence of the beta-alumina phase only at higher temperatures makes analysis of the kinetic data much more complex. At $1050^{\circ} \mathrm{C}$ the only phases present as determined by $\mathrm{XRD}$ and SEM analysis are the alumina and sodium aluminate. The sodium aluminate appears to attack the alumina substrate in a relatively uniform fashion. This leaves a relatively flat alumina surface after etching away the sodium aluminate reaction layer. At higher 
temperatures, the morphology of the surface after etching is quite different due to the formation of the beta-alumina phase. Since the beta-alumina forms laths that penetrate at the grain boundaries, alumina columns or plateaus are left after etching. The thickness measurement does not take into account this penetration at the grain boundaries. Due to this fact and to the change in the phases present in the reaction layer as a function of reaction temperature, a single activation energy calculated over the entire temperature region may not be appropriate and determination of the rate-controlling mechanism will have to wait for a more in-depth study on this subject.

\subsubsection{Mullite}

The alkali corrosion kinetics of mullite (Superior Technical Ceramics, Inc.) were investigated in the same $1.0+/-0.1$ vol \% alkali atmosphere. The reaction thickness of the mullite versus reaction time in the alkali-containing atmosphere is shown in Figure 18. The exponent, $\mathrm{n}$, of the linear regression of $\log (\mathrm{x})$ versus $\log (\mathrm{t})$ is $0.7,0.8,1.2$, and 1.2 for 950 , 1000,1050 , and $1100^{\circ} \mathrm{C}$, respectively. The reaction layer thickness appears to be linearly related to the reaction time. The scatter in the data at the lower temperatures is believed to be responsible for low values of $n$ at these temperatures. The natural log of the reaction rate constant versus reciprocal temperature is shown in Figure 19. The linear reaction rate constants are $6,10,25$ and $39 \mu \mathrm{m} / \mathrm{h}$ at $950^{\circ} \mathrm{C}, 1000^{\circ} \mathrm{C}, 1050^{\circ} \mathrm{C}$ and $1100^{\circ} \mathrm{C}$ 


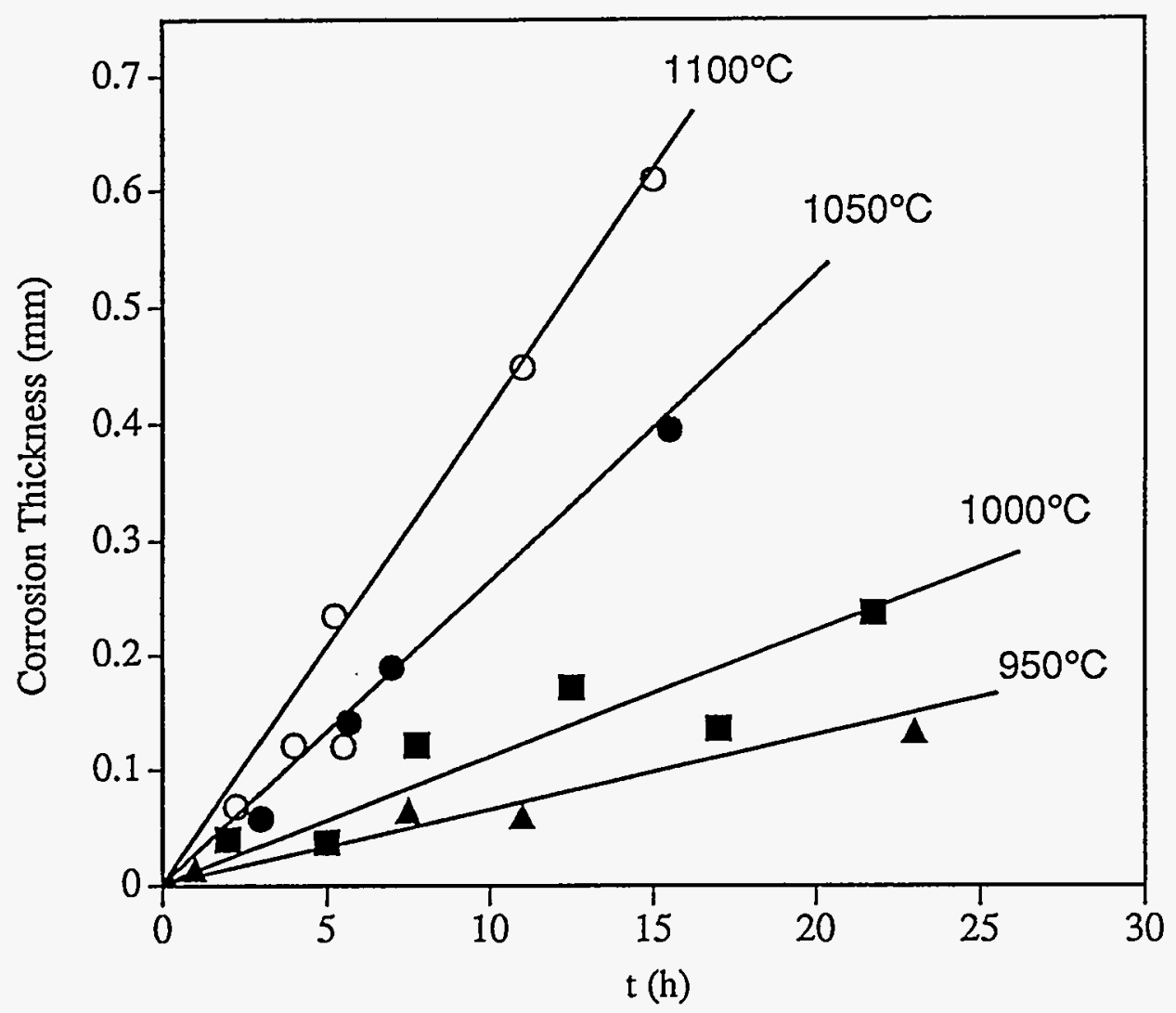

Figure 18. Corrosion thickness of mullite as a function of reaction temperature and time. 


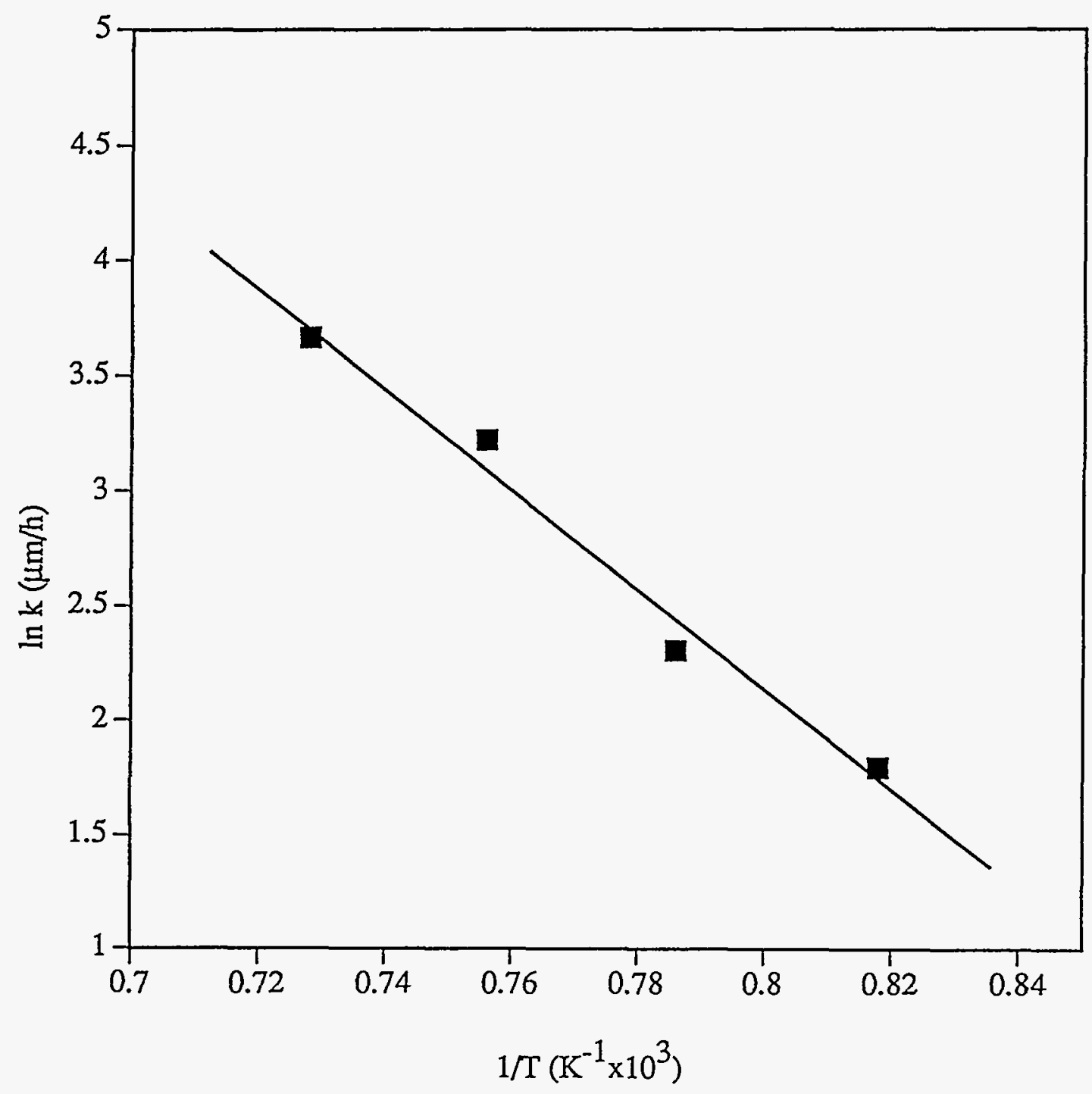

Figure 19. Arrhenius plot of rate constant versus temperature for the alkali corrosion of mullite 
respectively. The activation energy was determined to be $182 \mathrm{~kJ} / \mathrm{mol}$ (with an associated standard deviation of approximately $20 \mathrm{~kJ} / \mathrm{mol}$ ) from the plot of the reaction rate constant as a function of reciprocal temperature shown in Figure 19.

X-ray diffraction analysis of the as-received material showed only mullite and a trace of corundum were present. No cristobalite was detected. Density measurements (using ASTM Spec.\# C20-87) gave a true density of 3.004 and a bulk density of $2.998 \mathrm{~g} / \mathrm{cc}$ for the asreceived material. Elemental analysis using EDAX measurements of the samples (which were cut on a diamond saw) before corrosion show only aluminum and silicon as the major constituents with only a trace of iron, copper and potassium.

EDAX measurements after corrosion at $1000^{\circ} \mathrm{C}$ for $8 \mathrm{~h}$ show only aluminum, silicon and sodium. X-ray diffraction analysis of the mullite specimens after reaction in the alkalicontaining atmosphere revealed the presence of sodium aluminate and carnegieite. The peaks in the diffraction pattern shitt slightly as a function of reaction time at $1000^{\circ} \mathrm{C}$ suggesting that there might be some solid solution of the sodium aluminate and the carnegieite phases.

Figure 20 shows the SEM micrographs of the as-received mullite and the specimen corroded at $1000^{\circ} \mathrm{C}$ for $8 \mathrm{~h}$. The reaction layer exhibits a large number of microcracks as can be seen in Figure 20b. It is not certain whether these cracks form during the reaction process as a result of the differences in volumes of the substrate and the corrosion products or whether they form during the cooling period due to differences in the thermal expansions of the substrate and the corrosion layer. 
a.)

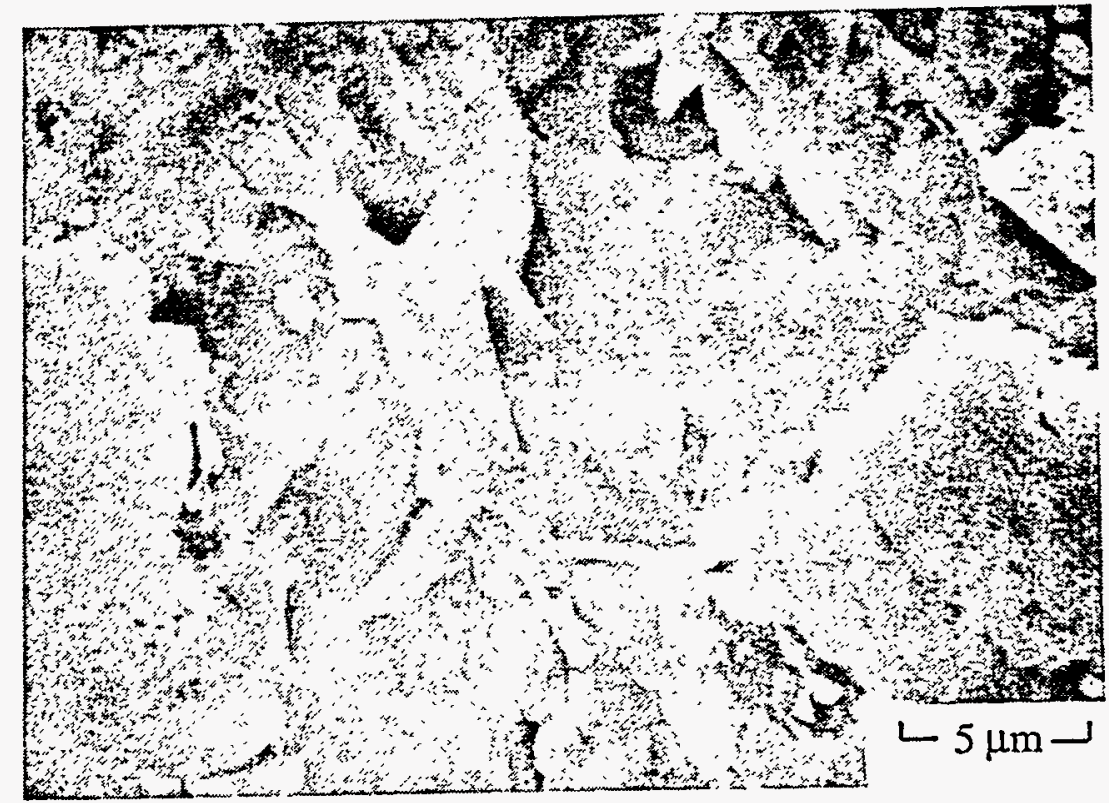

b.)

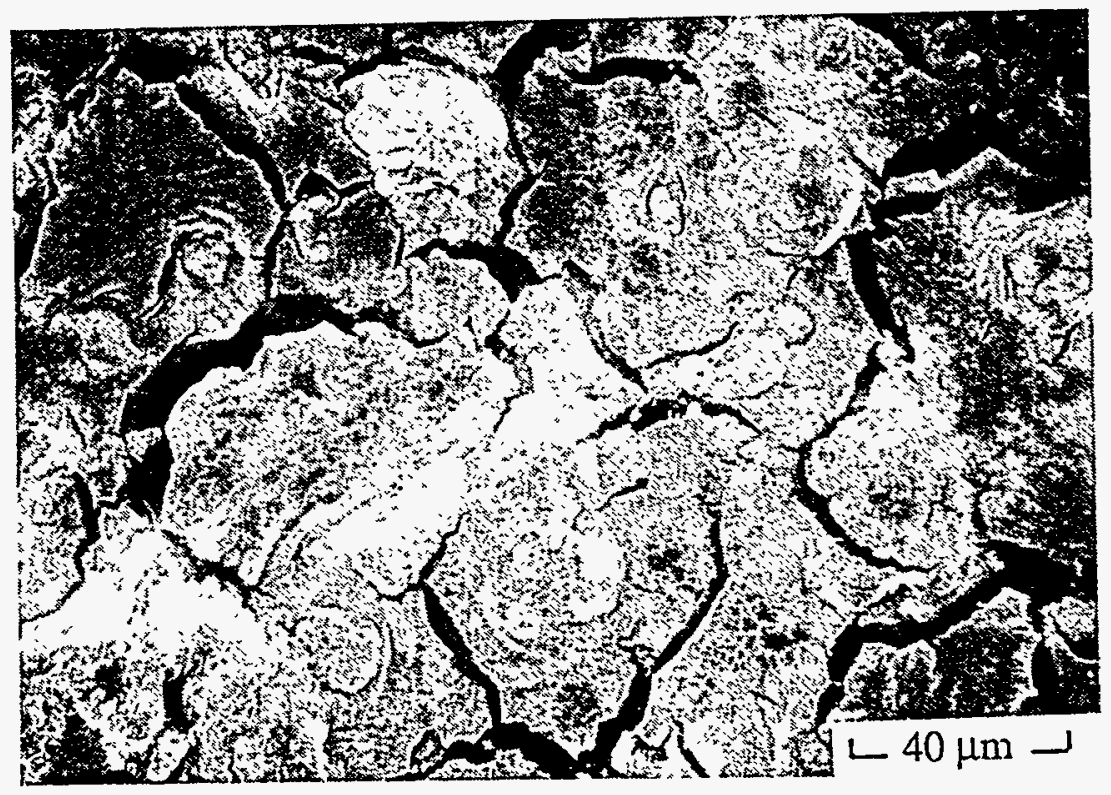

Figure 20. SEM micrograph of (a) cut surface of as-received mullite and (b) after $8 \mathrm{~h}$ at $1000 \mathrm{C}$ 


\subsubsection{Cordierite}

The alkali corrosion kinetics of cordierite (Coors) were also studied in the same $1.0+1-$ $0.1 \mathrm{vol} \%$ alkali containing environment. The thickness of the alkali reaction layer versus time is shown in Figure 21. The calculated $n$ values from the slope of the $\log (\mathrm{x})$ versus $\log (\mathrm{t})$ are 0.8 and 0.8 at 950 and $1000^{\circ} \mathrm{C}$, respectively. The corrosion layer thickness appears to be linearly dependent on the reaction time at 950 and $1000^{\circ} \mathrm{C}$. The SEM micrographs of the asreceived cordierite fracture surface and the surface after reaction at $950^{\circ} \mathrm{C}$ is shown in Figure 22. The as-received material appears very dense, as shown in Figure 22a. The alkali reaction layer that forms on the surface of the cordierite pellet after alkali exposure at $950^{\circ} \mathrm{C}$ for 15 $\mathrm{h}$ is very porous as shown in Figure $22 \mathrm{~b}$. The reaction kinetics at 1050 and $1100^{\circ} \mathrm{C}$ are somewhat different than those at 950 and $1000^{\circ} \mathrm{C}$. As shown in Figure 23, the reaction kinetics at higher temperatures becomes parabolic. The calculated $\mathrm{n}$ values from the slope of the $\log (\mathrm{x})$ versus $\log (\mathrm{t})$ are 0.5 and 0.4 at 1050 and $1100^{\circ} \mathrm{C}$, respectively. The SEM micrograph of the reaction layer after corrosion at $1100^{\circ} \mathrm{C}$ is shown in Figure 24. As seen in this figure, the corrosion layer appears to be very dense. The change of the reaction layer from a very porous structure at low temperatures to a dense structure at higher temperatures is believed to be the reason why the reaction kinetics changes from linear to parabolic. At the lower temperatures, the alkali species can permeate through the pores to reach the unreacted sample surface. Since diffusion through the gas phase is relatively fast, the reaction can proceed quickly. 


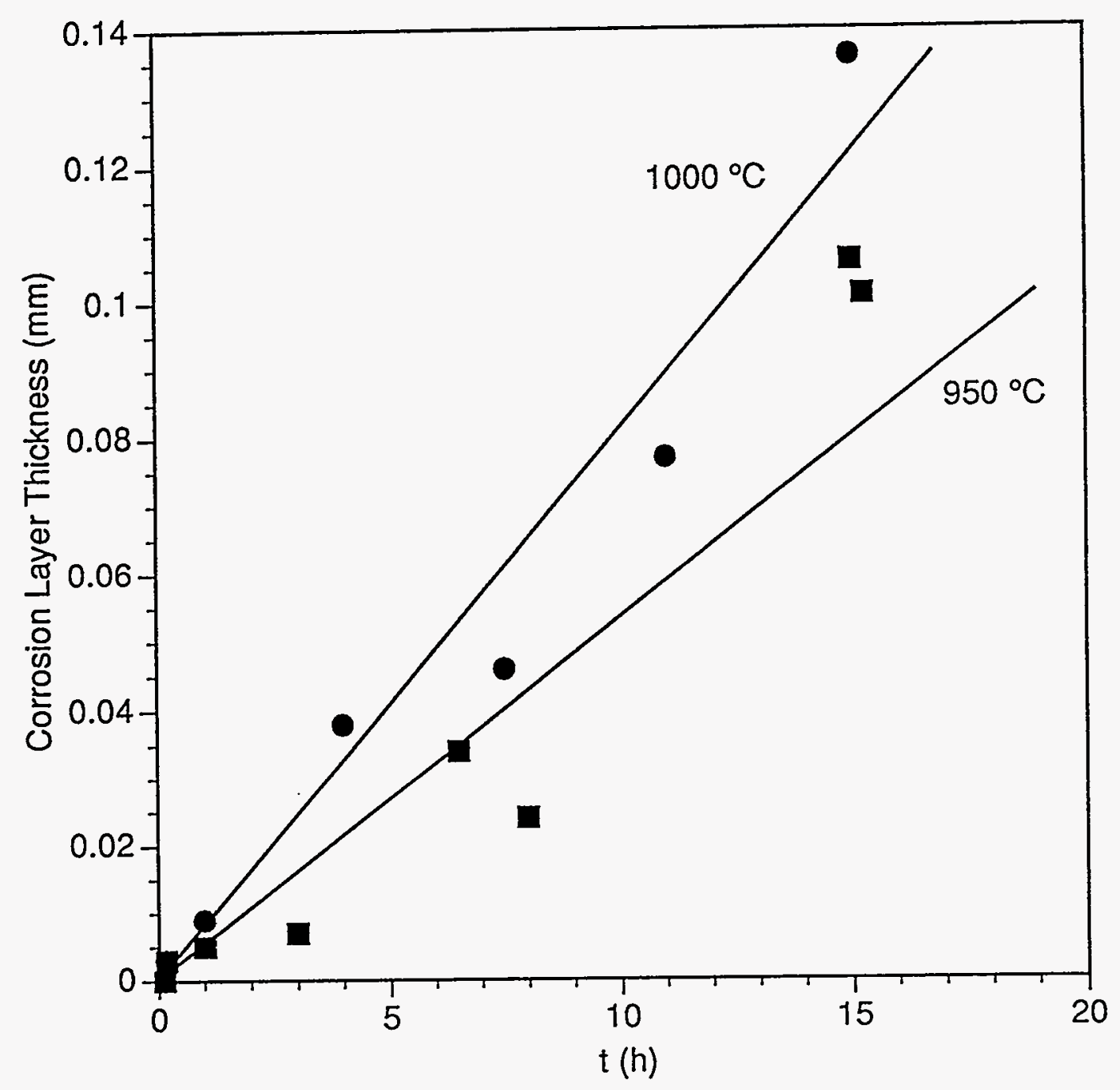

Figure 21. Reaction layer thickness versus time for the alkali corrosion of cordierite at 950 and $1000^{\circ} \mathrm{C}$ 
a.)

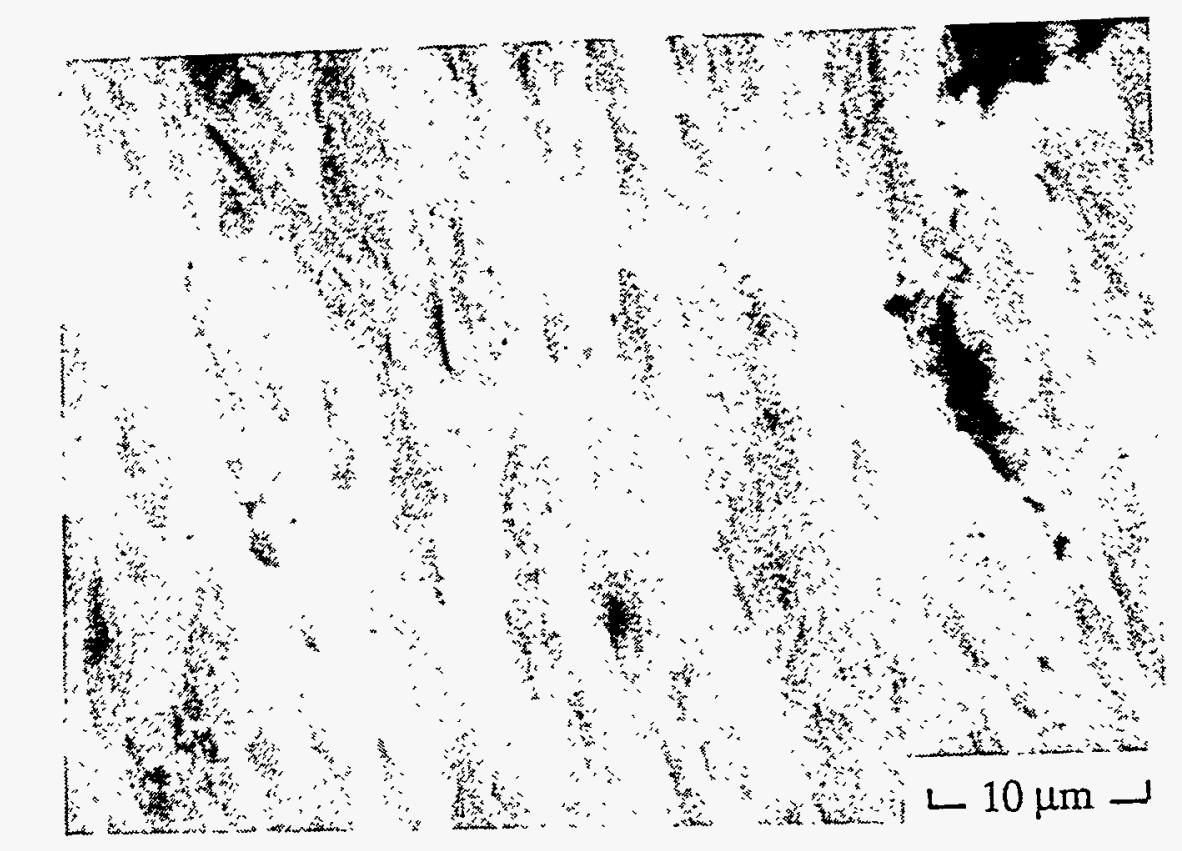

b.)

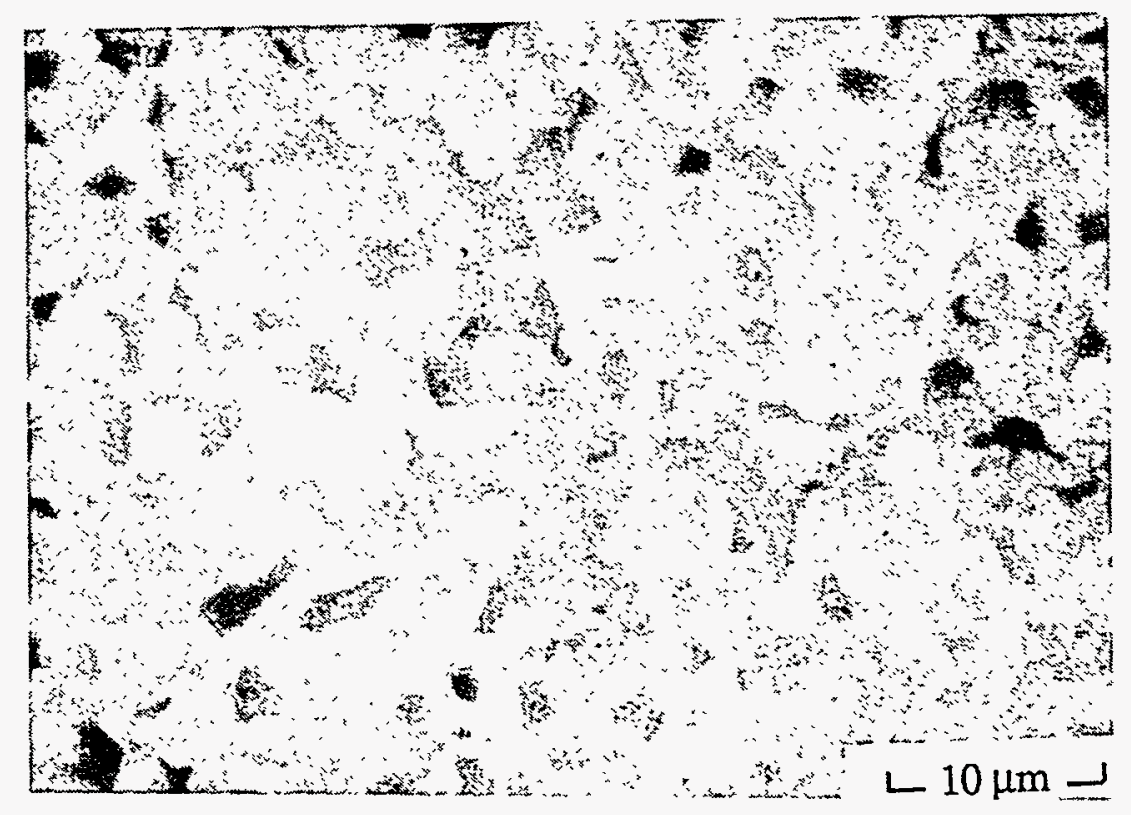

Figure 22. SEM micrograph of (a) fracture surface of as-received cordierite and (b) after $15 \mathrm{~h}$ at $950^{\circ} \mathrm{C}$ 


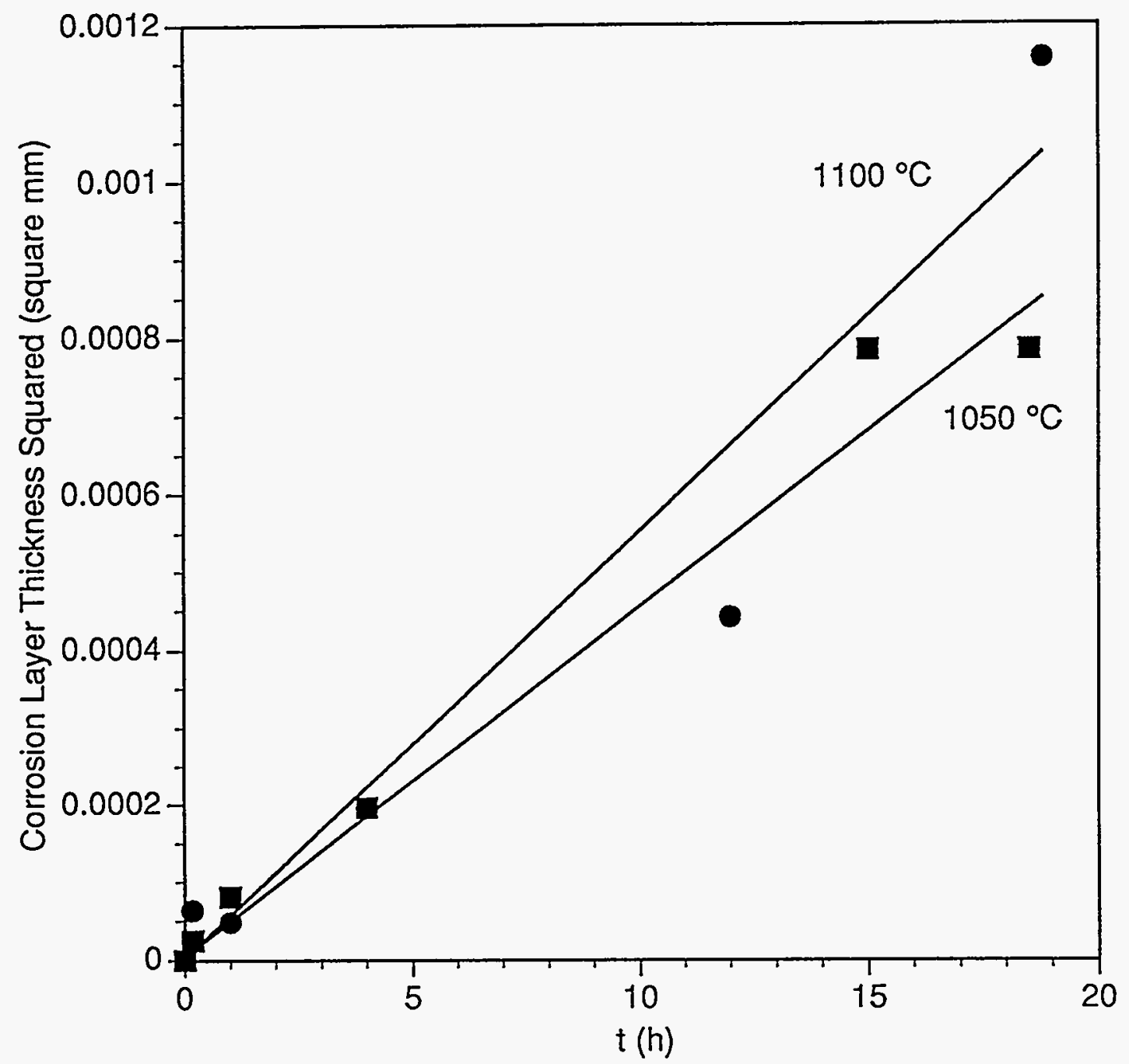

Figure 23. Reaction layer thickness squared versus time for the alkali corrosion of cordierite at 1050 and $1100^{\circ} \mathrm{C}$ 
a.)

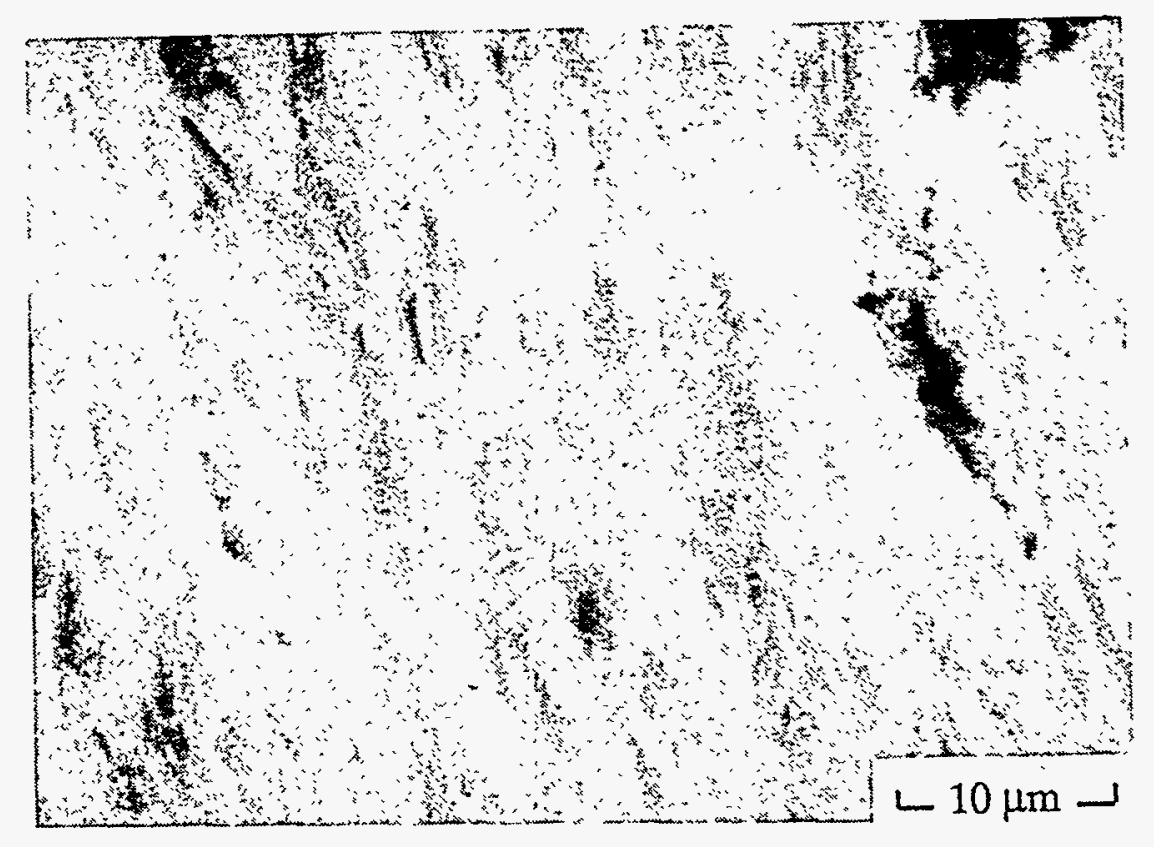

b.)

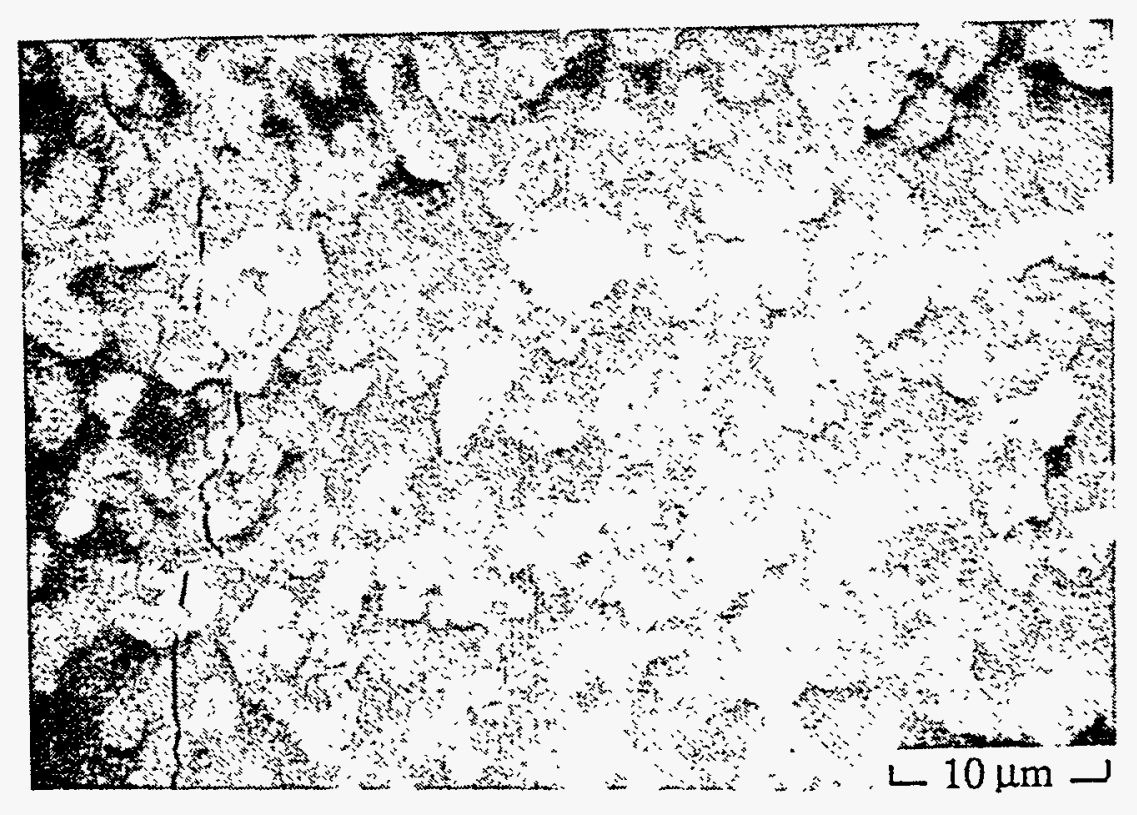

Figure 24. SEM micrograph of (a) fracture surface of as-received cordierite and (b) after $12 \mathrm{~h}$ at $1100 \mathrm{C}$ 
At higher temperatures, the pores disappear, which means that the alkali species must diffuse through the reaction layer in order to react with more of the sample. It may be that this diffusional process limits the reaction rate at higher temperatures, causing the reaction to change from interface controlled at low temperatures to diffusion controlled at higher temperatures.

A flat specimen of cordierite was also subjected to the alkali containing atmosphere at $1050^{\circ} \mathrm{C}$ and was analyzed by $\mathrm{x}$-ray diffraction. The resulting pattern was complex. The phases which occurred in the $\mathrm{x}$-ray diffraction patterns of the cordierite specimens after reaction in the alkali-containing atmosphere could not be identified.

\subsubsection{Zirconia}

The reaction thickness of the transformation toughened zirconia in the alkali-containing atmosphere versus reaction time is shown in Figure 25. The calculated $\mathrm{n}$ values from the slope of the $\log (x)$ versus $\log (t)$ were $3.0,1.6,1.1$, and 0.8 at $950,1000,1050$ and $1100^{\circ} \mathrm{C}$, respectively. The reaction layer thickness appears to be linearly related to the reaction time. The large value of $n(3.0)$ at $950^{\circ} \mathrm{C}$ is believed to be due to the inability of the measurement technique to detect variations in thickness in this range. After $15 \mathrm{~h}$ at $950^{\circ} \mathrm{C}$ the measured reaction layer thickness was only $0.008 \mathrm{~mm}$. For all times less than $8 \mathrm{~h}$, the measured reaction layer thickness was zero. There appears to be a large amount of scatter in the data 


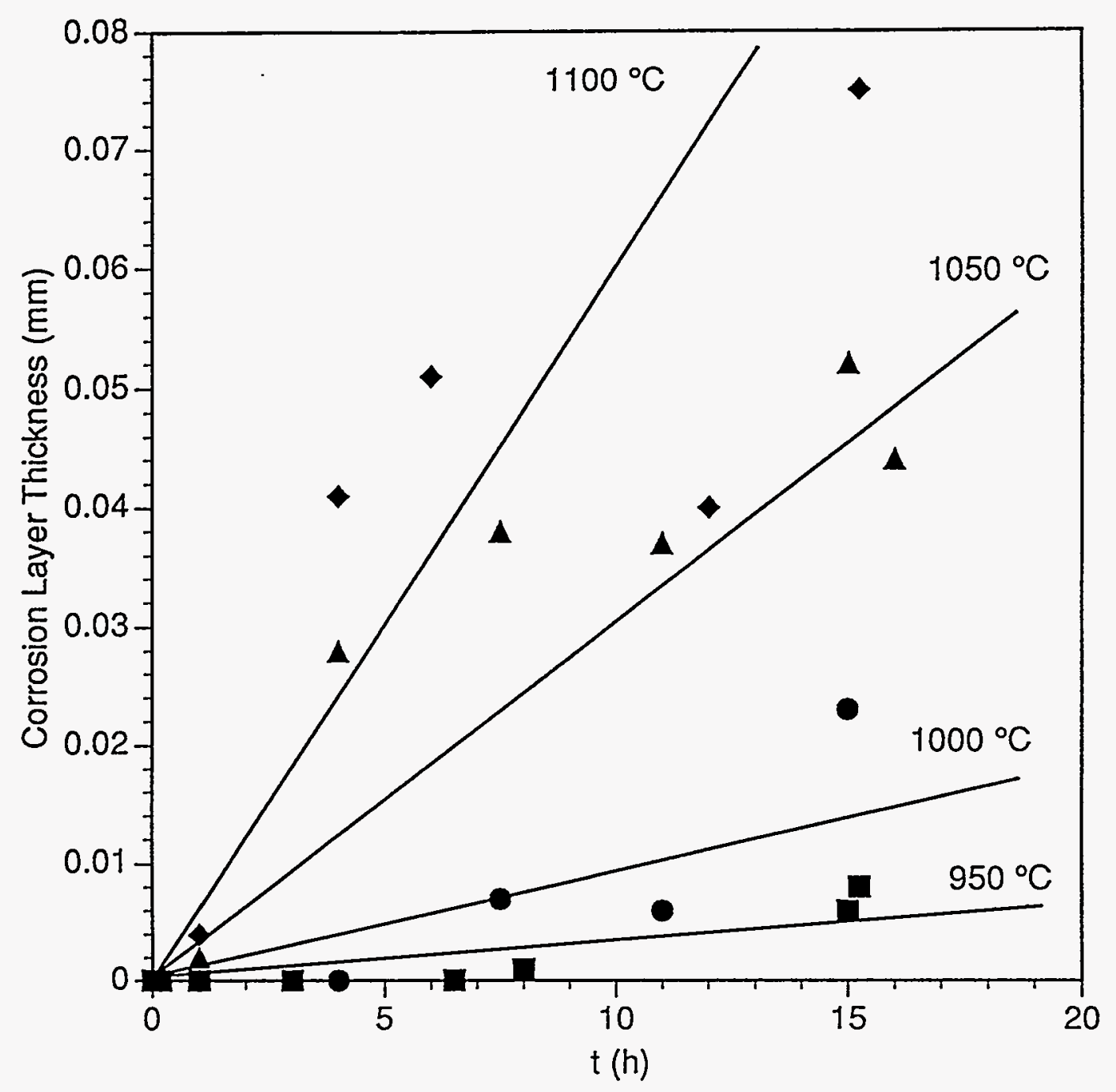

Figure 25. Reaction layer thickness versus time for the alkali corrosion of TTZ 
for this material at all temperatures. Two samples of TTZ were measured and fired at $1000^{\circ} \mathrm{C}$ in a box furnace without alkalis present. The average change in thickness of these samples after $12 \mathrm{~h}$ was $0.007 \mathrm{~mm}$. This procedure was repeated again with two more samples. The average change in the thickness of these samples was measured to be 0.010 $\mathrm{mm}$. It appears that heating these samples in the absence of alkalis causes an increase in the measured thickness of these samples. It is possible that a small amount of the tetragonal zirconia particles are transforming to monoclinic zirconia particles upon heating at $1000^{\circ} \mathrm{C}$, and that this is the reason for the increase in the thickness that is observed. This may also be the reason why such a large amount of scatter is observed in the plot of reaction layer thickness versus time. The activation energy was determined to be $229 \mathrm{~kJ} / \mathrm{mol}$ from the plot of the reaction rate constant as a function of reciprocal temperature shown in Figure 26. Xray diffraction analysis of the as-received material showed only very broad peaks. These peaks were in the same relative position but appeared somewhat sharper after a $1000^{\circ} \mathrm{C} 12$ $\mathrm{h}$ heat treatment. Elemental analysis using EDAX (energy dispersive analysis of $\mathrm{x}$-rays) measurements of the samples (which were cut on a diamond saw) before corrosion show only a trace of iron present (presumably from the diamond saw). Figure 27 shows the SEM micrographs of the as-received zirconia and the specimen corroded at $950^{\circ} \mathrm{C}$ for $15 \mathrm{~h}$. The reaction layer exhibits a large number of pores as can be seen in Figure $27 \mathrm{~b}$, as compared to the as-received material. The appearance of these pores in the reaction layer may allow the alkali species present in the gas phase to permeate through these voids to the unreacted sample surface. This will enhance the corrosion rate of the zirconia, allowing a faster supply 


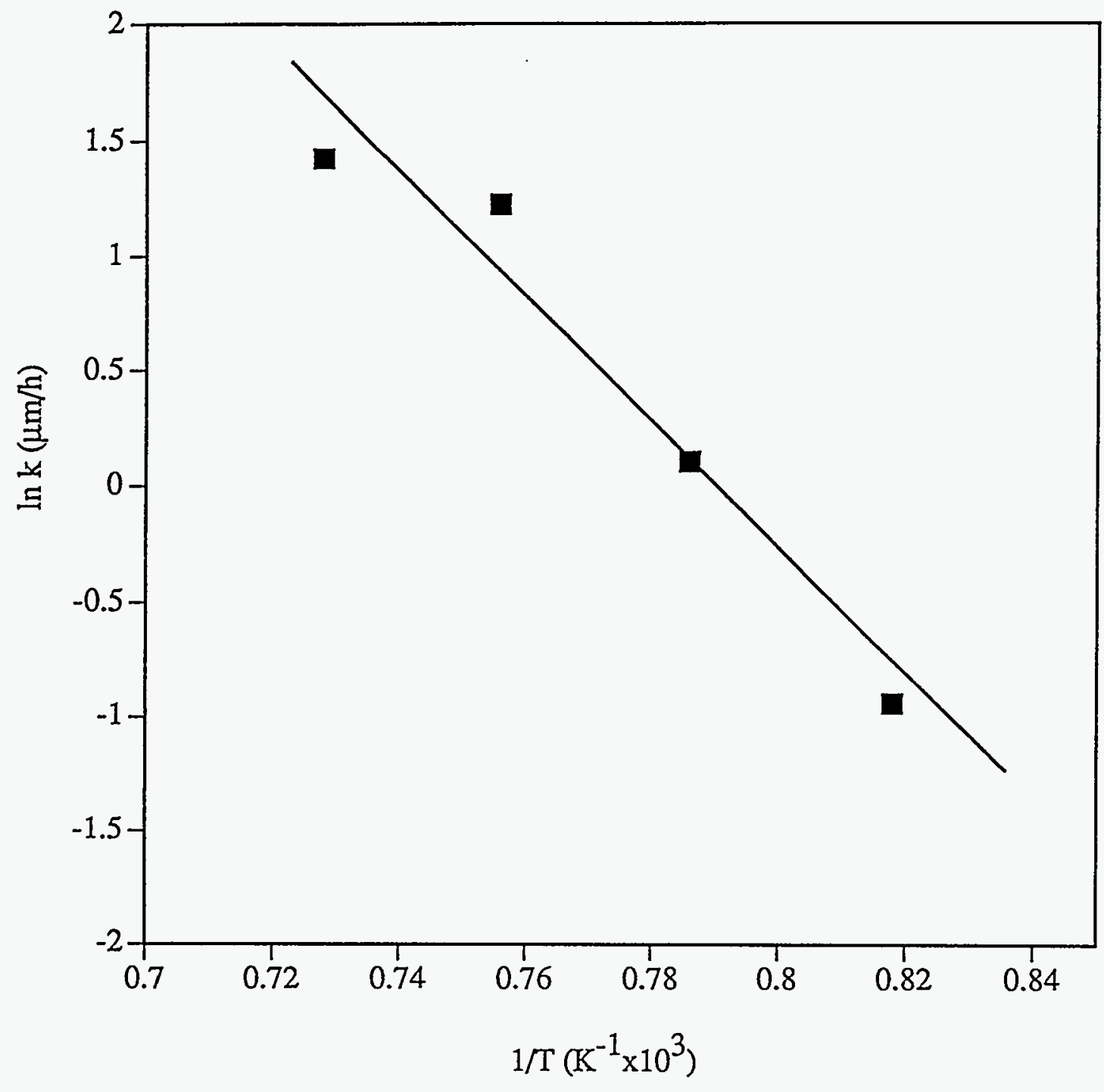

Figure 26. Arrhenius plot of rate constant versus temperature for the alkali corrosion of zirconia 
a.)

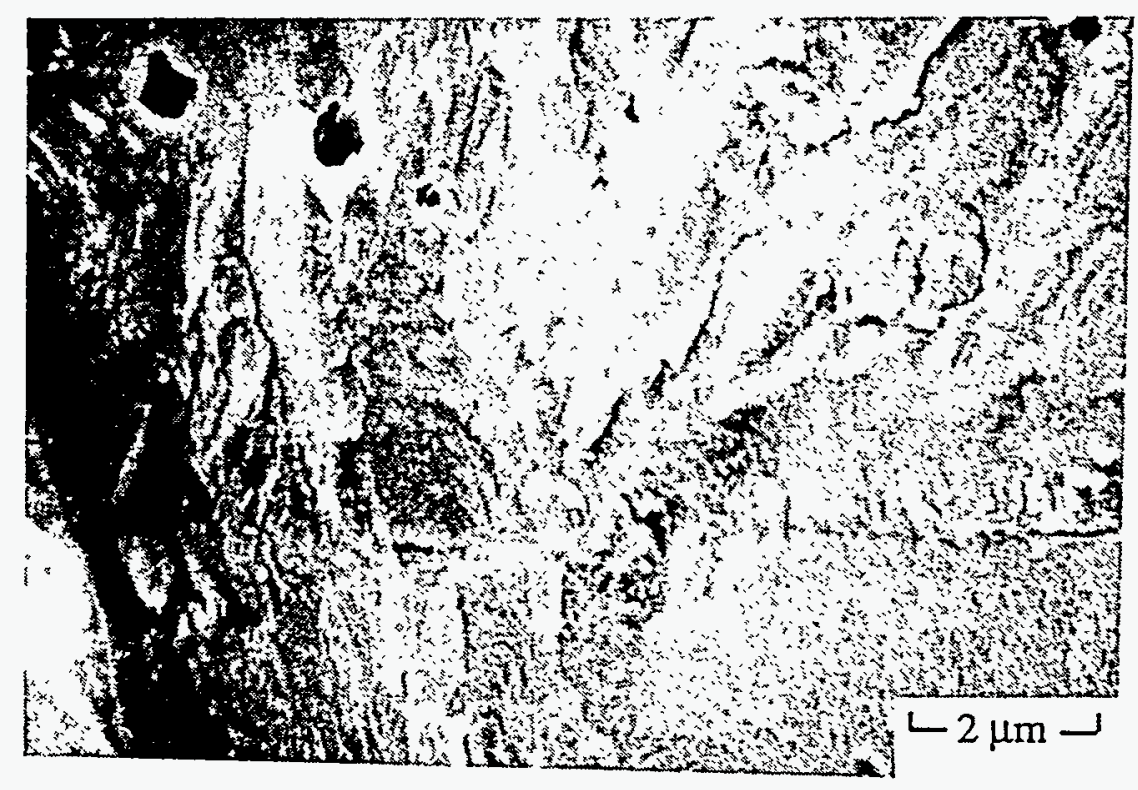

b.)

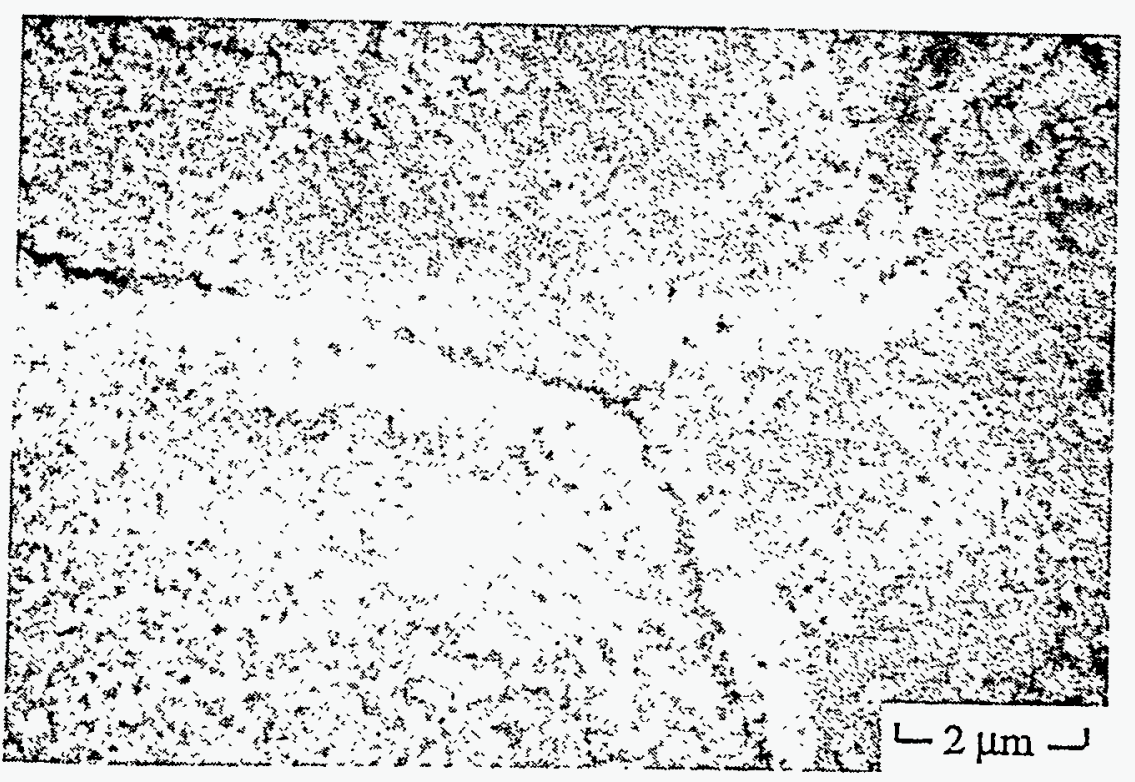

Figure 27. SEM micrograph of (a) fracture surface of as-received zirconia and (b) after $15 \mathrm{~h}$ at $950 \mathrm{C}$ 
of the alkali to the unreacted sample surface by alleviating the need for the alkalis to diffuse through the reaction layer.

Samples of the as-received TTZ were analyzed by $\mathrm{x}$-ray diffraction to determine the phases present. These samples were then heated in a box furnace at $1000^{\circ} \mathrm{C}$ for $12 \mathrm{~h}$ (with no alkalis present). The samples were $\mathrm{x}$-rayed again to determine if any phase changes had occurred. The results of these tests show that the TTZ does not undergo any detectable phase changes for the heat treatment used.

\subsubsection{Aluminum Titanate}

The alkali corrosion kinetics of aluminum titanate at $950^{\circ} \mathrm{C}$ were also investigated. The aluminum titanate pellet undergoes a severe reaction at $950^{\circ} \mathrm{C}$ with the alkalis. After only 3 hours at $950^{\circ} \mathrm{C}$, the reaction product formed on the surface of the aluminum titanante was approximately $1 / 8$ to $1 / 4$ of the size of the sample. The reaction product was too fragile to allow accurate measurement using the micrometer. Due to the severe reaction after only 3 h at $950^{\circ} \mathrm{C}$, additional testing of this material was suspended.

Aluminum titanate (without stabilizing agents) is not stable below about $1250^{\circ} \mathrm{C}$ where it decomposes into alumina and titania. It may be that the severity of the alkali reaction is due to the decomposition of the aluminum titanate and subsequent reaction of the alumina and titania with the alkalis. In order to test this possibility, flat samples of aluminum titanate (asreceived, cut) were $\mathrm{x}$-rayed before and after heating at $1000^{\circ} \mathrm{C}$ for $12 \mathrm{~h}$ (with no alkalis 
present) to determine if the material decomposes into alumina and titania. The $\mathrm{x}$-ray analysis showed that the aluminum titanate did not decompose as no significant amount of alumina or titania was detected. Although decomposition in the absence of alkalis apparently does not occur for this material, it may however occur with alkalis present. Alkali fluorides are often used as mineralizing agents to promote reactions which otherwise might be too sluggish to be observed. It is very possible that the alkalis present act as a mineralizer and facilitates the decomposition reaction, allowing rapid reaction with the alkalis.

The SEM micrographs of the as-received aluminum titanate fracture surface and after alkali reaction at $950^{\circ} \mathrm{C}$ is shown in Figure 28 . 
a.)

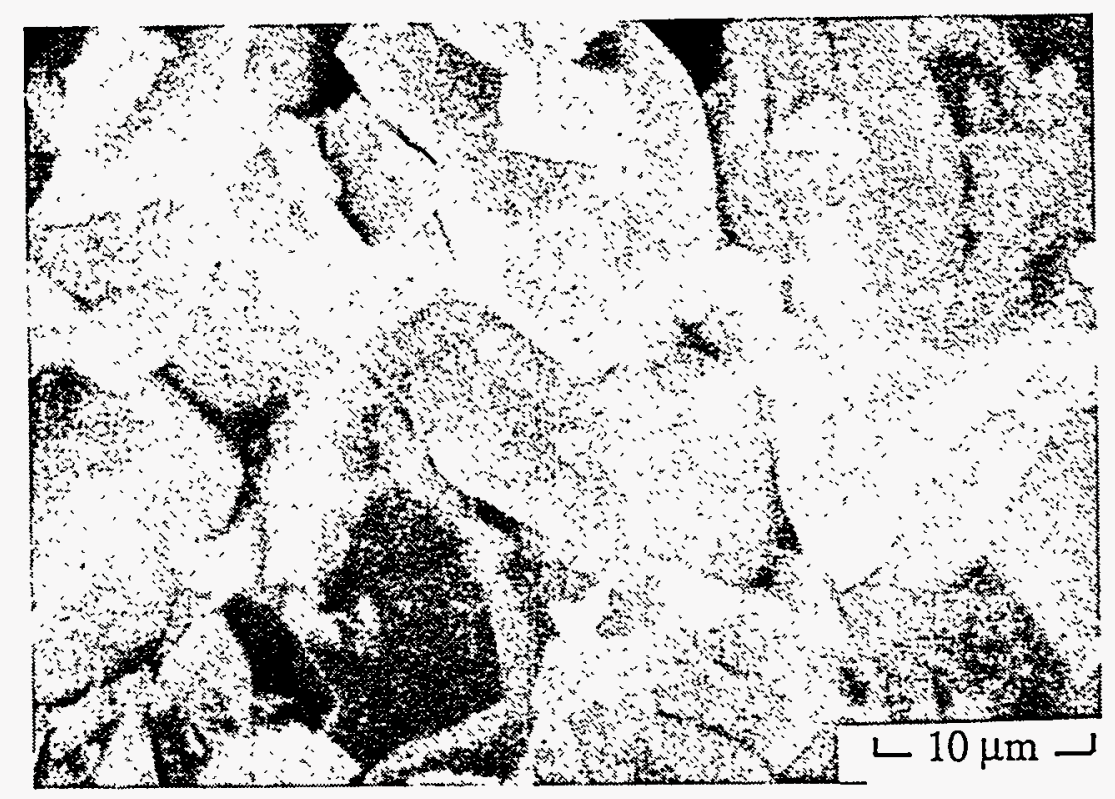

b.)

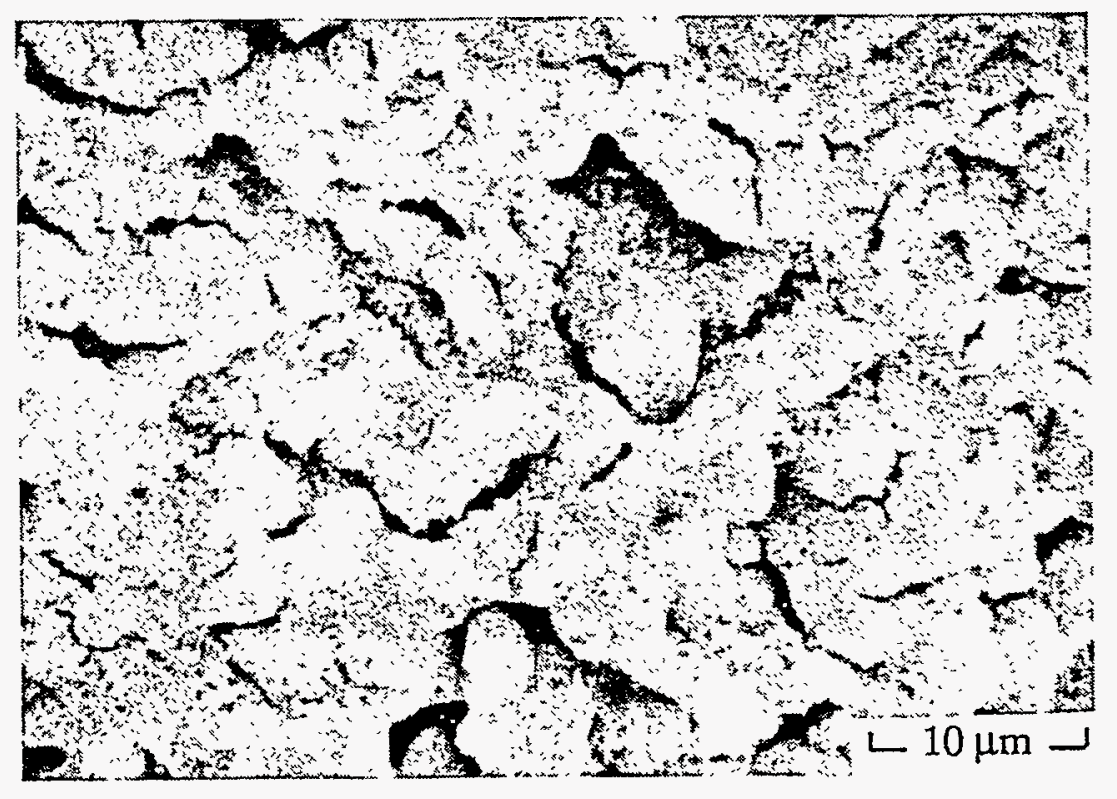

Figure 28. SEM micrograph of (a) fracture surface of as-received aluminum titanate and (b) after $3 \mathrm{~h}$ at $950 \mathrm{C}$ 


\subsection{Alkali Reaction Products}

\subsubsection{Soda - Cordierite}

The phase assemblages which were observed for selected compositions of soda and cordierite after reaction at the specified temperatures are shown in Table 5. For compositions containing less than $17.5 \mathrm{wt} \%$ soda, $\mathrm{XRD}$ and DTA analyses indicate that cordierite was decomposed by soda to form nepheline and forsterite below the solidus. The relative amounts of nepheline and forsterite increased with increasing soda content, and only a trace amount of cordierite was detected at $15 \%$ soda composition. For $17.5 \mathrm{wt} \%$ soda after a $1030^{\circ} \mathrm{C}$ for $63 \mathrm{hr}$ heat treatment, only nepheline and forsterite were detected in the x-ray diffraction pattern.

For compositions containing 17.5 to $30 \mathrm{wt} \%$ soda, the observed phases consisted of forsterite, nepheline, carnegieite solid solution, and an unknown phase. A large region of carnegieite solid solution was observed as evidenced by the shift in the two theta values of the diffraction peaks in the $\mathrm{x}$-ray patterns and the characteristic high-low inversion peak of carnegieite from the DTA curves. The formation temperature of carnegieite in this case was significantly lowered by the incorporation of magnesium oxide in the solid solution when compared to the transition temperature of pure nepheline to carnegieite. For compositions containing 17.5 to $30 \mathrm{wt} \%$ soda, no liquid phase was formed for temperatures at or below $1305^{\circ} \mathrm{C}$, in contrast to the compositions having less than $17.5 \%$ soda. 
Table 5. Phase Analysis of the Soda-Cordierite System

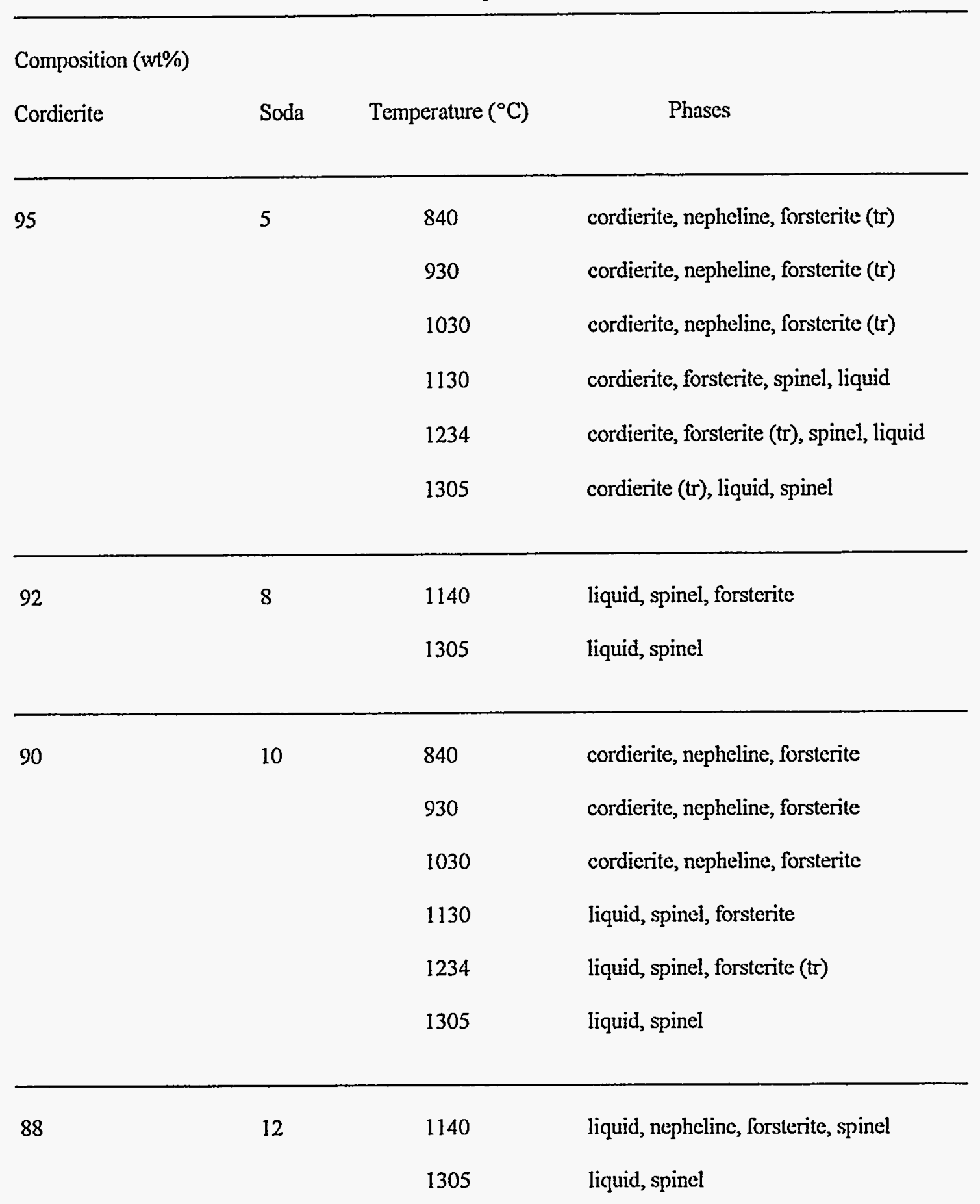


Table 5. Phase Analysis of the Soda-Cordierite System (continued)

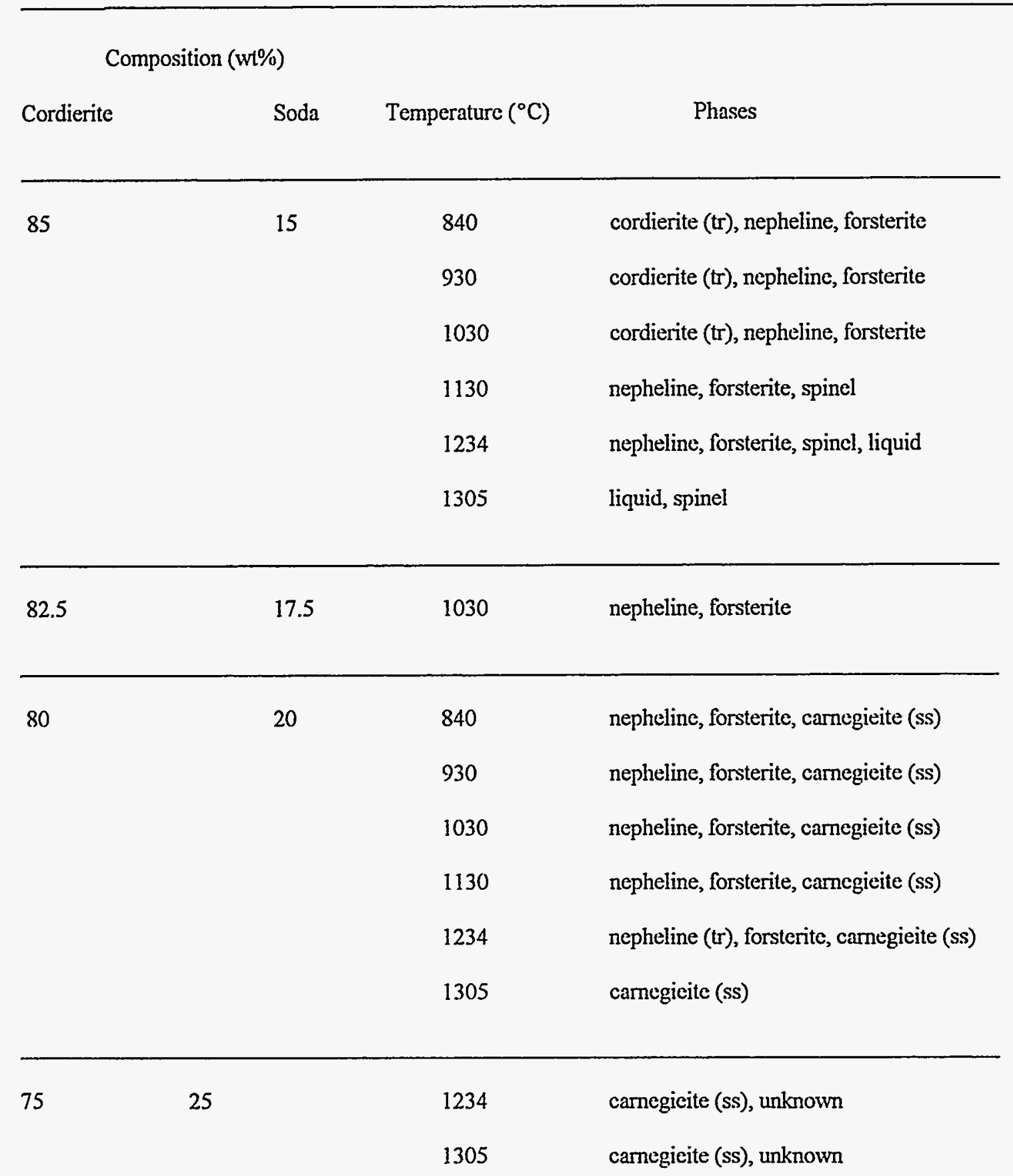


Table 5. Phase Analysis of the Soda-Cordierite System (continued)

\begin{tabular}{lccc}
\hline \multicolumn{2}{c}{ Composition (wt\%) } & & \\
Cordierite & Soda & Temperature $\left({ }^{\circ} \mathrm{C}\right)$ & Phases \\
\hline 70 & 30 & 930 & carnegieite (ss), unknown \\
& 1030 & carnegieite (ss), unknown \\
& 1130 & carnegieite (ss), unknown \\
& 1305 & carnegieite (ss), unknown \\
\hline
\end{tabular}

$\operatorname{tr}=$ trace; $\mathrm{ss}=$ solid solution 
The solidus temperature as determined by DTA appeared to vary with soda content, ranging from $1421^{\circ} \mathrm{C}$ at $2 \mathrm{wt} \%$ soda to $1325^{\circ} \mathrm{C}$ at $17.5 \mathrm{wt} \%$ soda as shown in Table 6 . Above the solidus temperature, the cordierite, forsterite, and nepheline phases showed varying degrees of dissolution in the liquid phase, and the spinel phase $\left(\mathrm{MgO} \cdot \mathrm{Al}_{2} \mathrm{O}_{3}\right)$ was precipitated from the liquid.

The compositions studied fall within the $\mathrm{MgO}-\mathrm{Al}_{2} \mathrm{O}_{3}-\mathrm{SiO}_{2}-\mathrm{Na}_{2} \mathrm{O}$ quaternary system. Portions of this system have been studied by several investigators with published phase diagrams including figures $855,856,2623-31$ and 7890 in Phase Diagrams for Ceramists (1964 through 1990 editions) ${ }^{142}$. This quaterary system is very complex as evidenced by the ternary and quaternary invariant points shown in figure 2623 of reference 142.

Very little information is available on the high soda portion of this system. Many of the diagrams show the nepheline (carnegieite) - forsterite join in agreement with the results of the current study for $17.5 \mathrm{wt} \%$ soda, $82.5 \mathrm{wt} \%$ cordierite. Silicates in general can form metastable phases with energies close to those of the stable phases. One of the reasons for this is that the intertetrahedral bond ( $\mathrm{Si}-\mathrm{O}-\mathrm{Si}$ ) is weak for the silica tetrahedra. Therefore, the energy liberated upon changing this bond angle from the metastable to the stable state is relatively small. The rate at which the transformation from the metastable state to the stable state can occur will be determined by the mobility and the driving force for the transformation. The viscosity of liquids and glassy phases within this system are usually relatively high. Since the driving force (which is the energy difference between the metastable and stable states) is small and in general the mobilities are low, the transformation from the 
Table 6. Solidus Temperature and High-Low Inversion Temperature of Carnegieite Solid Solution for the Compositions Studied

\begin{tabular}{ccc}
\hline Soda Content $(\mathrm{Wt} \%)$ & Solidus Temperature $\left({ }^{\circ} \mathrm{C}\right)$ & $\begin{array}{l}\text { Inversion } \\
\text { Temperature }\left({ }^{\circ} \mathrm{C}\right)\end{array}$ \\
\hline 2 & 1421 & -- \\
5 & 1102 & -- \\
8 & 1108 & -- \\
10 & 1112 & -- \\
12 & 1150 & -- \\
15 & 1200 & -- \\
17.5 & 1325 & --- \\
20 & 1333 & 616 \\
25 & 1336 & 640 \\
30 & -- & 657 \\
\hline
\end{tabular}


metastable to the stable state can be very sluggish. Due to this and to the limited amount of experimental information, the phases listed are referred to as observed phases rather than equilibrium phases. The determination as to whether these are the equilibrium phases will have to wait for a more comprehensive study to be conducted in this system.

\subsubsection{Potassia - Cordierite}

The phase assemblages which were observed for selected compositions of potassia and cordierite after reaction at the specified temperatures are shown in Table 7. For compositions containing less than $24 \mathrm{wt} \%$ potassia, XRD and DTA analyses indicate that cordierite was decomposed by potassia to form kaliophilite and forsterite below the solidus temperatures. The relative amounts of kaliophilite and forsterite increased with increasing potassia content at all temperatures as determined by $\mathrm{x}$-ray diffraction. The cordierite was completely decomposed at $24 \mathrm{wt} \%$ potassia to form kaliophilite and forsterite. For compositions containing $32 \mathrm{wt} \%$ potassia, the observed phases consisted of kaliophilite, $\mathrm{K}_{2} \mathrm{MgSiO}_{4}$, and an unknown phase.

As shown in Table 8, the solidus temperature varied with increasing potassia content, ranging from $1430^{\circ} \mathrm{C}$ at $3 \mathrm{wt} \%$ potassia to $1380^{\circ} \mathrm{C}$ at $32 \mathrm{wt} \%$ potassia as determined by the DTA analysis. The compositions studied fall within the $\mathrm{MgO}-\mathrm{Al}_{2} \mathrm{O}_{3}-\mathrm{SiO}_{2}-\mathrm{K}_{2} \mathrm{O}$ quaternary system. Portions of this system have been studied by several investigators with published 
Table 7. Phase Analysis of the Potassia-Cordierite System

\begin{tabular}{|c|c|c|c|}
\hline \multicolumn{2}{|c|}{ Composition (wt\%) } & \multirow[b]{2}{*}{ Temp. $\left({ }^{\circ} \mathrm{C}\right)$} & \multirow[b]{2}{*}{ Phases } \\
\hline Cordierite & Potassia & & \\
\hline 91 & 9 & $\begin{array}{l}840 \\
900 \\
1000 \\
1100\end{array}$ & $\begin{array}{l}\text { cordierite, kaliophilite, forsterite (tr) } \\
\text { cordierite, kaliophilite, forsterite (tr) } \\
\text { cordierite, kaliophilite, forsterite (tr) } \\
\text { cordierite, forsterite, unknown }\end{array}$ \\
\hline 84 & 16 & $\begin{array}{l}840 \\
900 \\
1000 \\
1100\end{array}$ & $\begin{array}{l}\text { cordierite, kaliophilite, forsterite } \\
\text { cordierite, kaliophilite, forsterite } \\
\text { cordierite, kaliophilite, forsterite } \\
\text { cordierite, kaliophilite, forsterite }\end{array}$ \\
\hline 76 & 24 & $\begin{array}{l}840 \\
900 \\
1000\end{array}$ & $\begin{array}{l}\text { kaliophilite, forsterite } \\
\text { kaliophilite, forsterite } \\
\text { kaliophilite, forsterite }\end{array}$ \\
\hline & & 98 & \\
\hline
\end{tabular}


Table 7. Phase Analysis of the Potassia-Cordierite System (continued)

Composition (wt\%)

$\begin{array}{llll}\text { Cordierite } & \text { Potassia } & \text { Temp. }\left({ }^{\circ} \mathrm{C}\right) & \text { Phases }\end{array}$

\begin{tabular}{llll}
\hline 76 & 1100 & kaliophilite, forsterite \\
\hline 68 & 32 & 840 & kaliophilite, KMS, unknown \\
& 900 & kaliophilite, KMS, unknown \\
& 1000 & kaliophilite, KMS, unknown \\
& 1100 & kaliophilite, KMS, unknown \\
\hline
\end{tabular}

$\operatorname{tr}=$ trace; $\mathrm{KMS}=\mathrm{K}_{2} \mathrm{MgSiO}_{4}$ 
Table 8. Solidus Temperature of the Potassia-Cordierite System

Potassia Content (wt\%)

Solidus Temperature $\left({ }^{\circ} \mathrm{C}\right)$

3

1430

9

1200

16

1280

24

1408

32

1380 
phase diagrams including figures 802-811, 4611 and 6876 in Phase Diagrams for Ceramists(1964 through 1990 editions) ${ }^{142}$. This quaternary system is also very complex as evidenced by the ternary and quaternary invariant points shown in figure 808 of reference 142. As discussed for the soda-cordierite system above, the phases presented represent the observed phases and not necessarily the equilibrium phases in this portion of the system.

\subsubsection{Soda - Zirconia}

Table 9 lists the compositions and the phase assemblages of the soda-zirconia reactions at different temperatures. The reaction products consist of sodium zirconate $\left(\mathrm{Na}_{2} \mathrm{ZrO}_{3}\right)$, and zirconia for all the compositions studied. DTA analysis of the samples showed the tetragonal to monoclinic zirconia transformation at $1170^{\circ} \mathrm{C}$; however, only the monoclinic phase was detected in the quenched samples due to the martensitic transformation below $1170^{\circ} \mathrm{C}$. No melting was observed in the DTA analysis up to $1400^{\circ} \mathrm{C}$ for the soda-zirconia system.

No phase diagrams could be found in the literature for the soda-zirconia system. The system $\mathrm{Na}_{2} \mathrm{O}-\mathrm{ZrO}_{2}-\mathrm{WO}_{3}$ has been investigated. ${ }^{143}$ However, no data are available on the soda-zirconia binary system in this reference. Destabilization of india/yttria dual stabilized zirconia in the presence of sodium vanadate has been investigated. ${ }^{144}$ The percent transformation to the monoclinic phase was monitored. No data, however, are presented on the soda-zirconia reaction products. 
Table 9. Phase Analysis of the Soda-Zirconia System

Composition (wt\%)

Zirconia Soda

Temperature $\left({ }^{\circ} \mathrm{C}\right) \quad$ Phases

\begin{tabular}{ccc}
\hline 95 & 840 & $\mathrm{~m}-\mathrm{ZrO}_{2}+\mathrm{Na}_{2} \mathrm{ZrO}_{3}(\mathrm{tr})$ \\
900 & $\mathrm{~m}-\mathrm{ZrO}_{2}+\mathrm{Na}_{2} \mathrm{ZrO}_{3}(\mathrm{tr})$ \\
1000 & $\mathrm{~m}-\mathrm{ZrO}_{2}+\mathrm{Na}_{2} \mathrm{ZrO}_{3}(\mathrm{tr})$ \\
1100 & $\mathrm{~m}-\mathrm{ZrO}_{2}+\mathrm{Na}_{2} \mathrm{ZrO}_{3}(\mathrm{tr})$ \\
1200 & $\mathrm{t}-\mathrm{ZrO}_{2}+\mathrm{Na}_{2} \mathrm{ZrO}_{3}(\mathrm{tr})$ \\
1300 & $\mathrm{t}-\mathrm{ZrO}_{2}+\mathrm{Na}_{2} \mathrm{ZrO}_{3}(\mathrm{tr})$ \\
& 1500 & $\mathrm{t}-\mathrm{ZrO}_{2}+\mathrm{Na}_{2} \mathrm{ZrO}_{3}(\mathrm{tr})$ \\
\hline 10 & 840 & \\
\hline 1000 & $\mathrm{~m}-\mathrm{ZrO}_{2}+\mathrm{Na}_{2} \mathrm{ZrO}_{3}$ \\
& $\mathrm{~m}-\mathrm{ZrO}_{2}+\mathrm{Na}_{2} \mathrm{ZrO}_{3}$ \\
& 1100 & $\mathrm{~m}-\mathrm{ZrO}_{2}+\mathrm{Na}_{2} \mathrm{ZrO}_{3}$ \\
1200 & $\mathrm{~m}-\mathrm{ZrO}_{2}+\mathrm{Na}_{2} \mathrm{ZrO}_{3}$ \\
1300 & $\mathrm{t}-\mathrm{ZrO}_{2}+\mathrm{Na}_{2} \mathrm{ZrO}_{3}$ \\
& $\mathrm{t}-\mathrm{ZrO}_{2}+\mathrm{Na}_{2} \mathrm{ZrO}_{3}$ \\
& $\mathrm{t}-\mathrm{ZrO}_{2}+\mathrm{Na}_{2} \mathrm{ZrO}_{3}$ \\
&
\end{tabular}


Table 9. Phase Analysis of the Soda-Zirconia System (continued)

Composition (wt\%)

Zirconia Soda $\quad$ Temperature $\left({ }^{\circ} \mathrm{C}\right) \quad$ Phases

\begin{tabular}{ccc}
\hline 85 & 840 & $\mathrm{~m}-\mathrm{ZrO}_{2}+\mathrm{Na}_{2} \mathrm{ZrO}_{3}$ \\
900 & $\mathrm{~m}-\mathrm{ZrO}_{2}+\mathrm{Na}_{2} \mathrm{ZrO}_{3}$ \\
15 & $\mathrm{~m}-\mathrm{ZrO}_{2}+\mathrm{Na}_{2} \mathrm{ZrO}_{3}$ \\
1100 & $\mathrm{~m}-\mathrm{ZrO}_{2}+\mathrm{Na}_{2} \mathrm{ZrO}_{3}$ \\
1200 & $\mathrm{t}-\mathrm{ZrO}_{2}+\mathrm{Na}_{2} \mathrm{ZrO}_{3}$ \\
1300 & $\mathrm{t}-\mathrm{ZrO}_{2}+\mathrm{Na}_{2} \mathrm{ZrO}_{3}$ \\
\hline 1500 & $\mathrm{t}-\mathrm{ZrO}_{2}+\mathrm{Na}_{2} \mathrm{ZrO}_{3}$ \\
\hline 100 & 840 & \\
\hline 1000 & $\mathrm{~m}-\mathrm{ZrO}_{2}+\mathrm{Na}_{2} \mathrm{ZrO}_{3}$ \\
& 1100 & $\mathrm{~m}-\mathrm{ZrO}_{2}+\mathrm{Na}_{2} \mathrm{ZrO}_{3}$ \\
& 1200 & $\mathrm{~m}-\mathrm{ZrO}_{2}+\mathrm{Na}_{2} \mathrm{ZrO}_{3}$ \\
1300 & $\mathrm{~m}-\mathrm{ZrO}_{2}+\mathrm{Na}_{2} \mathrm{ZrO}_{3}$ \\
& $\mathrm{t}-\mathrm{ZrO}_{2}+\mathrm{Na}_{2} \mathrm{ZrO}_{3}$ \\
& $\mathrm{t}-\mathrm{ZrO}_{2}+\mathrm{Na}_{2} \mathrm{ZrO}_{3}$ \\
& 1500 & $\mathrm{Na}_{2} \mathrm{ZrO}_{3}$ \\
&
\end{tabular}


Table 9. Phase Analysis of the Soda-Zirconia System (continued)

Composition (wt\%)

Zirconia Soda $\quad$ Temperature $\left({ }^{\circ} \mathrm{C}\right) \quad$ Phases

\begin{tabular}{ccc}
\hline 30 & 840 & $\mathrm{~m}-\mathrm{ZrO}_{2}(\mathrm{tr})+\mathrm{Na}_{2} \mathrm{ZrO}_{3}$ \\
900 & $\mathrm{~m}-\mathrm{ZrO}_{2}(\mathrm{tr})+\mathrm{Na}_{2} \mathrm{ZrO}_{3}$ \\
& 1000 & $\mathrm{~m}-\mathrm{ZrO}_{2}(\mathrm{tr})+\mathrm{Na}_{2} \mathrm{ZrO}_{3}$ \\
& 1100 & $\mathrm{~m}-\mathrm{ZrO}_{2}(\mathrm{tr})+\mathrm{Na}_{2} \mathrm{ZrO}_{3}$ \\
& 1300 & $\mathrm{t}-\mathrm{ZrO}_{2}(\mathrm{tr})+\mathrm{Na}_{2} \mathrm{ZrO}_{3}$ \\
$\mathrm{tr}=\mathrm{trace}$ & 1500 & $\mathrm{t}-\mathrm{ZrO}_{2}(\mathrm{tr})+\mathrm{Na}_{2} \mathrm{ZrO}_{3}$ \\
& & $\mathrm{t}-\mathrm{ZrO}_{2}(\mathrm{tr})+\mathrm{Na}_{2} \mathrm{ZrO}_{3}$ \\
\hline
\end{tabular}




\subsubsection{Soda - Calcia Stabilized Cubic Zirconia}

Table 10 lists the compositions and the phase assemblages of the soda-CSZ reactions at different temperatures. Based on XRD analysis, the reaction products at all temperatures consist of sodium zirconate $\left(\mathrm{Na}_{2} \mathrm{ZrO}_{3}\right)$, calcium zirconate $(\mathrm{CaZrO})$, and $\mathrm{CSZ}$ for compositions containing less than $30 \%$ soda. At higher soda content (30\%), the phases present are sodium zirconate, calcium zirconate, and unreacted sodium species.

It appears that the alkali reaction proceeded by preferentially attacking the zirconia in the calcia-zirconia solid solution (CSZ) with the precipitation of calcium zirconate. The presence of calcium zirconate in all specimens suggests that calcium zirconate has good alkali corrosion resistance at temperatures below $1100^{\circ} \mathrm{C}$. To further evaluate the alkali resistance of calcium zirconate, pure calcium zirconate synthesized at $1500^{\circ} \mathrm{C}$ was mixed with sodium carbonate (20 $\mathrm{wt} \%$ soda) and fired at $1100^{\circ} \mathrm{C}$ for $144 \mathrm{~h}$. Only calcium zirconate was detected in the $\mathrm{x}$-ray pattern after the heat treatment. DTA analysis of the reaction products showed no phase transition between $800-1100^{\circ} \mathrm{C}$ for all the compositions studied.

No phase diagrams could be found in the literature for the soda-calcia-zirconia system. The soda-zirconia system has been reviewed in the preceding section. 
Table 10. Phase Analysis of the Soda-CSZ System

Composition (wt\%)

Zirconia Soda Temperature $\left({ }^{\circ} \mathrm{C}\right) / \quad$ Phases

Time (h)

\begin{tabular}{|c|c|c|c|}
\hline \multirow[t]{4}{*}{95} & 5 & $840 / 100$ & $\mathrm{CSZ}+\mathrm{CaZrO}_{3}(\mathrm{tr})+\mathrm{Na}_{2} \mathrm{ZrO}_{3}(\mathrm{tr})$ \\
\hline & & $900 / 96$ & $\mathrm{CSZ}+\mathrm{CaZrO}_{3}(\mathrm{tr})+\mathrm{Na}_{2} \mathrm{ZrO}_{3}(\mathrm{tr})$ \\
\hline & & $1000 / 48$ & $\mathrm{CSZ}+\mathrm{CaZrO}_{3}(\mathrm{tr})+\mathrm{Na}_{2} \mathrm{ZrO}_{3}(\mathrm{tr})$ \\
\hline & & $1100 / 72$ & $\mathrm{CSZ}+\mathrm{CaZrO}_{3}(\mathrm{tr})+\mathrm{Na}_{2} \mathrm{ZrO}_{3}(\mathrm{tr})$ \\
\hline \multirow[t]{4}{*}{90} & 10 & $840 / 100$ & $\mathrm{CSZ}+\mathrm{CaZrO}_{3}+\mathrm{Na}_{2} \mathrm{ZrO}_{3}$ \\
\hline & & $900 / 96$ & $\mathrm{CSZ}+\mathrm{CaZrO}_{3}+\mathrm{Na}_{2} \mathrm{ZrO}_{3}$ \\
\hline & & $1000 / 48$ & $\mathrm{CSZ}+\mathrm{CaZrO}_{3}+\mathrm{Na}_{2} \mathrm{ZrO}_{3}$ \\
\hline & & $1100 / 72$ & $\mathrm{CSZ}+\mathrm{CaZrO}_{3}+\mathrm{Na}_{2} \mathrm{ZrO}_{3}$ \\
\hline \multirow[t]{4}{*}{85} & 15 & $840 / 100$ & $\mathrm{CSZ}+\mathrm{CaZrO}_{3}+\mathrm{Na}_{2} \mathrm{ZrO}_{3}$ \\
\hline & & $900 / 96$ & $\mathrm{CSZ}+\mathrm{CaZrO}_{3}+\mathrm{Na}_{2} \mathrm{ZrO}_{3}$ \\
\hline & & $1000 / 48$ & $\mathrm{CSZ}+\mathrm{CaZrO}_{3}+\mathrm{Na}_{2} \mathrm{ZrO}_{3}$ \\
\hline & & $1100 / 72$ & $\mathrm{CSZ}+\mathrm{CaZrO}{ }_{3}+\mathrm{Na}_{2} \mathrm{ZrO}_{3}$ \\
\hline
\end{tabular}


Table 10. Phase Analysis of the Soda-CSZ System (continued)

Composition (wt\%)

Zirconia Soda Temperature $\left({ }^{\circ} \mathrm{C}\right) / \quad$ Phases

Time (h)

\begin{tabular}{lll}
\hline 80 & $840 / 100$ & $\mathrm{CSZ}+\mathrm{CaZrO}_{3}+\mathrm{Na}_{2} \mathrm{ZrO}_{3}$ \\
& $900 / 96$ & $\mathrm{CSZ}+\mathrm{CaZrO}_{3}+\mathrm{Na}_{2} \mathrm{ZrO}_{3}$ \\
& $1000 / 48$ & $\mathrm{CSZ}+\mathrm{CaZrO}_{3}+\mathrm{Na}_{2} \mathrm{ZrO}_{3}$ \\
& $1100 / 72$ & $\mathrm{CSZ}+\mathrm{CaZrO}_{3}+\mathrm{Na}_{2} \mathrm{ZrO}_{3}$ \\
\hline 70 & & \\
\hline 30 & $840 / 100$ & $\mathrm{CaZrO}_{3}+\mathrm{Na}_{2} \mathrm{ZrO}_{3}+\mathrm{USS}$ \\
& $1000 / 48$ & $\mathrm{CaZrO}_{3}+\mathrm{Na}_{2} \mathrm{ZrO}_{3}+\mathrm{USS}$ \\
\hline
\end{tabular}

$\operatorname{tr}=$ trace, $\operatorname{CSZ}=$ Calcia Stabilized Zirconia (cubic), USS $=$ Unreacted Sodium Species 


\subsubsection{Soda - Aluminum Titanate}

In the first set of experiments for this system, sodium carbonate and aluminum titanate (which was prepared by sol-gel synthesis described in the procedure section) were used as the starting materials to prepare compositions along the $\mathrm{Na}_{2} \mathrm{O}-\mathrm{Al}_{2} \mathrm{TiO}_{5}$ join. Table 11 lists the compositions and the phase assemblages which were observed in the $\mathrm{x}$-ray diffraction patterns for the soda-aluminum titanate reaction products at different temperatures. The phase assemblages observed for these samples were used to construct a tentative subsolidus ternary phase diagram for the low soda side of the $\mathrm{Na}_{2} \mathrm{O}-\mathrm{Al}_{2} \mathrm{O}_{3}-\mathrm{TiO}_{2}$ system.

An unknown ternary phase appeared in the $\mathrm{x}$-ray diffaction patterns for this ternary system. This unknown phase persisted in the $\mathrm{x}$-ray patterns after repeated grinding and firing up to $1100^{\circ} \mathrm{C}$. The observed phase assemblages indicate that the $\mathrm{Na}_{2} \mathrm{O}-\mathrm{Al}_{2} \mathrm{TiO}_{5}$ section is not a true binary system, since all of the phases can not be expressed in terms of the end members $\left(\mathrm{Na}_{2} \mathrm{O}\right.$ and $\left.\mathrm{Al}_{2} \mathrm{TiO}_{5}\right)$.

Additional samples were prepared by using sodium carbonate, alumina and titania to investigate compositions outside the $\mathrm{Na}_{2} \mathrm{O}-\mathrm{Al}_{2} \mathrm{TiO}_{5}$ join. This additional experimentation was performed in order to confirm and refine the compatibility triangles constructed above. These samples were fired in open crucibles with the weight of the samples monitored before and after firing. The weight loss of the samples corresponded to the theoretical weight loss for the decomposition of sodium carbonate into soda and carbon dioxide within the experimental precision. No weight loss attributable to loss of soda was observed for any of the samples. 
Table 11. Phase Analysis of the Soda-Aluminum Titanate System

Composition (wt\%) Temperature $\left({ }^{\circ} \mathrm{C}\right) / \quad$ Observed Melting

$\mathrm{Al}_{2} \mathrm{TiO}_{5}$ Soda $\quad$ Time (h) Phases $\quad$ Temperature

$\begin{array}{lll}95 & 840 / 300 & \mathrm{NA}_{5} \mathrm{~T}_{4}+\mathrm{TiO}_{2}(\mathrm{tr})+\mathrm{un} \\ 900 / 200 & \mathrm{NA}_{5} \mathrm{~T}_{4}+\mathrm{TiO}_{2}(\mathrm{tr})+\text { un } \\ 1000 / 100 & \mathrm{NA}_{5} \mathrm{~T}_{4}+\mathrm{TiO}_{2}(\mathrm{tr})+\text { un } \\ 1100 / 100 . & \mathrm{NA}_{5} \mathrm{~T}_{4}+\mathrm{TiO}_{2}(\mathrm{tr})+\text { un }\end{array}$

\begin{tabular}{llll}
\hline 90 & $840 / 300$ & & \\
& $\mathrm{NA}(\mathrm{tr})+\mathrm{NT}_{3}(\mathrm{tr})+\mathrm{un}$ & \\
& & $\mathrm{NA}(\mathrm{tr})+\mathrm{NT}_{3}(\mathrm{tr})+\mathrm{un}$ & \\
& $1000 / 200$ & $\mathrm{NA}_{11}+\mathrm{un}$ & 1048 \\
& $1100 / 100$ & $\mathrm{NA}_{11}+\mathrm{Liq}$ & \\
\hline 85 & & & \\
& & & \\
& $840 / 300$ & $\mathrm{NA}+\mathrm{NT}_{3}+\mathrm{un}$ & 1000 \\
& $900 / 200$ & $\mathrm{NA}+\mathrm{NT}_{3}+\mathrm{un}$ &
\end{tabular}


Table 11. Phase Analysis of the Soda-Aluminum Titanate System (continued)

\begin{tabular}{|c|c|c|c|c|}
\hline \multicolumn{2}{|c|}{ Composition (wt\%) } & \multirow{2}{*}{$\begin{array}{l}\text { Temperature }\left({ }^{\circ} \mathrm{C}\right) / \\
\text { Time (h) }\end{array}$} & \multirow{2}{*}{$\begin{array}{l}\text { Observed } \\
\text { Phases }\end{array}$} & \multirow{2}{*}{$\begin{array}{l}\text { Melting } \\
\text { Temperature }\end{array}$} \\
\hline $\mathrm{Al}_{2} \mathrm{TiO}_{5}$ & Soda & & & \\
\hline 85 & 15 & $1100 / 100$ & $\mathrm{NA}_{11}+\mathrm{Liq}$ & \\
\hline \multirow[t]{4}{*}{80} & 20 & $840 / 300$ & $\mathrm{NA}+\mathrm{NT}_{3}+$ un & \\
\hline & & $900 / 200$ & $\mathrm{NA}+\mathrm{NT}_{3}+$ un & \\
\hline & & $1000 / 100$ & $\mathrm{NA}+\mathrm{Liq}$ & 993 \\
\hline & & $1100 / 100$ & $\mathrm{NA}_{11}+\mathrm{NA}+\mathrm{Liq}$ & \\
\hline \multirow[t]{4}{*}{70} & 30 & $840 / 300$ & $\mathrm{NA}+\mathrm{NT}_{3}+$ un (tr) & \\
\hline & & $900 / 200$ & $\mathrm{NA}+\mathrm{NT}_{3}+$ un $(\mathrm{tr})$ & \\
\hline & & $1000 / 100$ & $\mathrm{NA}+$ un & 1026 \\
\hline & & $1100 / 100$ & $\mathrm{NA}+\mathrm{Liq}$ & \\
\hline \multirow[t]{2}{*}{60} & 40 & $840 / 300$ & $\mathrm{NA}+\mathrm{N}_{4} \mathrm{~T}_{5}+$ un & \\
\hline & & $900 / 200$ & $\mathrm{NA}+\mathrm{N}_{4} \mathrm{~T}_{5}+\mathrm{un}$ & \\
\hline
\end{tabular}


Table 11. Phase Analysis of the Soda-Aluminum Titanate System (continued)

\begin{tabular}{|c|c|c|c|c|}
\hline \multicolumn{2}{|c|}{ Composition (wt\%) } & \multirow{2}{*}{$\begin{array}{l}\text { Temperature }\left({ }^{\circ} \mathrm{C}\right) / \\
\text { Time }(\mathrm{h})\end{array}$} & \multirow{2}{*}{$\begin{array}{l}\text { Observed } \\
\text { Phases }\end{array}$} & \multirow{2}{*}{$\begin{array}{l}\text { Melting } \\
\text { Temperature }\end{array}$} \\
\hline $\mathrm{Al}_{2} \mathrm{TiO}_{5}$ & Soda & & & \\
\hline \multirow[t]{2}{*}{60} & 40 & $1000 / 100$ & $\mathrm{NA}+\mathrm{Liq}$ & 966 \\
\hline & & $1100 / 100$ & $\mathrm{NA}+\mathrm{Liq}$ & \\
\hline
\end{tabular}

$\mathrm{NA}=\mathrm{NaAlO}_{2}, \quad \mathrm{NA}_{11}=\mathrm{NaAl}_{11} \mathrm{O}_{17}, \quad \mathrm{NT}_{3}=\mathrm{Na}_{2} \mathrm{Ti}_{3} \mathrm{O}_{7}, \quad \mathrm{NA}_{5} \mathrm{~T}_{4}=\mathrm{NaAl}_{5} \mathrm{Ti}_{2} \mathrm{O}_{12}, \mathrm{~N}_{4} \mathrm{~T}_{5}=$ $\mathrm{Na}_{8} \mathrm{Ti}_{5} \mathrm{O}_{14}$, un $=$ unknown single phase, $\mathrm{Liq}=$ liquid 
Table 12 lists the compositions and the phase assemblages of the $\mathrm{Na}_{2} \mathrm{O}-\mathrm{Al}_{2} \mathrm{O}_{3}-\mathrm{TiO}_{2}$ reactions at different temperatures and heat treatment times. The formation of $\beta$-alumina at $840^{\circ} \mathrm{C}$ appears to be very sluggish. As a result, the alumina phase observed in samples 2, 3, and 4 at $840^{\circ} \mathrm{C}$ is believed to be due to lack of sufficient reaction time for the system to reach equilibrium. At higher temperatures, $\beta$-alumina was formed and the free alumina phase was not observed for the same compositions. Based on the phase analysis for the compositions studied, a phase diagram showing the subsolidus equilibria for the $\mathrm{Na}_{2} \mathrm{O}-\mathrm{Al}_{2} \mathrm{O}_{3}-\mathrm{TiO}_{2}$ system was constructed as shown in Figure 29. The unknown ternary phase in this system persisted after repeated grinding and firing up to $1100^{\circ} \mathrm{C}$. The phase relations observed indicate that the composition of the unknown phase is likely to contain about $55 \% \mathrm{TiO}_{2}, 39 \% \mathrm{Al}_{2} \mathrm{O}_{3}$ and $6 \mathrm{wt} \% \mathrm{Na}_{2} \mathrm{O}$.

No phase diagram for the soda-alumina-titania system could be found in the literature. Mumme et $\mathrm{al}^{145}$ reported preparation of $\mathrm{NaTi}_{2} \mathrm{Al}_{5} \mathrm{O}_{12}$ by heating mixtures of sodium carbonate, alumina, and titania (anatase) in air at $800^{\circ} \mathrm{C}$ then in sealed capsules at $1300^{\circ} \mathrm{C}$ for $48 \mathrm{~h}$. The x-ray data for the unknown phase did not match the $\mathrm{x}$-ray data for $\mathrm{NaTi}_{2} \mathrm{Al}_{5} \mathrm{O}_{12}$ well. 
Table 12. Phase Analysis of the Soda-Alumina-Titania System

Phase

Sample Composition (wt\%) $\quad$ Temp $\left({ }^{\circ} \mathrm{C}\right) / \quad$ Observed $\quad$ Transition

No. $\quad \mathrm{Na}_{2} \mathrm{O} \quad \mathrm{Al}_{2} \mathrm{O}_{3} \quad \mathrm{TiO}_{2} \quad$ Time (h) Phases $\quad$ Temperatures

$\begin{array}{lllll}\text { 1. } & 32 & 20 & 48 & 956\end{array}$

$\begin{array}{ll}840 / 72 & \mathrm{NT}_{3}+\mathrm{N}_{4} \mathrm{~T}_{5}+\mathrm{NA} \\ 840 / 91 & \mathrm{NT}_{3}+\mathrm{N}_{4} \mathrm{~T}_{5}+\mathrm{NA} \\ 840 / 119 & \mathrm{NT}_{3}+\mathrm{N}_{4} \mathrm{~T}_{5}+\mathrm{NA} \\ 840 / 91 & \mathrm{NT}_{3}+\mathrm{N}_{4} \mathrm{~T}_{5}+\mathrm{NA} \\ 940 / 46 & \mathrm{NT}_{3}+\mathrm{NA}+\mathrm{Liq}\end{array}$

2.

$20 \quad 35 \quad 45$

991

$\begin{array}{lll}840 / 72 & \mathrm{NT}_{3}+\mathrm{NA}+\mathrm{A} & 1046 \\ 840 / 91 & \mathrm{NT}_{3}+\mathrm{NA}+\mathrm{A} & 1070 \\ 840 / 119 & \mathrm{NT}_{3}+\mathrm{NA}+\mathrm{A} & \\ 840 / 91 & \mathrm{NT}_{3}+\mathrm{NA}+\mathrm{A} & \\ 940 / 46 & \mathrm{NT}_{3}+\mathrm{NA}+\beta \mathrm{A} & \\ 1000 / 16 & \mathrm{NT}_{3}+\mathrm{NA}+\beta \mathrm{A} & \end{array}$


Table 12. Phase Analysis of the Soda-Alumina-Titania System (continued)

Phase

Sample Composition (wt\%) Temp $\left({ }^{\circ} \mathrm{C}\right) / \quad$ Observed $\quad$ Transition

No. $\quad \mathrm{Na}_{2} \mathrm{O} \mathrm{Al}_{2} \mathrm{O}_{3} \quad \mathrm{TiO}_{2} \quad$ Time (h) Phases $\quad$ Temperatures

2. $20 \quad 35 \quad 45 \quad 1100 / 67 \quad \beta A+X+\operatorname{Liq}$

3. $\quad 40 \quad 30 \quad 30$

$\begin{array}{lll}840 / 72 & \mathrm{NT}_{3}+\mathrm{NA}+\mathrm{A} & 1046 \\ 840 / 91 & \mathrm{NT}_{3}+\mathrm{NA}+\mathrm{A} & 1070 \\ 840 / 119 & \mathrm{NT}_{3}+\mathrm{NA}+\mathrm{A} & \\ 840 / 91 & \mathrm{NT}_{3}+\mathrm{NA}+\mathrm{A} & \\ 940 / 46 & \mathrm{NT}_{3}+\mathrm{NA}+\beta \mathrm{A} & \\ 1000 / 16 & \mathrm{NT}_{3}+\mathrm{NA}+\beta \mathrm{A} & \\ 1100 / 67 & \beta \mathrm{A}+\mathrm{X}+\mathrm{Liq} & \end{array}$

4.

$\begin{array}{lll}18 & 69 & 13\end{array}$

999

$840 / 72 \quad \mathrm{NT}_{3}+\mathrm{NA}+\mathrm{A}$

1040

$840 / 91 \quad \mathrm{NT}_{3}+\mathrm{NA}+\mathrm{A}+\beta \mathrm{A}$ 
Table 12. Phase Analysis of the Soda-Alumina-Titania System (continued)

\begin{tabular}{|c|c|c|c|c|c|c|}
\hline \multirow{3}{*}{$\begin{array}{l}\text { Sample } \\
\text { No. }\end{array}$} & \multirow{2}{*}{\multicolumn{3}{|c|}{ Composition (wt\%) }} & \multirow{3}{*}{$\begin{array}{l}\text { Temp }\left({ }^{\circ} \mathrm{C}\right) / \\
\text { Time (h) }\end{array}$} & \multirow{3}{*}{$\begin{array}{l}\text { Observed } \\
\text { Phases }\end{array}$} & \multirow{3}{*}{$\begin{array}{l}\text { Phase } \\
\text { Transition } \\
\text { Temperatures }\end{array}$} \\
\hline & & & & & & \\
\hline & $\mathrm{Na}_{2} \mathrm{O}$ & $\mathrm{Al}_{2} \mathrm{O}_{3}$ & $\mathrm{TiO}_{2}$ & & & \\
\hline \multirow[t]{5}{*}{4.} & 18 & 69 & 13 & $840 / 119$ & $\mathrm{NT}_{3}+\mathrm{NA}+\mathrm{A}+\beta \mathrm{A}$ & \\
\hline & & & & $840 / 91$ & $\mathrm{NT}_{3}+\mathrm{NA}+\mathrm{A}+\beta \mathrm{A}$ & \\
\hline & & & & $940 / 46$ & $\mathrm{NT}_{3}+\mathrm{NA}+\beta \mathrm{A}$ & \\
\hline & & & & $1000 / 16$ & $\mathrm{NT}_{3}+\mathrm{NA}+\beta \mathrm{A}$ & \\
\hline & & & & $1100 / 67$ & $\beta A+N A+L i q$ & \\
\hline \multirow[t]{8}{*}{5.} & 4 & 84 & 12 & & & 1037 \\
\hline & & & & $840 / 72$ & $\mathrm{NT}_{3}+\mathrm{BA}+\mathrm{A}$ & \\
\hline & & & & $840 / 91$ & $\mathrm{NT}_{3}+\beta \mathrm{A}+\mathrm{A}$ & \\
\hline & & & & $840 / 119$ & $\mathrm{NT}_{3}+\beta \mathrm{A}+\mathrm{A}$ & \\
\hline & & & & $840 / 91$ & $\mathrm{NT}_{3}+\beta \mathrm{A}+\mathrm{A}$ & \\
\hline & & & & $940 / 46$ & $\mathrm{NT}_{3}+\beta \mathrm{A}+\mathrm{A}$ & \\
\hline & & & & $1000 / 16$ & $\mathrm{NT}_{3}+\beta \mathrm{A}+\mathrm{A}$ & \\
\hline & & & & $1100 / 67$ & $\beta A+A+L i q$ & \\
\hline
\end{tabular}


Table 12. Phase Analysis of the Soda-Alumina-Titania System (continued)

\begin{tabular}{|c|c|c|c|c|c|}
\hline \multirow{2}{*}{$\begin{array}{l}\text { Sample } \\
\text { No. }\end{array}$} & \multicolumn{2}{|c|}{ Composition (wt\%) } & \multirow{2}{*}{$\begin{array}{l}\text { Temp }\left({ }^{\circ} \mathrm{C}\right) / \\
\text { Time }(\mathrm{h})\end{array}$} & \multirow{2}{*}{$\begin{array}{l}\text { Observed } \\
\text { Phases }\end{array}$} & \multirow{2}{*}{$\begin{array}{l}\text { Phase } \\
\text { Transition } \\
\text { Temperatures }\end{array}$} \\
\hline & $\mathrm{Na}_{2} \mathrm{O}$ & $\mathrm{Al}_{2} \mathrm{O}_{3} \quad \mathrm{TiO}_{2}$ & & & \\
\hline \multirow[t]{8}{*}{6.} & 2 & $45 \quad 53$ & & & nonẹ \\
\hline & & & $840 / 72$ & $A+T+X$ & \\
\hline & & & $840 / 91$ & $\mathrm{~A}+\mathrm{T}+\mathrm{X}$ & \\
\hline & & & $840 / 119$ & $A+T+X$ & \\
\hline & & & $840 / 91$ & $A+T+X$ & \\
\hline & & & $940 / 46$ & $A+T+X$ & \\
\hline & & & $1000 / 16$ & $A+T+X$ & \\
\hline & & & $1100 / 67$ & $A+T+X$ & \\
\hline
\end{tabular}

a

$\begin{array}{lllll}7 . & 9 & 15 & 76 & \text { none }\end{array}$

$\begin{array}{ll}840 / 72 & \mathrm{NT}_{6}+\mathrm{T}(\mathrm{tr})+\mathrm{X} \\ 840 / 91 & \mathrm{NT}_{6}+\mathrm{T}(\mathrm{tr})+\mathrm{X} \\ 840 / 119 & \mathrm{NT}_{6}+\mathrm{T}(\mathrm{tr})+\mathrm{X} \\ 840 / 91 & \mathrm{NT}_{6}+\mathrm{T}(\mathrm{tr})+\mathrm{X}\end{array}$


Table 12. Phase Analysis of the Soda-Alumina-Titania System (continued)

\begin{tabular}{|c|c|c|c|c|c|}
\hline \multirow{3}{*}{$\begin{array}{l}\text { Sample } \\
\text { No. }\end{array}$} & \multirow{2}{*}{\multicolumn{2}{|c|}{ Composition (wt \%) }} & \multirow{3}{*}{$\begin{array}{l}\text { Temp }\left({ }^{\circ} \mathrm{C}\right) / \\
\text { Time }(\mathrm{h})\end{array}$} & \multirow{3}{*}{$\begin{array}{l}\text { Observed } \\
\text { Phases }\end{array}$} & \multirow{3}{*}{$\begin{array}{l}\text { Phase } \\
\text { Transition } \\
\text { Temperatures }\end{array}$} \\
\hline & & & & & \\
\hline & $\mathrm{Na}_{2} \mathrm{O}$ & $\mathrm{Al}_{2} \mathrm{O}_{3} \quad \mathrm{TiO}_{2}$ & & & \\
\hline \multirow[t]{3}{*}{7.} & 9 & 76 & $940 / 46$ & $\mathrm{NT}_{6}+\mathrm{T}(\mathrm{tr})+\mathrm{X}$ & \\
\hline & & & $1000 / 16$ & $\mathrm{NT}_{6}+\mathrm{T}(\mathrm{tr})+\mathrm{X}$ & \\
\hline & & & $1100 / 67$ & $X+\operatorname{Liq}$ & \\
\hline
\end{tabular}

$\mathrm{NA}=\mathrm{NaAlO}_{2}, \quad \beta A=\mathrm{NaAl}_{11} \mathrm{O}_{17}, \mathrm{NT}_{3}=\mathrm{Na}_{2} \mathrm{Ti}_{3} \mathrm{O}_{7}, \mathrm{NT}_{6}=\mathrm{Na}_{2} \mathrm{Ti}_{6} \mathrm{O}_{13}, \mathrm{~N}_{4} \mathrm{~T}_{5}=\mathrm{Na}_{8} \mathrm{Ti}_{5} \mathrm{O}_{14}$, $\mathrm{A}=\mathrm{Al}_{2} \mathrm{O}_{3}, \mathrm{~T}=\mathrm{TiO}_{2}, \mathrm{X}=$ unknown ternary phase 


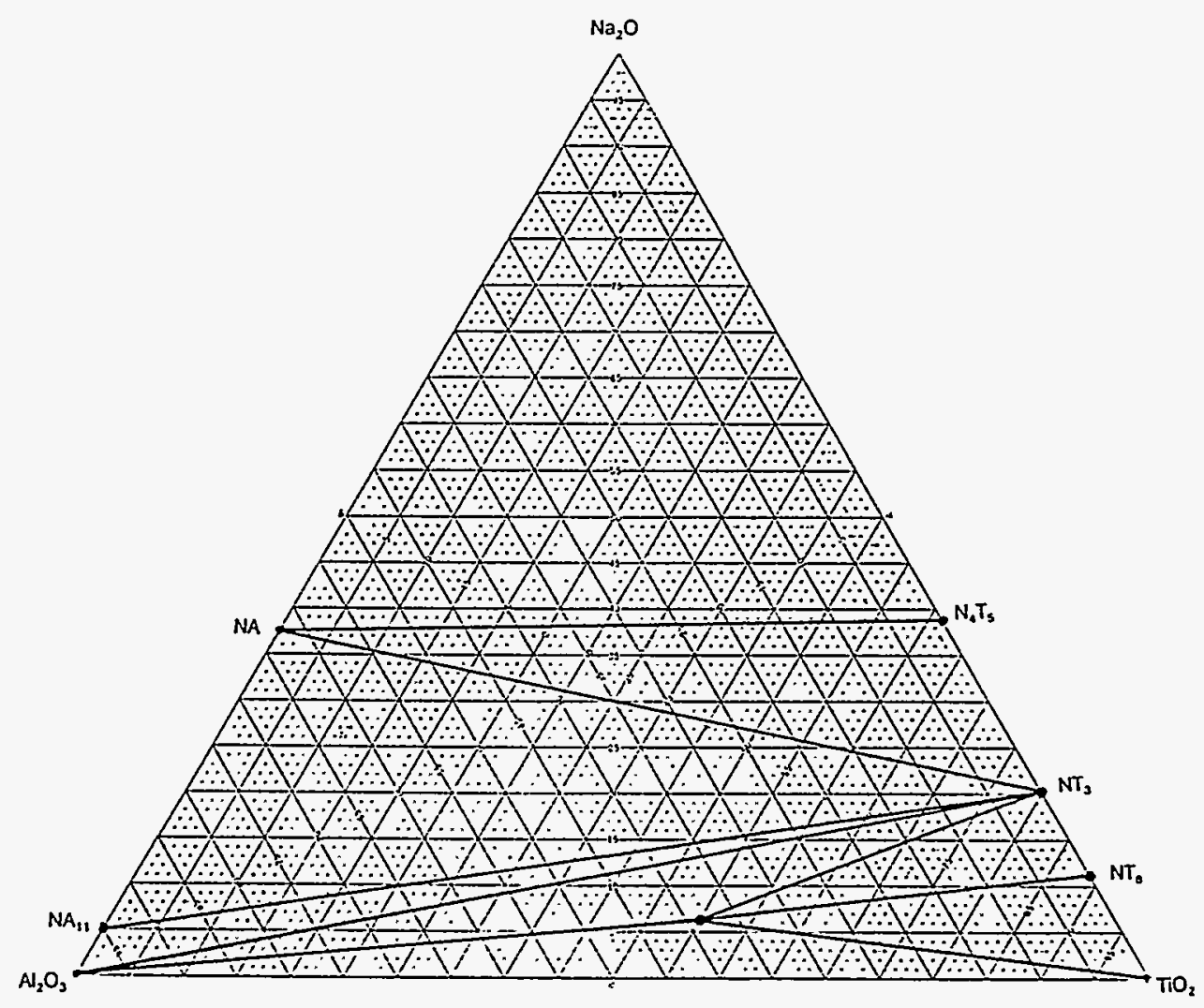

Figure 29. Subsolidus phase equilibria in the soda-alumina-titania system 


\section{Chapter 5. Summary and Conclusions}

The gaseous alkali corrosion kinetics of silicon carbide, silicon nitride, alumina, mullite, cordierite, transformation toughened zirconia, and aluminum titanate were systematically investigated from $950^{\circ} \mathrm{C}$ to $1100^{\circ} \mathrm{C}$ in dry air containing $1.0+/-0.1$ vol\% alkali. Linear reaction rates were observed at all temperatures for the alkali corrosion of $\mathrm{Si}_{3} \mathrm{~N}_{4}$ and $\mathrm{SiC}$ indicating that this process is interfaced-controlled with an activation energy of 199 and $104 \mathrm{~kJ} / \mathrm{mol}$, respectively. The reaction rate constants for $950,1000,1050$, and $1100^{\circ} \mathrm{C}$ are $3.0,7.4,13.0$, and $27.2 \mu \mathrm{m} / \mathrm{h}$, respectively for $\mathrm{Si}_{3} \mathrm{~N}_{4}$ and $3.0,4.0,5.3$, and $9.2 \mu \mathrm{m} / \mathrm{h}$, respectively for $\mathrm{SiC}$. The overall reaction in both of these materials involves a complex absorption-dissolution-oxidation process and the rate-controlling step appears to be the interfacial oxidation of $\mathrm{Si}_{3} \mathrm{~N}_{4}$ or $\mathrm{SiC}$ to $\mathrm{SiO}_{2}$.

Linear alkali reaction rates of $0.12,0.24$, and $0.45 \mu \mathrm{m} / \mathrm{h}$ at 1050,1100 and $1150^{\circ} \mathrm{C}$ were observed for alumina, resulting in the formation of sodium aluminate which occurs in a relatively planar fashion at low temperatures and in beta-alumina at higher temperatures with an experimental activation energy of $200 \mathrm{~kJ} / \mathrm{mol}$. The beta alumina forms in laths along the grain boundaries such that the fast ion conduction plane is perpendicular to the sample surface.

Linear reaction rates of $6,10,25$, and $39 \mu \mathrm{m} / \mathrm{h}$ at $950,1000,1050$, and $1100^{\circ} \mathrm{C}$ were observed for mullite with an experimental activation energy of $182 \mathrm{~kJ} / \mathrm{mol}$. The alkali reaction of mullite resulted in the formation of sodium aluminate and carnegieite. The alkali 
reaction rate of cordierite is linear at low temperatures and parabolic at higher temperatures, apparently due to the change in reaction layer morphology from a highly porous to a more dense structure. The linear reaction rates were 6 and $9 \mu \mathrm{m} / \mathrm{h}$ at 950 and $1000^{\circ} \mathrm{C}$. Parabolic reaction rates of 0.0046 and $0.0055 \mathrm{~mm}^{2} / \mathrm{h}$ were observed at 1050 and $1100^{\circ} \mathrm{C}$, respectively. The observed alkali reaction rate of transformation toughened zirconia is linear at all temperatures with an experimental activation energy of $229 \mathrm{~kJ} / \mathrm{mol}$. The linear reaction rates were $0.4,1.1,3.4$, and $4.2 \mu \mathrm{m} / \mathrm{h}$ at $950,1000,1050$, and $1100^{\circ} \mathrm{C}$, respectively. The fragile alkali reaction layer which formed on aluminum titanate resulted in a very large dimensional change (approximately $25 \%$ ) for short times at $950^{\circ} \mathrm{C}$.

The reaction products which formed from long isothermal heat treatments of cordierite, zirconia, and calcia stabilized zirconia powders mixed with sodium or potassium carbonate was investigated. Observed phases as a function of composition, temperature and time has been presented. Subsolidus phase equilibria in the soda-alumina-titania system was investigated and a tentative subsolidus ternary phase diagram for the low soda portion of this system has also been presented. 


\section{Chapter 6. Future Work}

This project has been very fertile in the sense that it has opened many areas of potentially useful research. Although the current work has investigated the comparative alkali corrosion rates of a large number of low expansion ceramics, there are many questions which still need to be addressed with respect to the alkali corrosion resistance of high temperature structural ceramics.

Elucidation of the effects of sintering aids (impurity concentration and distribution), density of the starting material, alkali concentration, steam concentration, and additional atmospheric impurities such as $\mathrm{SO}_{2}$ and $\mathrm{CO}_{2}$ on the observed reaction rates would be very beneficial. The current research has focused on measuring the alkali reaction rates of commercially available low expansion ceramics. Future research should be conducted to investigate the effects of the alkali corrosion on the mechanical properties of each material. Corrosion pitting or penetration of the alkali at the grain boundaries can have a significant impact on the mechanical properties while causing relatively little change in the specimens physical dimensions.

The rates of alkali reaction of $\mathrm{SiC}$ and $\mathrm{Si}_{3} \mathrm{~N}_{4}$ both appear to be controlled by the interfacial oxidation reactions as discussed in this dissertation. The reaction rate constants for these two materials converge as the temperature decreases until at $950^{\circ} \mathrm{C}$ they are approximately equal. It would be very interesting to test these materials at temperatures lower than $950^{\circ} \mathrm{C}$ to determine if the reaction rates remain the same or depart at lower 
temperatures. $\mathrm{Si}_{3} \mathrm{~N}_{4}$, while having a higher reaction rate constant than $\mathrm{SiC}$ at high temperatures, may have a lower rate constant at lower temperatures if the same rate controlling mechanisms are operative at low temperatures.

Aluminum titanate undergoes a severe alkali reaction at $950^{\circ} \mathrm{C}$ as reported in this work. Since aluminum titanate is not stable at this temperature, it is not clear what effect the decomposition of aluminum titanate to alumina and titania has on the alkali reaction rate. Comparison of the alkali reaction rate of magnesia stabilized aluminum titanate to the unstabilized aluminum titanate may shed some light on this problem.

In general, the alkali corrosion reactions appeared to occur preferentially at the grain boundary regions. It is not certain what effect sintering aids or other impurities will have on the measured corrosion rates. Comparison of the relative reaction rates of pure single crystal materials to the materials tested in the current study may provide additional information in this area. 


\section{REFERENCES}

${ }^{1} \mathrm{~J}$. Hastie, E. Plante and D. Bonnell, "Alkali Vapor Transport in Coal Conversion and Coal Combustion Systems", ACS Symposium Series, vol. 179 Metal Bonding and Interactions in High Temperature Systems with Emphasis on Alkali Metals (1982)

${ }^{2}$ T. Sun "Alkali Corrosion of Ceramic Materials", Ceramic News, 2 [4] 1-2 (1991)

${ }^{3} \mathrm{D}$. Gaskell, "Introduction to Metallurgical Thermodynamics", Hemisphere Publishing Corporation, 1981

${ }^{4}$ G. Castellan, "Physical Chemistry", Addison-Wesley Publishing Corporation, 1983

${ }^{5} \mathrm{~F}$. Hummel, "Phase Equilibria in Ceramic Systems", Marcel Dekker, Incorporated, 1984

${ }^{6} \mathrm{E}$. Levien, C. Robbins, and H. McMurdie, "Phase Diagrams for Ceramists", The American Ceramic Society, 1964

${ }^{7}$ W. Kingery, H. Bowen and D. Uhlmann, "Introduction to Ceramics", JohnWiley and Sons, 1976

${ }^{8} \mathrm{~J}$. Burke, "The Kinetics of Phase Transformations in Metals", Pergamon Press Limited Publishers, Long Island City, New York, 1965

${ }^{9}$ Silicon Nitride-1; p. 41. Edited by S. Somiya, M. Mitomo, and M Yoshimura. Elsevier Science Publishers, New York, NY, 1990.

${ }^{10}$ Y. Inomata, Silicon Carbide Ceramics-1, edited by S. Somiya and Y. Inomata (Elsevier Science Publishers, New York, 1991), p. 9. 
${ }^{11}$ A. F. McLean, "Materials Approach to Engine/Component Design"; PP. 1023-34 in Ceramic Materials and Components for Engines, Proceedings of the Second International Symposium. Edited by W. Bunk and H. Hausner. Verlag Deutsche Keramische Gesellschaft, Germany, 1986.

${ }^{12} \mathrm{~A}$. Bennett, "Requirements for Engineering Ceramics in Gas Turbine Engines," Mater. Sci. Technol., 2, 895-99 (1986).

${ }^{13}$ D. W. Richerson, Modern Ceramic Engineering; pp. 116-34. Marcel Dekker, NY, New York, 1982.

${ }^{14} \mathrm{H}$. Kim and A.J. Moorehead, "High-Temperature Gaseous Corrosion of Silicon Nitride in $\mathrm{H}_{2}-\mathrm{H}_{2} \mathrm{O}$ and Ar- $\mathrm{O}_{2}$ Environments," J. Am. Ceram. Soc., 73 [10] 3007-14 (1990).

${ }^{15} \mathrm{E}$. Gulbransen, K. Andrew and F. Brassart, "The Oxidation of $\mathrm{SiC}$ at 1150 to $1400^{\circ} \mathrm{C}$ and at $9 \times 10^{-3}$ to $5 \times 10^{-1}$ Torr Oxygen Pressure," J. Electrochem. Soc., 113 [12] 1311-14 (1966). ${ }^{16} \mathrm{~W}$. Vaughn and H. Maahs, "Active to Passive Transition in the Oxidation of Silicon Carbide and Silicon Nitride in Air," J. Am. Ceram. Soc., 73 [6] 1540-43 (1990).

${ }^{17}$ S. Ip, M. McNallan and D. Park, "Active Oxidation of SiC-Based Ceramics in $\mathrm{Ar}-2 \% \mathrm{Cl}_{2}-$ $\mathrm{O}_{2}$ Gas Mixtures at $100^{\circ} \mathrm{C}, "$ J. Am. Ceram. Soc., 75 [7] 1942-48 (1992).

${ }^{18} \mathrm{~J}$. Hinze and $\mathrm{H}$. Graham,"The Active Oxidation of $\mathrm{Si}$ and $\mathrm{SiC}$ in the Viscous Gas-Flow Regime," J. Electrochem. Soc., 123 [7] 1066-73 (1976).

${ }^{19} \mathrm{H}$. Du, R. E. Tressler, and K. E. Spear, "Thermodynamics of the Si-N-O System and Kinetic Modeling of Oxidation of $\mathrm{Si}_{3} \mathrm{~N}_{4}$," J. Electrochem. Soc., 136 [11] 3210-15 (1989).

${ }^{20} \mathrm{D}$. Cubicciotti and K. H. Lau, "Kinetics of Oxidation of Hot-pressed Silicon Nitride 
Containing Magnesia," J. Am. Ceram. Soc., 61 [11-12] 512-17 (1978).

${ }^{21}$ D. Cubicciotti and K. H. Lau, "Kinetics of Oxidation of Yttria Hot-pressed Silicon Nitride," J. Electrochem. Soc., 126 [10] 1723-28 (1979).

${ }^{22} \mathrm{~T}$. Hirai, K. Nihara, and T. Goto, "Oxidation of CVD $\mathrm{Si}_{3} \mathrm{~N}_{4}$ at $1550^{\circ} \mathrm{C}$ to $1650^{\circ} \mathrm{C}$," J. Am. Ceram. Soc., 63 [7-8] 419-24 (1980).

${ }^{23}$ J. Costello and R. Tressler, "Oxidation Kinetics of Hot-Pressed and Sintered alpha-SiC," J. Am. Ceram. Soc., 64 [6] 327-331 (1981).

${ }^{24} \mathrm{~L}$. Ogbuji, "Development of Oxide Scale Microstructure on Single-Crystal SiC," J. Mater. Sci., $162753-59$ (1981).

${ }^{25}$ S. Singhal, "Oxidation Kinetics of Hot-Pressed Silicon Carbide," J. Mater. Sci., 11 1246$53(1976)$

${ }^{26}$ M. Maeda, K. Nakamura and M. Yamada, "Oxidation Resistance Evaluation of Silicon Carbide Ceramics with Various Additives," J. Am. Ceram. Soc., 72 [3] 512-14 (1989).

${ }^{27}$ T. Narushima, T. Goto and T. Hirai, "High Temperature Passive Oxidation of Chemically Vapor Deposited Silicon Carbide," J. Am. Ceram. Soc., 72 [8] 1386-90 (1989).

${ }^{28} \mathrm{D}$. Mieskowski, T. Mitchell and A. Heuer, "Bubble Formation in Oxide Scales on SiC," J. Am. Ceram. Soc., 67 [1] C17-18 (1984).

${ }^{29} \mathrm{~J}$. Costello and R. Tressler, "Isotope Labeling Studies of the Oxidation of Silicon at $1000^{\circ} \mathrm{C}$ and $1300^{\circ} \mathrm{C}$," J. Electrochem. Soc., 131 [8] 1944-47 (1984).

${ }^{30}$ S. Singhal and F. Lange, "Effect of Alumina Content on the Oxidation of Hot-Pressed Silicon Carbide," J. Am. Ceram. Soc., 58 [9-10] 433-35 (1975). 
${ }^{31}$ R. Harris, "Oxidation of 6H-alpha Silicon Carbide Platelets," J. Am. Ceram. Soc., 58 [1-2] 7-9 (1975).

${ }^{32}$ J. Costello and R. Tressler, "Oxidation Kinetics of Silicon Carbide Crystals and Ceramics: I, In Dry Oxygen," J. Am. Ceram. Soc., 69 [9] 674-81 (1986).

${ }^{33}$ Z. Zheng, R. Tressler and K. Spear, "Oxidation of Single-Crystal Silicon Carbide," J. Electrochem. Soc., 137 [3] 854-858 (1990).

${ }^{34}$ A. Heuer, L. Ogbuji and T. Mitchell, "The Microstructure of Oxide Scales on Oxidized Si and SiC Single Crystals," J. Am. Ceram. Soc., 63 [5-6] 354-55 (1980).

${ }^{35}$ N. Jacobson, K. Lee and D. Fox, "Reactions of Silicon Carbide and Silicon(IV) Oxide at Elevated Temperatures," J. Am. Ceram. Soc., 75 [6] 1603-11 (1992).

${ }^{36} \mathrm{D}$. Butt, R. Tressler and $\mathrm{K}$. Spear, "Corrosion of SiC Materials in $\mathrm{N}_{2}-\mathrm{H}_{2}-\mathrm{CO}$ Gaseous Environments: II, Durability and Mechanical Properties," J. Am. Ceram. Soc., 75 [12] 326877 (1992).

${ }^{37} \mathrm{D}$. Butt, R. Tressler and K. Spear, "Corrosion of $\mathrm{SiC}$ Materials in $\mathrm{N}_{2}-\mathrm{H}_{2}-\mathrm{CO}$ Gaseous Environments: I, Thermodynamics and Kinetics of Reactions," J. Am. Ceram. Soc., 75 [12] $3257-67$ (1992).

${ }^{38} \mathrm{~A}$. Bennett, "Requirements for Engineering Ceramics in Gas Turbine Engines," Mater. Sci. Tech., 2 895-99 (1986).

${ }^{39} \mathrm{~J}$. Hinze and H. Graham, "The Active Oxidation of Si and Silicon Carbide in the Viscous Gas-Flow Regime," J. Electrochem. Soc., 123 [7] 1066-1073 (1976).

${ }^{40} \mathrm{~W}$. Trip and $\mathrm{H}$. Graham, "Oxidation of $\mathrm{Si}_{3} \mathrm{~N}_{4}$ in the Range $1300^{\circ} \mathrm{C}$ to $1500^{\circ} \mathrm{C}$," J. Am. 
Ceram. Soc., 59 [9-10] 399-403 (1976).

${ }^{41} \mathrm{~S}$. Lin, "Mass Spectroscopic Analysis of Vapors in Oxidation of $\mathrm{Si}_{3} \mathrm{~N}_{4}$ Compacts," J. Am. Ceram. Soc., 58 [3-4] 160 (1976).

${ }^{42} \mathrm{~T}$. Hirai, K. Niihara and T. Goto, "Oxidation of CVD $\mathrm{Si}_{3} \mathrm{~N}_{4}$ at $1550^{\circ} \mathrm{C}$ to $1650^{\circ} \mathrm{C}$, J. Am. Ceram. Soc., 63 [7-8] 419-24 (1980).

${ }^{43} \mathrm{~L}$. Ogbuji, "Role of $\mathrm{Si}_{2} \mathrm{~N}_{2} \mathrm{O}$ in the Passive Oxidation of CVD $\mathrm{Si}_{3} \mathrm{~N}_{4}$ " J. Am. Ceram. Soc., 75 [11] 2995-3000 (1992).

${ }^{44}$ S. Singhal, "Thermodynamics and Kinetics of Oxidation of Hot-Pressed Silicon Nitride," J. Mater. Sci., 11 500-09 (1976).

${ }^{45}$ T. Easler, R. Bradt and R. Tressler, "Effects of Oxidation and Oxidation Under Load on the Strength Distributions of $\mathrm{Si}_{3} \mathrm{~N}_{4}$, J. Am. Ceram. Soc., 65 [6] 317-20 (1982).

${ }^{46} \mathrm{~K}$. Luthra, "A Mixed Interface Reaction/Diffusion Control Model for Oxidation of $\mathrm{Si}_{3} \mathrm{~N}_{4}$," J. Electrochem. Soc., 138 [10] 3001-3007 (1991).

${ }^{47} \mathrm{D}$. Cubicciotti and K. Lau, "Kinetics of Oxidation of Hot-Pressed Silicon Nitride Containing Magnesia," J. Am. Ceram. Soc., 61 [11-12] 512-17 (1978).

${ }^{48}$ D. Cubicciotti and K. Lau, "Kinetics of Oxidation of Hot-Pressed Silicon Nitride," J. Electrochem. Soc., 126 [10] 1723-28 (1979).

${ }^{49} \mathrm{H}$. Du, R. Tressler, K. Spear and C. Pantano, "Oxidation Studies of Crystalline CVD Silicon Nitride," J. Electrochem. Soc., 136 [5] 1527-36 (1989).

${ }^{50} \mathrm{H}$. Du, R. Tressler and K. Spear, "Thermodynamics of the Si-N-O System and Kinetic Modeling of Oxidation Studies of Silicon Nitride," J. Electrochem. Soc., 136 [11] 3210-15 
(1989).

${ }^{51}$ T. Narushima, T. Goto, Y. Iguchi and T. Hirai, "High Temperature Oxidation of CVD Silicon Carbide in Wet Oxygen at 1823 to 1923K," J. Am. Ceram. Soc., 73 [12] 3580-84 (1990).

${ }^{52}$ A. Suzuki, H. Ashida, N. Furui, K. Mameno and H. Matsunami, "Thermal Oxidation of $\mathrm{SiC}$ and Electrical Properties of $\mathrm{Al}-\mathrm{SiO}_{2}-\mathrm{SiC} \mathrm{MOS}$ Structure," Jpn. J. Appl. Phys., 21 [4] $579-85(1982)$.

${ }^{53}$ E. Fitzer and R. Ebi, "Kinetic Studies on the Oxidation of Silicon Carbide Thin Films," pp. 320-28 in Silicon Carbide 1973. Edited by R.C. Marshal et al. University of South Carolina Press, Columbia, SC, 1974.

${ }^{54}$ R. Harris and R. Call, "Oxidation of 6H Alpha-Silicon Carbide," pp. 329-36 in Silicon Carbide 1973. Edited by R.C. Marshal et al. University of South Carolina Press, Columbia, SC, 1974.

${ }^{55} \mathrm{C}$. Fung and J. Kopanski, "Thermal Oxidation of $3 \mathrm{C}$ Silicon Carbide Single-Crystal Layers on Silicon," Appl. Phys. Lett., 45 [7] 757-59 (1984).

${ }^{56} \mathrm{H}$. Cappelen, K. Johansen and K. Motzfeldt, "Oxidation of Silicon Carbide in Oxygen and Water Vapor at $1500^{\circ} \mathrm{C}$," Acta. Chem. Scand. Ser., 35, 247-54 (1981).

${ }^{57} \mathrm{P}$. Jorgensen, M. Wadsworth and I. Cutler, "Effects of Water Vapor on Oxidation of Silicon Carbide," J. Am. Ceram. Soc., 44 [6] 258-61 (1961).

${ }^{58}$ W. Lu, A. Steckl, T. Chow and W. Katz, "Thermal Oxidation of Sputtered Silicon Carbide Thin Films," J. Electrochem. Soc., 131 [8] 1907-14 (1984). 
${ }^{59}$ M. Maeda, K. Nakamura and T. Ohkubo, "Oxidation of Silicon Carbide in a Wet Atmosphere," J. Mater. Sci., 23, 3933-38 (1988).

${ }^{60}$ D. Choi, D. Fischbach and W. Scott, "Oxidation of Chemically Vapor Deposited Silicon Nitride and Single-Crystal Silicon," J. Am. Ceram. Soc., 72 [7] 1118-1123 (1989).

${ }^{61} \mathrm{~N}$. Jacobson, "Corrosion of Silicon-Based Ceramics in Combustion Environments," J. Am. Ceram. Soc., 76 [1] 3-28 (1993).

${ }^{62} \mathrm{~K}$. Luthra, "Some New Perspectives on Oxidation of Silicon Carbide and Silicon Nitride," J. Am. Ceram. Soc., 74 [5] 1095-1103 (1991).

${ }^{63} \mathrm{~N}$. Jacobson and J. Smialek, "Hot Corrosion of Sintered alpha-SiC at $1000^{\circ} \mathrm{C}$," J. Am. Ceram. Soc., 68 [8] 432-39 (1985).

${ }^{64}$ T. Sato, Y. Kanno, T. Endo, and M. Shimada, "Corrosion of $\mathrm{Si}_{3} \mathrm{~N}_{4}$ in Molten Alkali Sulfate and Carbonate," Adv. Ceram. Mater., 2 [3] 228-31 (1987).

${ }^{65} \mathrm{M}$. McNallan, P. Hsu and S. Lee, "Oxidation of Si-Based Ceramics in the Presence of Alkali Halide Vapors," J. Min. Met. Mat., 45 [12] 22-5 (1993).

${ }^{66} \mathrm{P}$. Becher, "Strength Degradation in $\mathrm{SiC}$ and $\mathrm{Si}_{3} \mathrm{~N}_{4}$ Ceramics by Exposure to Coal Slags at High Temperatures," J. Mat. Sci., 19, 2805-2814 (1984).

${ }^{67} \mathrm{~N}$. Jacobson, C. Stearns and J. Smialek, "Burner Rig Corrosion of SiC at $1000^{\circ} \mathrm{C}$," Adv. Ceram. Mater., 1 [2] 154-61 (1986).

${ }^{68} \mathrm{~N}$. Jacobson, "Kinetics and Mechanism of Corrosion of $\mathrm{SiC}$ by Molten salts," J. Am. Ceram. Soc., 69 [1] 74-82 (1986).

${ }^{69}$ D. S. Fox and N. S. Jacobson, "Molten-Salt Corrosion of Silicon Nitride: I, Sodium 
Carbonate," J. Am. Ceram. Soc., 71 [2] 28-38 (1988).

${ }^{70}$ N. S. Jacobson and D. S. Fox, "Molten-Salt Corrosion of Silicon Nitride: II, Sodium Sulfate," J. Am. Ceram. Soc., 71 [2] 39-48 (1988).

${ }^{71}$ D. S. Fox, N. S. Jacobson, and J. L. Smialek, "Hot Corrosion of Silicon Carbide and Silicon Nitride"; pp. 227-49 in Corrosion and Corrosive Degradation of Ceramics. Edited by R. E. Tressler and M. McNallan. American Ceramic Society, Westerville, Ohio, 1990.

${ }^{72}$ M. I. Mayer and F. L. Riley, "Sodium-Assisted Oxidation of Reaction Bonded Silicon Nitride," Proc. Br. Ceram. Soc., 26, 251 (1978).

${ }^{73}$ M. I. Mayer and F. L. Riley, "Sodium-Assisted Oxidation of Reaction Bonded Silicon Nitride," J. Mater. Sci., 13, 1319-28 (1978).

${ }^{74}$ R. E. Tressler, M. D. Meiser, and T. Yonushonis, "Molten Salt Corrosion of SiC and $\mathrm{Si}_{3} \mathrm{~N}_{4}$, J. Am. Ceram. Soc., 59 [5-6] 278-79 (1976).

${ }^{75}$ W. C. Bourne and R. E. Tressler, "Molten Salt Degradation of $\mathrm{Si}_{3} \mathrm{~N}_{4}$ Ceramics," Am. Ceram. Soc. Bull., 59 [4] 443-52 (1980).

${ }^{76} \mathrm{~J}$. Schlichting, "Oxidation and Hot Corrosion Behavior of $\mathrm{Si}_{3} \mathrm{~N}_{4}$ and SiAlON"; pp.627-34 in Nitrogen Ceramics. Edited by F. L. Riley. Noordhoff, Leyden, 1977.

${ }^{77}$ Y. Shinata, M. Hara, T. Nakagawa and C. Shimizu, "Hot Corrosion of Reaction-Sintered $\mathrm{Si}_{3} \mathrm{~N}_{4}$ in Molten Sodium Sulfate," High Temperature Coatings of Advanced Materials, Edited by Y. Saito et al, Elsevier Science Publishers, 1992.

${ }^{78} \mathrm{~J}$. Smialek and N. Jacobson, "Mechansim of Strength Degredation for Hot Corrosion of alpha-SiC," J. Am. Ceram. Soc., 59 [10] 741-52 (1986). 
${ }^{79}$ D. Fox and J. Smialek, "Burner Rig Hot Corrosion of Silicon Carbide and Silicon Nitride,"

J. Am. Ceram. Soc., 73 [2] 303-11 (1990):

${ }^{80}$ M. Feber, J. Ogle, V. Tennery and T. Henson, "Characterization of Corrosion Mechanisms Ocurring in a Sintered SiC Exposed to Basic Coal Slags," J. Am. Ceram. Soc., 68 [4] 191-97 (1985).

${ }^{81} \mathrm{M}$. Feber and V. Tennery, "Behavior of Tubular Ceramic Heat Exchanger Materials in Acidic Ash from Coal-Oil-Mixture Combustion," Ceram. Bull., 62 [2] 236-43 (1983).

${ }^{82} \mathrm{D}$. Mckee and D. Chatterji, "Corrosion of Silicon Carbide in Gases and Alkaline Melts," J. Am. Ceram. Soc., 59 [9-10] 441-44 (1976).

${ }^{83} \mathrm{~N}$. Jacobson and J. Smialek, "Corrosion Pitting of SiC by Molten Salts," J. Electrochem Soc., 133 [12] 2615-21 (1986).

${ }^{84}$ F.H. Horn "Screw Dislocations, Etch Figures, and Holes," Philos. Mag., 43, 1210-13 (1952)

${ }^{85}$ S. Amelinckx, G. Strumane and W.W. Webb, "Dislocations in Silicon Carbide," J. Appl. Phys. 31, 1359-70 (1960)

${ }^{86}$ E. Buchner and O. Rubisch, pp 428-34 in Silicon Carbide-1973. Edited by R.C.

Marshall and J. W. Faust. University of South Carolina Press, Columbia, SC, 1974

${ }^{87}$ R.E. Tressler, M.D. Meiser and T. Yonushonis, "Molten Salt Corrosion of SiC and

$\mathrm{Si}_{3} \mathrm{~N}_{4}$ Ceramics" J. Am. Ceram. Soc., 59 [5-6] 278-79 (1976)

${ }^{88}$ J.R. Blachere and F.S. Petit, "High Temperature Corrosion of Ceramics", DOE/ER/10915-3, 1984 
${ }^{89}$ J.M. van Hoek, F. J. van Loo and R. Metselaar, "Corrosion of Alumina by Potassium Vapor", J. Am. Ceram. Soc., 75[1] 109-11 (1992)

${ }^{90} \mathrm{C}$. Wagner, J. Chem. Phys., 21, 1819-27 (1953)

${ }^{91}$ K. Kiukkola and C. Wagner, J. Electrochem. Soc., 104, 308 (1957)

${ }^{92}$ K. Kiukkola and C. Wagner, J. Electrochem. Soc., 104, 379-87 (1957)

${ }^{93}$ Y.F. Yao and J.T. Kummer, J. Inorg. Nuc. Chem., 29, 2453-75 (1967)

${ }^{94}$ N. Weber and J. T. Kummer, Proc. Ann. Power Sources Conf., 21, $37-39$ (1967)

${ }^{95}$ R.H. Radzilowski, Y.F. Yoa, and J.T. Kummer, J. Appl. Phys., 40, 4716-4725 (1969)

${ }^{96}$ R. A. Huggins, "Alkali Ion Transport in Materials of the Beta-Alumina Family", pp155-

175 in Transport in Materials of the Beta-Alumina Family

${ }^{97}$ G.D. With, P.J. Vrugt and A.C. Van De Ven, "Sodium Corrosion Resistance of

Translucent Alumina: Effect of Additives and Sintering Conditions", J. Matls. Sci. Lett., [20] 1215-21 (1985)

${ }^{98} \mathrm{H}$. Togawa, K. Tsuchida and A. Kato, "Interaction Between Beta-alumina and Liquid Sodium at $700 \mathrm{Cl}, 10,96-100(1990)$

${ }^{99}$ T. Sun, "Alkali Corrosion of Coal Gasifier Linings", Master's thesis, Virginia Polytechnic Institute, 1986

${ }^{100}$ D.W. Susinitzky and C.B. Carter, "Localization of Potassium in Alumina", J. Am.

Ceram. Soc., 68 [11] 569-74 (1985)

${ }^{101} \mathrm{~J}$. Jung, A. Reck and R. Ziegler, "The Compatibility of Alumina Ceramics with Liquid Sodium", J. Nuc. Matls., 119, 339-50 (1983) 
${ }^{102} \mathrm{~J} . \mathrm{D}$. Hodge, "Investigation of the Reaction of Sodium with Aluminum Oxide", J.

Electrochem. Soc., 133, 833-36 (1986)

${ }^{103}$ R.E. Farris and J.E. Allen. "Aluminous Refractories-Alkali Reactions", Iron and Steel Eng., 50, 67-74 (1973)

${ }^{104}$ G. R. Rigby and R. Hutton, "Action of Alkali-Vanadium Oxide Slags on AluminaSilica Refractories", J. Am. Ceram. Soc., 45, 68-73 (1962)

${ }^{105}$ I.D. Kashcheev, P.S. Mamykin and M. Bartushka, "The Corrosion of a Mullite Ceramic by a Sodium-Containing Silicate Melt", Translated from Ogneupory, 11, 39-43 (1975) by Plenum Publishing Co., NY, NY

${ }^{106}$ K. Hiragushi K. Mizutani and T. Nagai, "A New Approach to Blast Furnace

Refractories", Iron and Steel Eng., 55, 47-53 (1978)

${ }^{107}$ P. Havranek, "Alkali Attack on Blast Furnace Refractories", Trans. J. Brit. Ceram. Soc., $77,92-97(1978)$

${ }^{108}$ C.R. Kennedy, "Alkalil attack on a Mullite Refractory in the Grand Forks Energy Technology Center Slagging Gasifier", J. Matls. Ener. Sys., 3, 27-31 (1981)

${ }^{109}$ I.M. Lachman, R.D. Bagley and R. M. Lewis, "Thermal Expansion of Extruded Cordierite Ceramics", Ceram. Bull., 60 [2] 202-205 (1981)

${ }^{110} \mathrm{R}$. Bianco and N. Jacobson, "Corrosion of Cordierite Ceramics by Sodium Sulphate at 1000 C", J. Matls. Sci., 24, 2903-2910 (1989)

"II.N. Samaddar, W.D. Kingery and A.R. Cooper, "Dissolution in Ceramic Systems: II, Dissolution of Alumina, Mullite, Anaorthite, and Silica in a Calcium-Aluminum-Silicate 
Slag", J. Am. Ceram. Soc., 47, 249-54 (1964)

${ }^{112}$ T. Sun, Private Communication

${ }^{113}$ S.R. Sholes and C.H. Greene, "Modern Glass Practice", CBI Publishing Company, Inc., Boston MA, 1975

${ }^{114}$ D. W. Susnitzky, W. Hertl and C.B. Carter, "Destabilization of Zirconia Thermal

Barriers in the Presence of Vanadium Pentoxide", J. Am. Ceram. Soc., 71 \{11\} 992-1004

${ }^{115} \mathrm{M}$. Van Roode and J. Price, "Corrosion Resistant Coatings for Ceramic Heat Exchanger Tubes Operating in Highly Corrosive Environments", pp 625-33 in High Performance Ceramic Coatings and Films, Published by Elsevier Science Publishers, 1991 ${ }^{116} \mathrm{H}$. Wada and M. Yoshiba, "Vanadium Pentoxide-Sodium Sulfate-Sodium Chloride Molten Salt Corrosion Behaviour of Various High Temperature Structural Ceramics", pp 355-64 in High Temperature Corrosion of Advanced Materials and Protective Coatings, Published by Elsevier Science Publishers, 1992

${ }^{117}$ D.W. Mckee and P.A. Siemers, "Resistance of Thermal Barrier Ceramic Coatings to Hot Salt Corrosion", Thin Sol. Films, 73, 439-445 (1980)

${ }^{118}$ S.J. Charlton and M.J. Watts, "An Investigation of Thermal Insulation of IDI Diesel Engine Swirl Chambers", Proc. Instn. Mech. Eng., 205, 263-69 (1991)

${ }^{119}$ T. Mani and A. Damodaran, "Aluminum Titanate Powder Synthesis via Thermal Decomposition of Transparent Gels", J. Am. Ceram. Soc., 74 [8] 1807-10 (1991)

${ }^{120} \mathrm{H}$. Morishima and N. Ootsuka, "Development of Aluminum Titanate-Mullite 
Composite Having High THermal Shock Resistance", J. Am. Ceram. Soc., 69 [10]C226C227 (1986)

${ }^{121}$ F. Parker, "Aluminum Titanate-Zirconium Titanate-Zirconia Composites: A New Family of Low-Thermal-Expansion Ceramics", J. Am. Ceram. Soc., 73 [4] 929-32 (1990)

${ }^{122}$ J.J Brown, N. Brown and T. Sun, "Sol-Gel Beta-Aluminum Titanate Thin Film Coating", Patent Application Filed 7/93

${ }^{123}$ C. Ball, W. Buykx, F. DIckson, K. Hawkins, D. Levins, R. Smart, K. Smith, G. Stevens, K. Watson, D. Weedon and T. White, "Titanate Ceramics for the Stabilization of Partially Reprocessed Nuclear Fuel Elements", J. Am. Ceram. Soc., 72 [3] 404-14 (1989)

${ }^{124}$ M. Kang, "Alkali/Steam Corrosion Resistance of Commercial SiC Products Coated with Sol-gel Deposited Mg-Doped $\mathrm{Al}_{2} \mathrm{TiO}_{5}$ and $\mathrm{CMZP"}$ ", Master's Thesis, Virginia Polytechnic Institute, 1994

${ }^{125}$ T. Sun, G. Pickrell and J. Brown, "Corrosion Kinetics of Silicon Nitride in Dry Air Containing Sodium Nitrate Vapors," submitted for publication in the Journal of the American Ceramic Society.

${ }^{126}$ A. Paul, Chemistry of Glasses; p. 89. Chapman and Hall, New York, NY, 1990.

${ }^{127}$ D. J. Choi, D. B. Fischback, and W. D. Scott, "Oxidation of Chemically-Vapor-Deposited Silicon Nitride and Single-Crystal Silicon," J. Am. Ceram. Soc., 72 [7] 1118-23 (1989).

${ }^{128}$ S. C. Singhal, "Oxidation and Corrosion-Erosion Behavior of $\mathrm{Si}_{3} \mathrm{~N}_{4}$ and $\mathrm{SiC}^{12}$; pp. 533-48 in Ceramics for High-Performance Applications. Edited by J. J. Burke, A. E. Gorum, and R. N. katz. Metals and Ceramics Information Center, Columbus, Ohio, 1974. 
${ }^{129} \mathrm{~W}$. C. Tripp and H. C. Graham, "Oxidation of $\mathrm{Si}_{3} \mathrm{~N}_{4}$ in the Range $1300^{\circ} \mathrm{C}$ to $1500^{\circ} \mathrm{C}$," J. Am. Ceram. Soc., 59 [9-10] 399-403 (1976).

${ }^{130}$ J. Schlichting and L. J. Gauckler, "Oxidation of Some $\beta-\mathrm{Si}_{3} \mathrm{~N}_{4}$ Materials," Powder Metall. Int., 9 [1] 36-39 (1977).

${ }^{131}$ H. Du, R. E. Tressler, and C. G. Pantano, "Oxidation Studies of Crystalline CVD Silicon Nitride," J. Electrochem. Soc., 136 [5] 1527-36 (1989).

${ }^{132}$ E. W. Sucov, "Diffusion of Oxygen in Vitreous Silica," J. Am. Ceram. Soc., 46 [1] 14-20 (1963).

${ }^{133}$ E. L. Williams, "Diffusion of Oxygen in Fused Silica," J. Am. Ceram. Soc., 48 [4] 190-94 (1965).

${ }^{134} \mathrm{~K}$. Muehlenbachs and H. A. Schaeffer, "Oxygen Diffusion in Vitreous Silica-Utilization of Natural Isotopic Abundances," Can. Mineral., 15, 179-84 (1977).

${ }^{135}$ Y. Oishi, R. Terai, and H. Ueda, "Oxygen Diffusion in Liquid Silicates and Relation to Their Viscosity"; pp. 297-310 in Mass Transport Phenomena in Ceramics. Edited by A. R. Cooper and A. H. Heuer. Plenum Press, New York, 1975.

${ }^{136}$ K. E. Spear, R. E. Tressler, Z. Zheng, and H. Du, "Oxidation of Silicon Carbide Single Crystals and CVD Silicon Nitride"; pp. 1-18 in Corrosion and Corrosive Degradation of Ceramics. Edited by R. E. Tressler, and M. McNallan. American Ceramic Society, Westerville, Ohio, 1990.

${ }^{137}$ E. M. Levin, C. R. Robbins, and H. F. McMurdie (Eds.), Phase Diagram for Ceramists, American Ceramic Society, Columbus, Ohio, 1964. 
${ }^{138} \mathrm{~K}$. Schwerdtfeger, "Dissolution of Solid Oxides in Oxide Melts," J. Phys. Chem., 70 [7] 2131-37 (1966).

${ }^{139}$ K. L. Luthra, "A Mixed Interface Reaction/Diffusion Control Model for Oxidation of $\mathrm{Si}_{3} \mathrm{~N}_{4}$," J. Electrochem. Soc., 138 [10] 3001-3007 (1991).

${ }^{140}$ I. A. Aksay and J. A. Pask, "Stable and Metastable Phase Equilibria in the System $\mathrm{Al}_{2} \mathrm{O}_{3}$ $\mathrm{SiO}_{2}$," J. Am. Ceram. Soc., 58 [11-12] 507-12 (1975).

${ }^{141} \mathrm{~J}$. Van Hoek, "Alkali Metal Corrosion of Alumina", PhD Dissertation, Technical University of Eindhoven, Published by Philips Research Lab, 1990

142" Phase Diagrams for Ceramists", vols 1-8, 1964-1990, published by the American Ceramic Society

${ }^{143} \mathrm{G}$. Spinnler and L. Chang, "Phase Relations in the Systems $\mathrm{A}_{2} \mathrm{O}-\mathrm{Metal}$ Oxide-WO${ }_{3}$ ", J. Am. Ceram. Soc., 64 [9] 535-55 (1981)

${ }^{144}$ R. Jones and R. Reidy, "Vanadate Hot Corrosion Behavior of India, Yttria-Stabilized Zirconia", J. Am. Ceram. Soc., 76 [10] 2660-62 (1993)

${ }^{145}$ W. Mumme and A. Wadsley, "The Crystal Structure of NaTi2A15O12", Acta Cryst. 23, 754-758 (1967) 